\title{
Metal-Oxide Nanowire Molecular Sensors and Their Promises
}

\author{
Hao Zeng 1므, Guozhu Zhang ${ }^{1, *}$, Kazuki Nagashima ${ }^{1,2}$, Tsunaki Takahashi 1,2 $\mathbb{D}$, Takuro Hosomi ${ }^{1,2}$ \\ and Takeshi Yanagida 1,3,*
}

1 Department of Applied Chemistry, Graduate School of Engineering, The University of Tokyo, 7-3-1, Hongo, Bunkyo-ku, Tokyo 113-8654, Japan; zenghao@g.ecc.u-tokyo.ac.jp (H.Z.); kazu-n@g.ecc.u-tokyo.ac.jp (K.N.); takahashi-t@g.ecc.u-tokyo.ac.jp (T.T.); t-hosomi@g.ecc.u-tokyo.ac.jp (T.H.)

2 JST-PRESTO, 4-1-8 Honcho, Kawaguchi, Saitama 332-0012, Japan

3 Institute for Materials Chemistry and Engineering, Kyushu University, 6-1 Kasuga-Koen, Kasuga, Fukuoka 816-8580, Japan

* Correspondence: gz-zhang@g.ecc.u-tokyo.ac.jp (G.Z.); yanagida@g.ecc.u-tokyo.ac.jp (T.Y.)

\section{check for} updates

Citation: Zeng, H.; Zhang, G.; Nagashima, K.; Takahashi, T.; Hosomi, T.; Yanagida, T. Metal-Oxide Nanowire Molecular Sensors and Their Promises. Chemosensors 2021, 9, 41. https://doi.org/10.3390/ chemosensors 9020041

Academic Editor: Simas Rackauskas

Received: 15 January 2021

Accepted: 19 February 2021

Published: 22 February 2021

Publisher's Note: MDPI stays neutral with regard to jurisdictional claims in published maps and institutional affiliations.

Copyright: (c) 2021 by the authors. Licensee MDPI, Basel, Switzerland. This article is an open access article distributed under the terms and conditions of the Creative Commons Attribution (CC BY) license (https:/ / creativecommons.org/licenses/by/ $4.0 /)$.

\begin{abstract}
During the past two decades, one-dimensional (1D) metal-oxide nanowire (NW)-based molecular sensors have been witnessed as promising candidates to electrically detect volatile organic compounds (VOCs) due to their high surface to volume ratio, single crystallinity, and well-defined crystal orientations. Furthermore, these unique physical/chemical features allow the integrated sensor electronics to work with a long-term stability, ultra-low power consumption, and miniature device size, which promote the fast development of "trillion sensor electronics" for Internet of things (IoT) applications. This review gives a comprehensive overview of the recent studies and achievements in 1D metal-oxide nanowire synthesis, sensor device fabrication, sensing material functionalization, and sensing mechanisms. In addition, some critical issues that impede the practical application of the 1D metal-oxide nanowire-based sensor electronics, including selectivity, long-term stability, and low power consumption, will be highlighted. Finally, we give a prospective account of the remaining issues toward the laboratory-to-market transformation of the 1D nanostructure-based sensor electronics.
\end{abstract}

Keywords: nanowire; oxide; gas sensor; device; 1D nanostructure; sensing mechanism

\section{Introduction}

For the upcoming "trillion sensor electronics" era, molecular sensor and electronic recognition devices, which collect the enormous chemical information as big data from various volatile organic molecules (VOCs), are gaining increasing interests in health care [1-3], environment [1,4,5], security [6-9] and agriculture areas [3,4,10,11]. Among various molecular sensors, chemiresistive sensors integrated with metal-oxide semiconductor (MOS) nanostructures are of particular interest due to their high sensitivity and fast response [12-16]. Especially with the advancement of nanomaterial fabrication technology, a large number of functional MOS nanostructures, such as nanodots $[17,18]$, nanowires [19-22], nanosheets [23-25], and hierarchical nanostructures [26-28], are synthesized as building blocks for the fabrication of sensor electronics.

Among these nanostructured forms, 1D MOS nanowires offer an ideal platform for nanoscale sensor integration due to their high surface to volume ratio, comparable sized Debye length, high crystallinity, excellent surface chemical reaction, and low power consumption [29-31]. Ever since the first report of using the 1D metal-oxide nanostructure as the gas sensor by Comini, great progress has been achieved in the past two decades [32] To date, hundreds of papers have been published on molecular sensors integration based on 1D metal-oxide nanostructures $\left(\mathrm{SnO}_{2}\right.$ [29], $\mathrm{In}_{2} \mathrm{O}_{3}$ [33], $\mathrm{Fe}_{2} \mathrm{O}_{3}$ [34], $\mathrm{V}_{2} \mathrm{O}_{5}$ [35], $\mathrm{CeO}_{2}$ [36], $\mathrm{ZnO}$ [37], $\mathrm{WO}_{3}$ [38], $\mathrm{NiO}$ [39], $\mathrm{CuO}$ [40], $\mathrm{NaNbO}_{3}$ [41], $\mathrm{Zn}_{2} \mathrm{SnO}_{4}$ [42,43], CdIn $\mathrm{O}_{4}$ [44], etc.), and the numbers of publications related to nanowires and metal-oxide nanowire sensors can be seen in Figure 1. Meanwhile, to fulfill multiple demands of molecule detection 
and monitoring, nanowire-based sensor devices with different structures, such as flat [45], suspended [46], bridging [47], and vertical structure [48], have also been addressed. Despite much effort being devoted to advancing the metal-oxide nanowire-based molecular sensor electronics, molecular sensors based on 1D MOS nanowires have not yet been successfully commercialized compared to the MOS film structures.

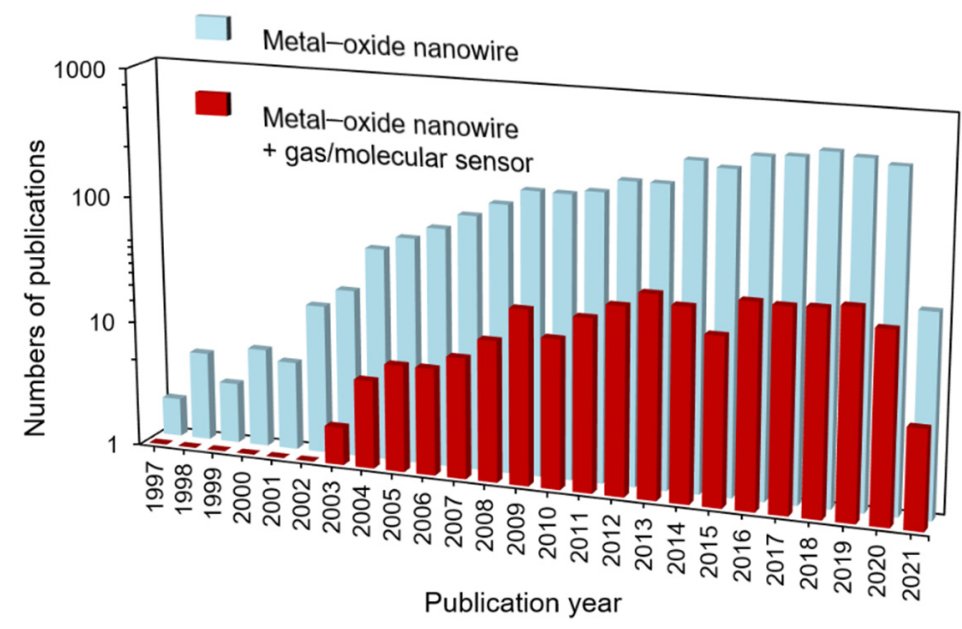

Figure 1. Numbers of publications in the area of nanowires and nanowire sensors from 1997 to 2021 (internet search of the Web of Science on 15 January 2021). Keywords for search: metal-oxide nanowire; metal-oxide nanowire + gas $/$ molecular sensor.

The inherent limitations for the practical applications of the 1D MOS nanowire-based molecular sensors can be summarized as follows:

(1) Lack of effective method for the large-scale synthesis of geometrically uniform single-crystalline nanowires-as is known, the electrical [49], optical [50], thermal [51], and chemical [52] properties of nanomaterials are strongly affected by their size and shape due to the quantum confinement effect [53]. The electrical conduction becomes more sensitive to the field-effect as the nanowire diameter decreases [54]. Until now, although highly crystalline MOS nanowire with various diameters [55], compositions [28-40] and heterostructures [56,57] can be grown in vapor phase (physical vapor deposition (PVD) [58,59], pulsed laser ablation deposition (PLD) $[60,61]$ and chemical vapor deposition (CVD) [62,63], etc.) and solution phase (hydrothermal $[64,65]$ and solvothermal $[66,67])$, the large-scale synthesis of geometry uniform (diameter) nanowires is still a big challenge [68].

(2) Poor reproducibility - it has been demonstrated that the nanowires present a fantastic performance as they are integrated into single nanowire devices [69]. For such a kind of device, lithography and sputtering techniques are frequently utilized to design and deposit interdigitated electrodes on randomly distributed nanowires for the device fabrication [70]. However, this process is only accessible for fundamental laboratory research, and assembling scalable and controllable nanowires on arbitrary substrates remain a major challenge toward performance reproducible sensor device fabrication [71].

(3) Poor environmental/thermal stability-to deeply exploit the data science from the obtained sensor signal, the long-term stability of the sensor response is highly required for time-series data collection [72]. However, performance degradation usually occurs in the nanowire-based sensor electronics because the surrounding oxygen, water, and contaminates would react with the active nanowire surface as well as the nanowire-electrode contact when the sensors are exposed to ambient air for molecular detection $[47,73,74]$.

(4) Poor sensor selectivity-although the sensitivity of the single nanowire sensor devices has been demonstrated to possess an exponential enhancement as compared with those thin-film devices $[75,76]$, it is still desired to significantly improve the selectivity of nanowire-based sensor electronics. Therefore, further efforts are still encouraged to promote MOS nanowire-based sensor electronics for the IoT applications. 
Here, in this review, we first give a comprehensive overview of the recent studies and achievements in 1D MOS nanowire synthesis, sensor device fabrication, device functionalization, and sensing mechanisms. Then, some critical issues that impede the practical application of the 1D MOS nanowire-based sensor electronics, including selectivity, longterm stability, and low power consumption, will be pointed out. Finally, we give an outlook of the remaining issues towards the lab-to-market transfer of the 1D nanostructure-based sensor electronics.

\section{Metal-oxide Nanowires Growth}

Nanowire-based electronics offers an excellent possibility for future systems beyond the limitation of Moore's law and provides a promising platform to explore the physical origin and intrinsic properties. In recent decades, significant efforts and progress have been made, and many methods have been developed to synthesize 1D metaloxide nanowires, including PVD, CVD, PLD, thermal oxidization and solution-based growth for single-crystalline nanowires, and template growth, electro-spun for polycrystalline/amorphous nanowires. Here, this section will mainly focus on the metal-oxide nanowires growth mechanism.

\subsection{Vapor-Liquid-Solid Growth (VLS Growth)}

The vapor-liquid-solid (VLS) mechanism is widely employed to grow high-quality nanowires [77-89]. In a typical VLS growth, as shown in Figure 2, a metallic catalyst droplet is firstly formed via heating the pre-deposited metal catalyst thin film. Then, by continuously feeding the vapor species to the metallic catalyst at an elevated temperature, a liquid eutectic alloy is formed. Finally, once the alloy reaches super-saturation, nanowires can be anisotropically grown from the nucleated seeds at the liquid-solid interface and the length of nanowires can be controlled by the growth time.

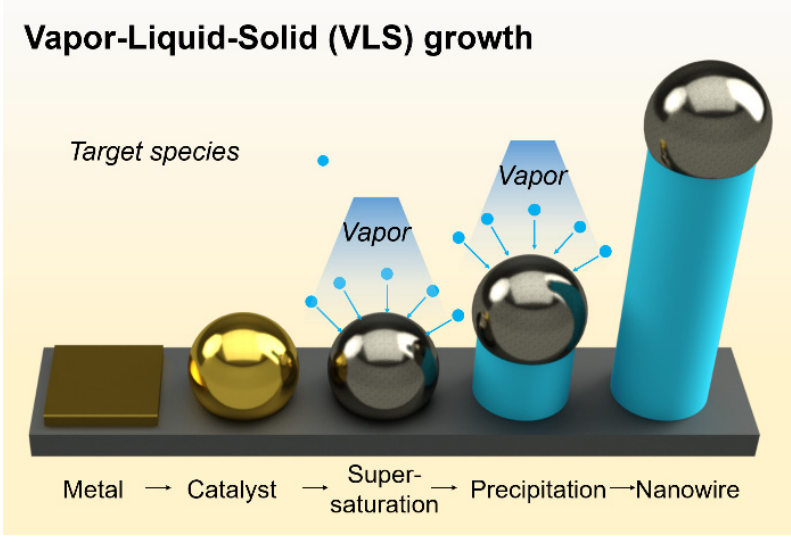

Figure 2. A typical vapor-liquid-solid (VLS) growth mechanism in metal-oxide nanowire fabrication.

In 1998, the Lieber group firstly reported a laser ablation technique for gaining VLS silicon nanowires [81]. Following this interesting work, various methods such as CVD, PVD, PLD, electron beam evaporation, and molecular beam epitaxy (MBE) have been developed to grow the metal-oxide nanowires ITO [90-92], $\mathrm{NiO}$ [93-95], ZnO [83,96], $\mathrm{SnO}_{2}[97,98], \mathrm{TiO}_{2}[99,100], \mathrm{In}_{2} \mathrm{O}_{3}[101,102], \mathrm{MgO}[103-105]$, etc. [106,107].

In recent years, the Yanagida Lab (The University of Tokyo) has made great efforts in the VLS growth of metal-oxide nanowires [85,86,94,98,99,105,108-131]. They have pointed out that materials flux is an important variable which has been underestimated in VLS nanowires growth. For example, via precisely controlling the material flux within an order of magnitude, the structure and composition of VLS growth ITO nanowires can be altered from Rutile structure (Sn 100\%, In 0\%) to Fluorite structure (Sn 28\%, In 72\%) and Bixbyite structure (Sn 21\%, In 79\%) [86]. Moreover, the proposed "material flux window" concept from their group has been successfully applied for the synthesis of $\mathrm{SnO}_{2}, \mathrm{In}_{2} \mathrm{O}_{3}, \mathrm{ITO}, \mathrm{ZnO}$, 
$\mathrm{NiO}, \mathrm{MnO}, \mathrm{CaO}, \mathrm{Sm}_{2} \mathrm{O}_{3}, \mathrm{Eu}_{2} \mathrm{O}_{3}$ and $\mathrm{MgO}$ nanowires [85]. Nevertheless, the VLS process of metal-oxides growth generally requires relatively high temperatures $\left(600-1000{ }^{\circ} \mathrm{C}\right)$, which essentially limits their practical applications.

To solve this problem, Zhu et al. demonstrated a rational method to reduce the growth temperature via using the concept of "materials flux window" [83]. As shown in Figure 3a, it was found that a reduction in growth temperature can be successfully achieved via precisely controlling the vapor flux which originates from the suppression of nucleation at the vapor-solid interface. By optimizing an appropriate vapor flux for VLS nanowire, this concept can be applied to reduce the growth temperature for various metal-oxides, including $\mathrm{ZnO}$ (from 750 to $400{ }^{\circ} \mathrm{C}$ ), $\mathrm{SnO}_{2}$ (from 750 to $400{ }^{\circ} \mathrm{C}$ ), and $\mathrm{MgO}$ (from 800 to $350^{\circ} \mathrm{C}$ ), as shown in Figure $3 \mathrm{~b}-\mathrm{d}$. In addition, it has shown a successful application of this concept for the VLS growth $\mathrm{SnO}_{2}$ nanowire on tin-doped indium oxide (ITO) glass at $500{ }^{\circ} \mathrm{C}$ and $\mathrm{ZnO}$ nanowires on polyimide (PI) substrates at $350^{\circ} \mathrm{C}$.
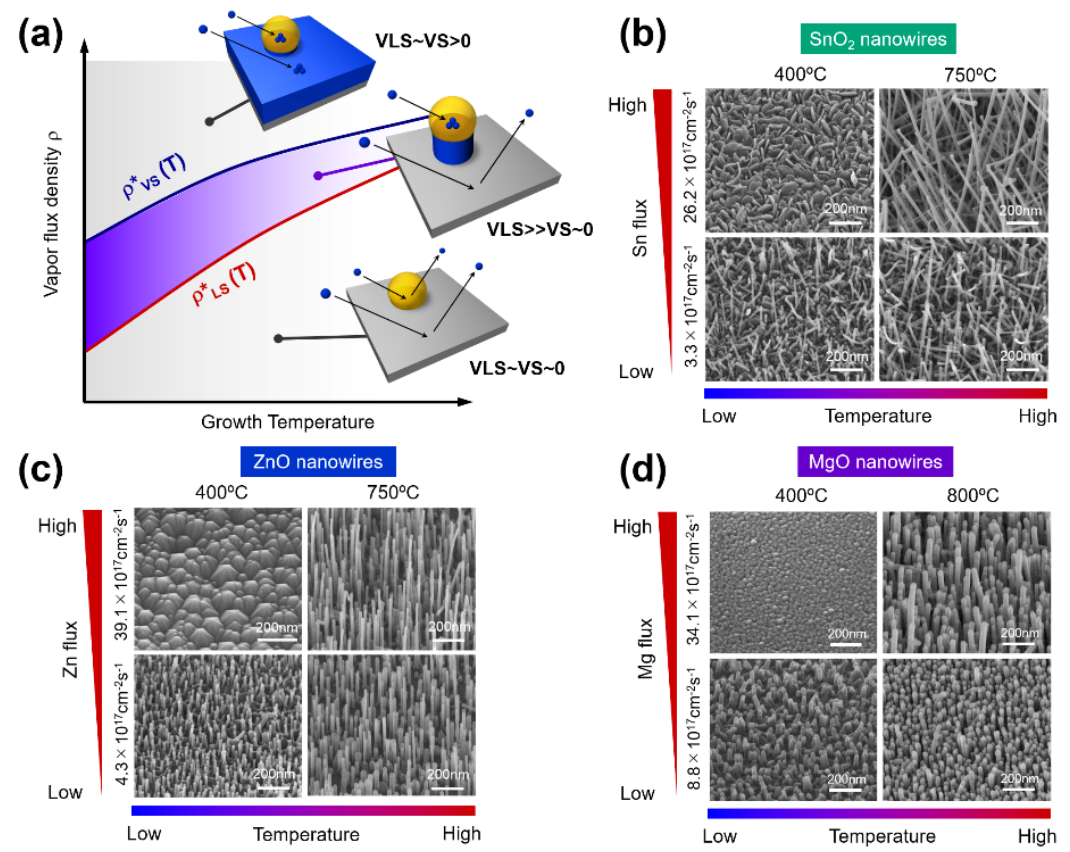

Figure 3. (a) The concept of "materials flux window" for nanowire growth (VLS, Vapor-Liquid-Solid; VS, Vapor-Solid); SEM image of (b) $\mathrm{SnO}_{2}$ nanowires; (c) $\mathrm{ZnO}$ nanowires; and (d) $\mathrm{MgO}$ nanowires fabricated under the guidance of 'materials flux window'. Reprinted from reference [83] with permission from the American Chemical Society.

\subsection{Vapor-Solid Growth (VS Growth)}

In the absence of a metal catalyst, 1D material structures can also be directly formed from the vapor phase into the solid phase, that is, the VS growth (Figure 4). In the view of the current studies, VS growth mechanisms are generally concluded as three types: (1) The anisotropic growth mechanism: nanowires can be synthesized via the preferential reactivity and binding of gas reactants on a specific surface to minimize the total surface energy [132-134]; (2) The defect-induced growth (or screw dislocations) mechanism: the growth of crystal proceeds by adding atoms at the kink sites of a surface step [135-139]; (3) The self-catalytic growth mechanism: metal-oxide can be decomposed into metal and oxygen by heating under vacuum condition, then the metal vapors are condensed and forming liquid droplets on a lower temperature substrate, and such droplets are the ideal catalysts for metal-oxide nanowire growth [140-151]. Similar to VLS growth, various metal-oxide nanowires, such as $\mathrm{Ga}_{2} \mathrm{O}_{3}, \mathrm{ZnO}, \mathrm{MgO}, \mathrm{In}_{2} \mathrm{O}_{3}$, and $\mathrm{SnO}_{2}$ [140-153], have been successfully synthesized via VS growth. Furthermore, by using surface-roughness-assisted or seed-layer-assisted VS growth, nanowires can be also grown in a selective area [154-156]. 


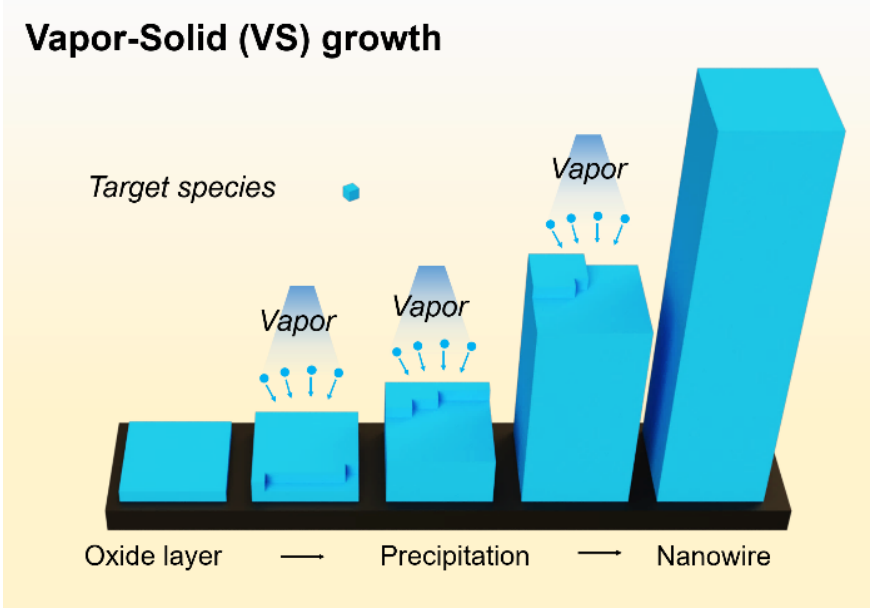

Figure 4. A typical Vapor-Solid (VS) growth mechanism in nanowire fabrication.

Compared with VLS growth, VS growth nanowires are suffering from insufficient ability to control uniformity, which usually results in a tapered morphology of nanowires. Recently, Anzai et al. reported a negative effect of VS growth on the tapered $\mathrm{SnO}_{2}$ nanowire electrical performance [79]. By using spatially resolved single nanowire electrical measurements, plane-view electron energy-loss spectroscopy and molecular dynamics simulations, it has been observed that the VS growth will generate a large number of defects in the oxides, thus making an unintentional doping in the nanowire structure. As shown in Figure $5 d$, such an unintentionally doping effect will cause a seven orders increase in the conductance, which entirely alters the intrinsic properties of nanowires. Furthermore, in light of their latest results, oxygen deficiency is the critical factor of the unintentionally doping effect in the VS growth [157]. Moreover, increasing oxygen partial pressure during the VS growth is an alternative way to prevent this drawback.

(a)

(c)
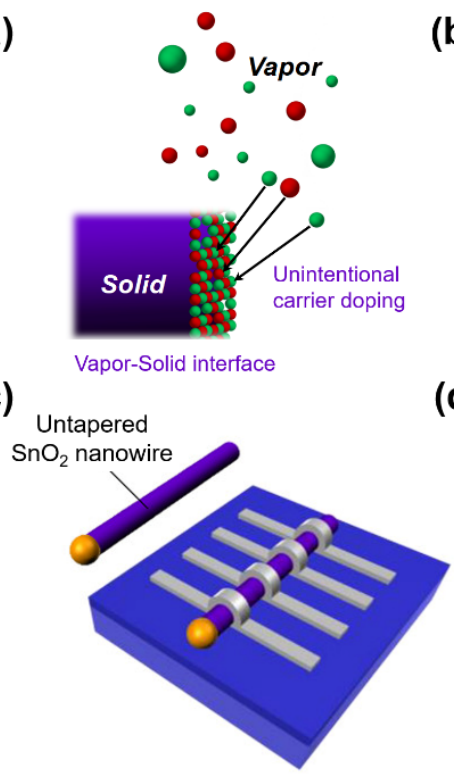

(b)

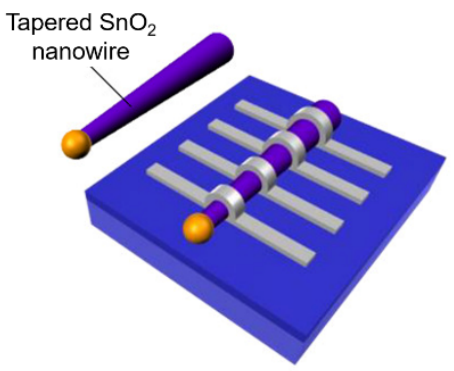

(d)

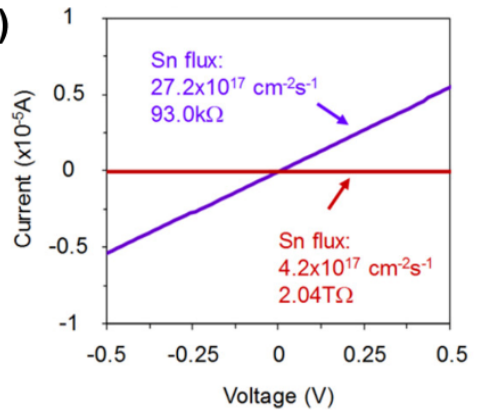

Figure 5. Anomalous electrical properties of VS growth nanowire: (a) a schematic image of unintentional carrier doping occurs at the vapor-solid interface during VS growth; (b) single tapered VS+VLS growth $\mathrm{SnO}_{2}$ nanowire device; (c) single untapered VLS growth $\mathrm{SnO}_{2}$ nanowire device; (d) IV curves of VS growth $(93.0 \mathrm{k} \Omega$ ) and VLS growth nanowire (2.04 T 2$)$; Reprinted from reference [79] with permission from the American Chemical Society. 


\subsection{Solution Phase Growth}

The solution-phase growth, for example, the hydrothermal growth, is extensively used for the synthesis of metal-oxide nanowires [64,65,158-160]. Compared with the vapor phase growth (both VLS and VS), a much lower temperature is required for the solution growth, which allows the nanowires to be directly integrated on the flexible organic substrates for the modern wearable device. In addition, the morphology and properties of the solution phase growth nanowires can be conveniently manipulated by tuning the concentration of the composition, introducing additional composition, or adding additives in the solvent.

In the case of $\mathrm{ZnO}$ nanowires, the concept of a "concentration window" in the control of $\mathrm{ZnO}$ nanowire morphology has been demonstrated by He et al., as shown in Figure 6a [111]. Via carefully controlling the concentration of $\mathrm{Zn}$ ionic species within a specific concentration range, a selective growth on the (0001) plane can be realized. Meanwhile, under the guidance of a "concentration window", Sakai et al. achieved a significant improvement in the growth rate of $\mathrm{ZnO}$ nanowires (up to $2000 \mathrm{~nm} / \mathrm{h}$ ) with the assistance of ammonia, as shown in Figure $6 \mathrm{~b}$ [161]. Moreover, Joo et al. pointed out that the axial and the radial growth of $\mathrm{ZnO}$ nanowire can also be controlled by introducing and tuning the amount of $\mathrm{Cd}(\mathrm{Cu}, \mathrm{Mg}, \mathrm{Ca})$ ions or $\mathrm{Al}(\mathrm{In}, \mathrm{Ga})$ ions in the growth solution, respectively [161]. Not only in the growth of $\mathrm{ZnO}$ nanowires, other anisotropic 1D nanowires can also be controlled via tuning the concentration of additives. For example, Choi et al. reported a straightforward process for synthesizing tungsten oxide nanostructure with various morphologies [162]. By changing the composition of the solvent, the crystalline phase of tungsten oxide, such as mono-clinic $\mathrm{W}_{18} \mathrm{O}_{49}$ nanowires (with ethanol), hexagonal $\mathrm{WO}_{3}$ platelets (with water/ethanol ratio (1:9)), and monoclinic $\mathrm{WO}_{3}$ nanosheets (with water) can be alternatively controlled. Currently, many kinds of nanowires, such as $\mathrm{SnO}_{2}$, $\mathrm{ZnO}, \mathrm{TiO}_{2}, \mathrm{In}_{2} \mathrm{O}_{3}, \mathrm{MnO}_{2}$, and $\mathrm{WO}_{3}$, have been successfully synthesized via solution-phase growth with/without the assistance of the seed layer [160,163-173]. Owing to the low cost, less hazardous, no metal catalysts, the effectively controllable morphology and properties, the solution phase growth strategy has been successfully integrated into a well-developed micro-electro-mechanical system (MEMS) [174-176].
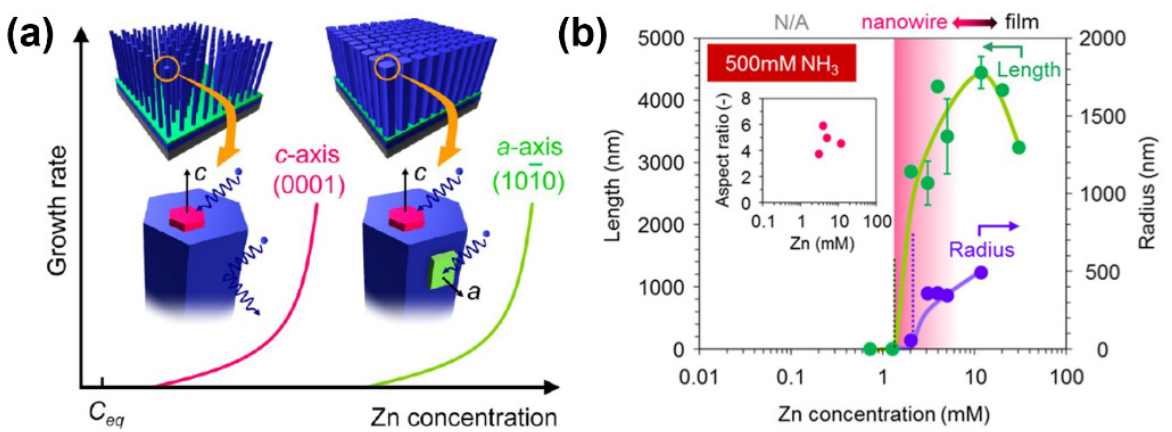

Figure 6. Face-selective control of hydrothermal zinc oxide nanowire: (a) schematic of a concentration dependence on the crystal growth of hydrothermal $\mathrm{ZnO}$ nanowires as a crystal-plane dependence on a critical nucleation concentration. Reprinted from reference [111] with permission from the American Chemical Society; (b) Zn concentration dependence of $\mathrm{ZnO}$ nanowire morphology with HMTA $15 \mathrm{mM}$ with ammonia addition $500 \mathrm{mM}$. The $\mathrm{Zn}$ concentration range, where a nanowire can be grown, is highlighted by a red color. Reprinted from reference [161] with permission from the Nature Publishing Group.

\subsection{Thermal Oxidation Growth}

The thermal oxidation method is an easy way to massively grow metal-oxide nanowires in situ [177]. For example, Sn and Ga oxide nanowires can be easily obtained as the environment temperature increases over their melting points in the air or water vapor surroundings [31,178]. Interestingly, $\mathrm{Zn}, \mathrm{W}, \mathrm{Fe}, \mathrm{Mo}$, and $\mathrm{Cu}$ oxide nanowires can be grown 
by the thermal oxidation method at an even lower temperature [179-187]. As shown in Figure $7 \mathrm{a}-\mathrm{c}$, several possible mechanisms have been invoked to account for the thermal oxidation growth: (1) Evaporation and condensation [179,188]; (2) Fast internal diffusion along a tunnel centered on the core of a screw dislocation [180,189]; (3) Surface diffusion along the sides of nanowires [181,190]. For example, $\alpha-\mathrm{Fe}_{2} \mathrm{O}_{3}$ nanowires are spontaneously grown due to the fact $\mathrm{Fe}$ ions tend to leave from the compressed regions at the $\mathrm{Fe}_{2} \mathrm{O}_{3} / \mathrm{Fe}_{3} \mathrm{O}_{4}$ interface and diffuse to the stress-free $\mathrm{Fe}_{2} \mathrm{O}_{3}$ surface layer, whereas $\mathrm{CuO}$ nanowires are basically grown due to the continuous diffusion of $\mathrm{Cu}$ ions from the substrate to the tip of nanowires through the internal grain boundary, as depicted in Figure 7d,e [181,189].
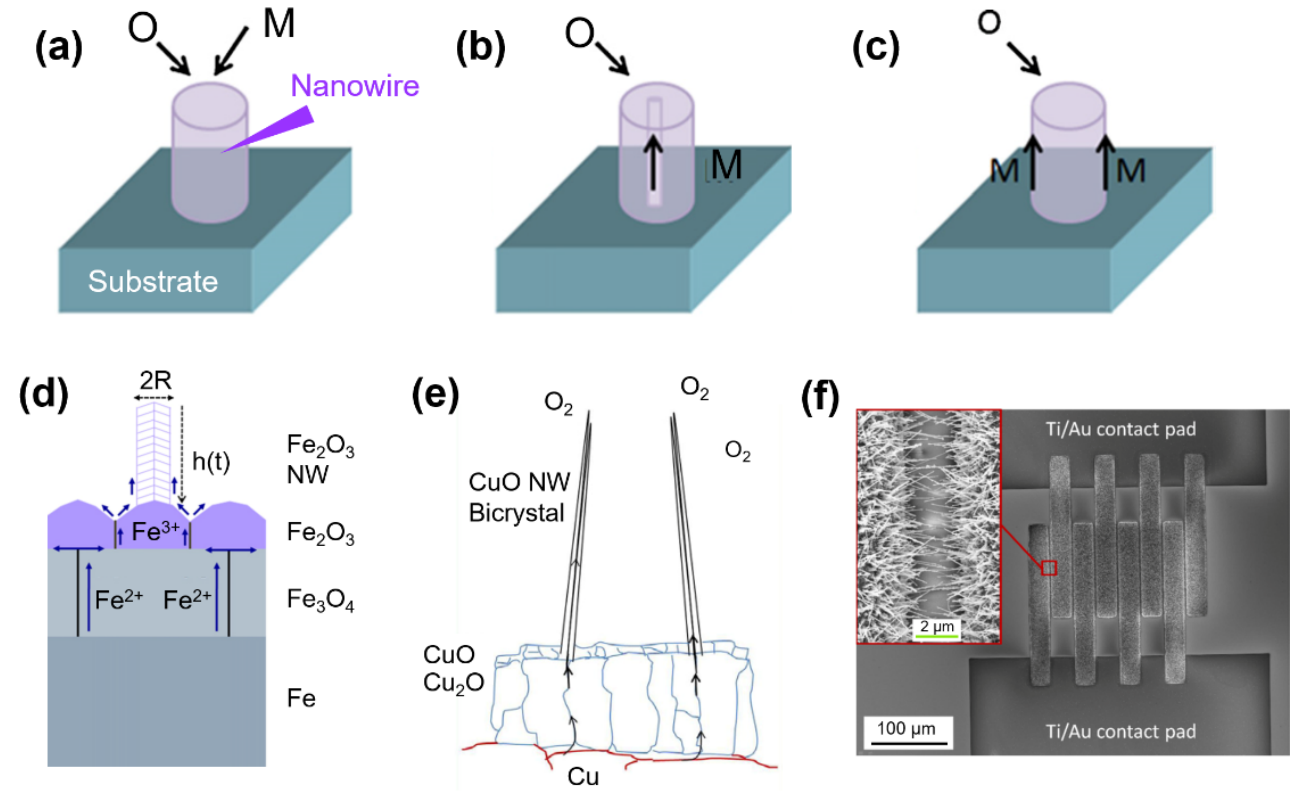

Figure 7. The various mechanisms proposed for metal-oxide nanowire (NW) growth during the oxidation of metal: (a) evaporation and condensation; (b) internal diffusion along with the core of a screw dislocation; (c) surface diffusion along the sidewall of nanowires; (d) $\mathrm{Fe}_{2} \mathrm{O}_{3}$ nanowire growth following the surface diffusion mechanism. Reprinted with permission from Reference [181] Copyright 2012 Elsevier; (e) CuO nanowire growth follows the internal diffusion mechanism. Reprinted with permission from Reference [189] Copyright 2011 Elsevier; and (f) CuO nanowire device fabricated by thermal oxidation method. Reprinted with permission from Reference [177] Copyright 2012 Elsevier.

Owing to the in situ growth behavior of nanowires, a novel and simple technology has been reported by Steinhauer et al. for the fabrication of $\mathrm{CuO}$ nanowire sensors [177]. Via heating the $\mathrm{Cu}$ layer loaded on the patterned electrodes in air, $\mathrm{CuO}$ nanowires were naturally grown from the electrodes. By increasing the growth time, nanowires on foreign electrodes were mutually attached, forming the nanowire-nanowire conductive junctions as a functional sensing channel. Due to its simplicity and lack of post-processing steps after nanowire synthesis, this technique has been extensively employed to integrate $\mathrm{CuO}$ nanowires in a sensing device [191-193].

\subsection{Template-Assisted Growth}

Metal-oxide nanowires can be achieved by merely depositing oxide materials into an organic template such as poly(methyl methacrylate) (PMMA) or an inorganic template such as anodic aluminum oxide (AAO). The diameter, density, and length of the nanowires can be conveniently controlled based on the template design, as shown in Figure 8. Kolmakov et al. has shown a typical inorganic template-assisted growth method to synthesize $\mathrm{SnO}_{2}$ nanowires [29]. By depositing $\mathrm{Sn}$ into nanoporous alumina and further etching the template by $\mathrm{NaOH}$ solution (or cracking by sonication), highly crystalline Sn nanowires 
are harvested. Then, via processing an air annealing on the metallic $\mathrm{Sn}$ nanowires, $\mathrm{SnO}_{2}$ nanowires are obtained.

(a)

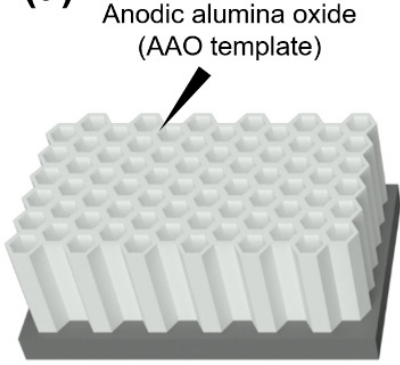

(b)

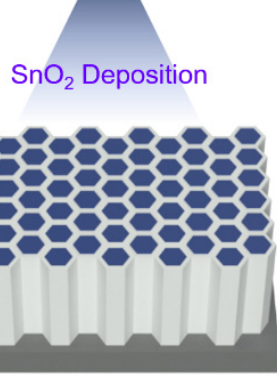

(c)

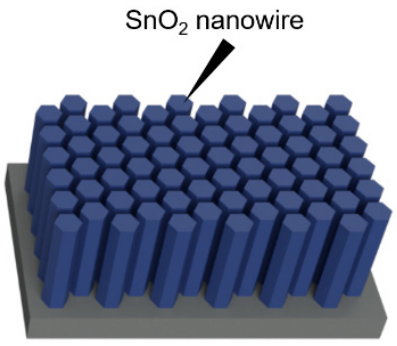

Figure 8. Schematic image of (a) the highly regular AAO template; (b) the template cross-section with nanowires deposited inside the nanopores; and (c) nanowires after removing the AAO template.

Ra et al. reported the use of an organic template for obtaining $\mathrm{ZnO}$ nanowires [194]. As depicted in Figure 9, a-carbon was first deposited on the $\mathrm{SiO}_{2} / \mathrm{Si}$ wafer as an etch-stop layer. Then, the wafer was coated by a sacrificial layer via plasma-enhanced chemical vapor deposition (PECVD). Then, the PECVD layer was patterned using conventional lithography and etched by the $\mathrm{CF}_{4}$ / Ar inductively coupled plasma (ICP) process. Then, an atomic layer deposition (ALD) process was used to create a $70 \mathrm{~nm} \mathrm{ZnO} \mathrm{layer} \mathrm{over} \mathrm{the} \mathrm{pre-patterned}$ sacrificial layer. Then, by ICP etching with $\mathrm{Cl}_{2}$ / Ar discharges, the $\mathrm{ZnO}$ layer was removed except for the spacer part. Finally, $\mathrm{ZnO}$ nanowire arrays were obtained by removing the sacrificial oxide layer. A similar fabrication process for $\mathrm{CuO}, \mathrm{NiO}$, and $\mathrm{Cr}_{2} \mathrm{O}_{3}$ nanowires has also been recently reported [195]. Such patterning methods by using lithography techniques can prevent the problems associated with the alignment of the nanowires.

(a)

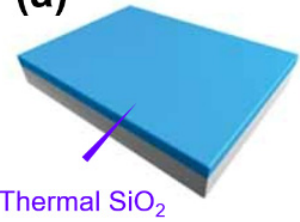

(e)

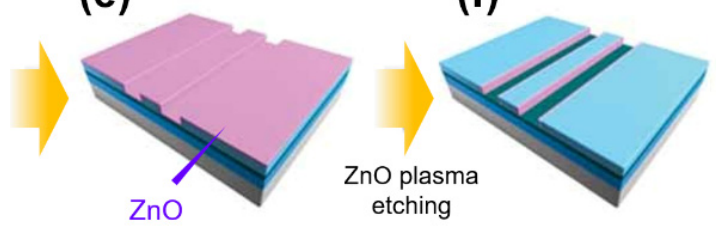

(c)

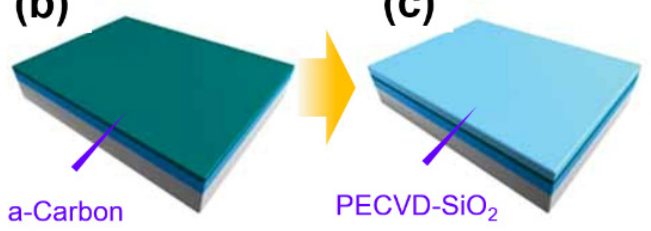

(d)

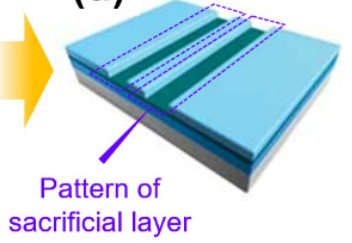

sacrificial layer
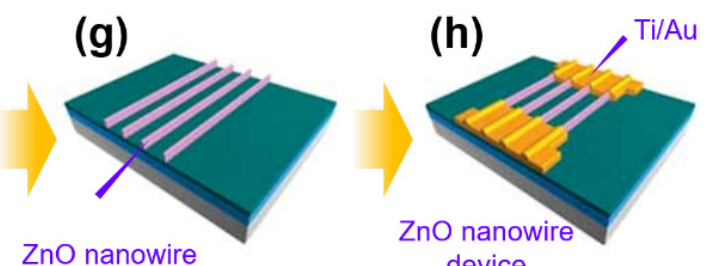

device

Figure 9. Schematic diagram illustrating the fabrication processes of the $\mathrm{ZnO}$ nanowire device based on nanoscale spacer lithography: (a) thermal $\mathrm{SiO}_{2}$ deposition; (b) a-carbon deposition (etch-stop layer); (c) Plasma-enhanced chemical vapor deposition (PECVD) of $\mathrm{SiO}_{2}$ (sacrificial layer); (d) sacrificial layer patterning; (e) $\mathrm{ZnO}$ atomic layer deposition (ALD); (f) top view after $\mathrm{ZnO}$ plasma etching; (g) sacrificial layer removal; and (h) $\mathrm{ZnO}$ nanowire device after metal electrode deposition. Reprinted from reference [194] with permission from the Copyright 2008 Wiley.

\subsection{Electro-Spun Growth}

Electro-spinning is one of the easiest, template-free, versatile, and cost-effective approaches to produce 1D nanostructures. Almost all the oxides and mixed oxides nanowires can be fabricated using this method [196-210]. Figure 10 shows a typical example of nanowires/nanofibers fabrication by electro-spun growth [201]. As shown in Figure 10a, an appropriate ratio of dimethylformamide, poly(vinyl acetate) (PVA), titanium(IV) propox- 
ide, and acetic acid are mixed as the precursor solution. Then, the solution is loaded into a syringe, which is connected to a high-voltage supply. Afterward, the precursor solution was directly spun onto the $\mathrm{Al}_{2} \mathrm{O}_{3}$ substrate with pre-patterned Pt electrode arrays. Finally, nanofibers are pressed under $120^{\circ} \mathrm{C}$ to prevent sticking and further calcined in air at $450{ }^{\circ} \mathrm{C}$, and thus $\mathrm{TiO}_{2}$ nanofibers sensors with the mat-like structure are obtained. Due to the simple and inexpensive fabrication process, electrospinning has attracted increasing attention in the commercial field.

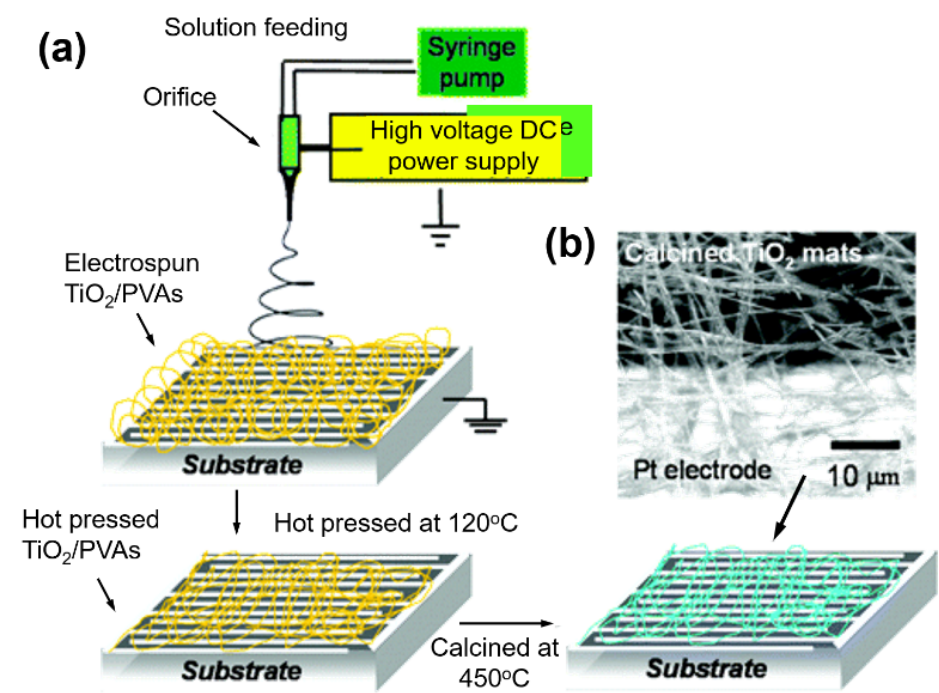

Figure 10. (a) Schematic diagram of the processing steps used to fabricate $\mathrm{TiO}_{2}$ nanofiber mats on $\mathrm{Al}_{2} \mathrm{O}_{3}$ substrates with interdigitated Pt electrode arrays. PVA (Polyvinyl acetate); and (b) the micrograph of a calcined TiO2 nanofiber mat on top of the $\mathrm{Al}_{2} \mathrm{O}_{3}$ substrate (dark region) and Pt electrode (bright region). Reprinted from reference [201] with permission from the American Chemical Society.

\section{Metal-oxide Nanowire Devices Fabrication}

To study the intrinsic properties of nanowires and use their functionality as a sensing element, one necessary process is transferring nanowires from the growth substrate and integrating them with contact electrodes on a platform. As shown in Figure 11, the current nanowire-based device can be divided into two types: (a) individual nanowire device; and (b) multiple nanowire devices.

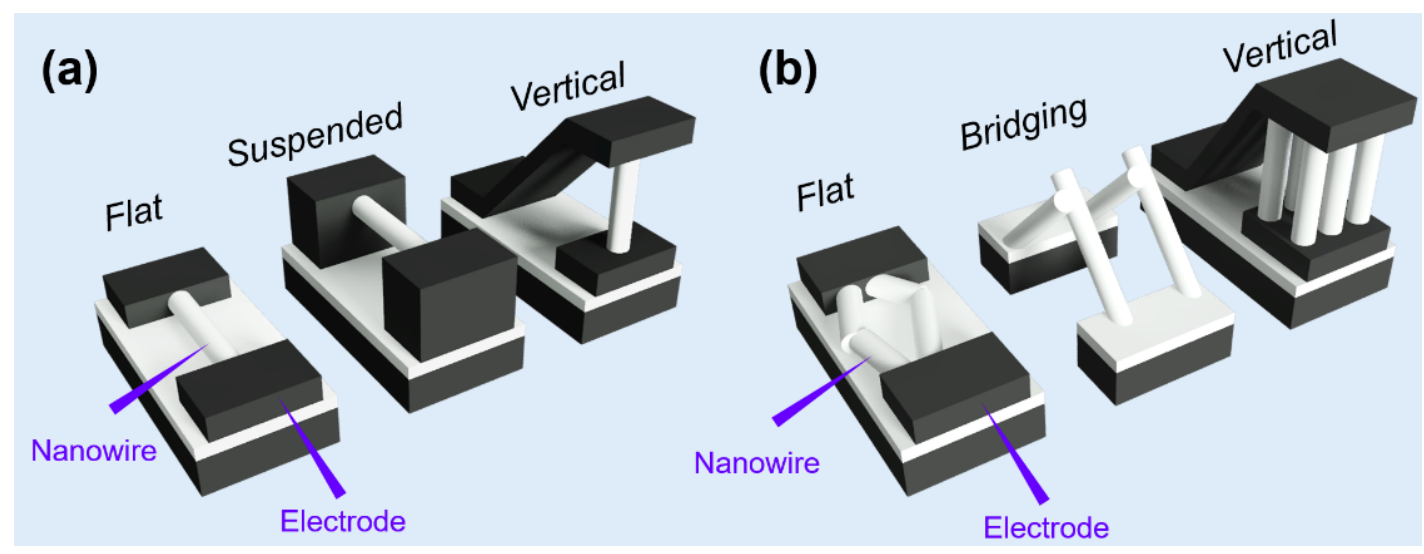

Figure 11. Schematic image of (a) an individual nanowire device with different structures (flat, suspended, and vertical); and (b) multiple nanowire device (flat, bridging, and vertical). 


\subsection{Individual Metal-Oxide Nanowire Device}

Due to the fast development of modern electronics, individual metal-oxide nanowire devices such as the field-effect transistor (FET) offer a great chance to explore the electrical, chemical, and mechanical properties of the nanowire.

\subsubsection{Device with Flat Structure}

A "pick and place" is a common technique in fabricating individual nanowire devices. First, one must "pick" metal-oxide nanowires from the growth substrate. The substrate with nanowires should be immersed in a readily volatile solvent such as isopropanol, ethanol, methanol, and even water. Then, the metal-oxide nanowires are transferred from the growth substrate and dispersed into solvents under the ultrasonic wave. One must then 'place' the nanowires. One drop of solvents containing dispersed nanowires should be placed on the platform with pre-deposited electrode pads and dried by simple evaporation. With the assistance of optical scope or SEM observation, the relative positions of nanowires to the pre-deposited markers are recorded. Then, the platform should be covered with a layer of photoresist by spin coating technique. By combining laser/electron-beam lithography and sputtering deposition (or using focused ion beam technique), nanowires can be connected with the electrode pads. Finally, the additional metal and photoresist can be removed by a lift-off process in the organic solvent such as N-methyl-2-pyrrolidone (NMP), dimethylformamide (DMF), and ethanol. The schematic image of the individual nanowire device fabrication process can be seen in Figure 12. Other novel fabrication processes can be seen in the latest review [211].

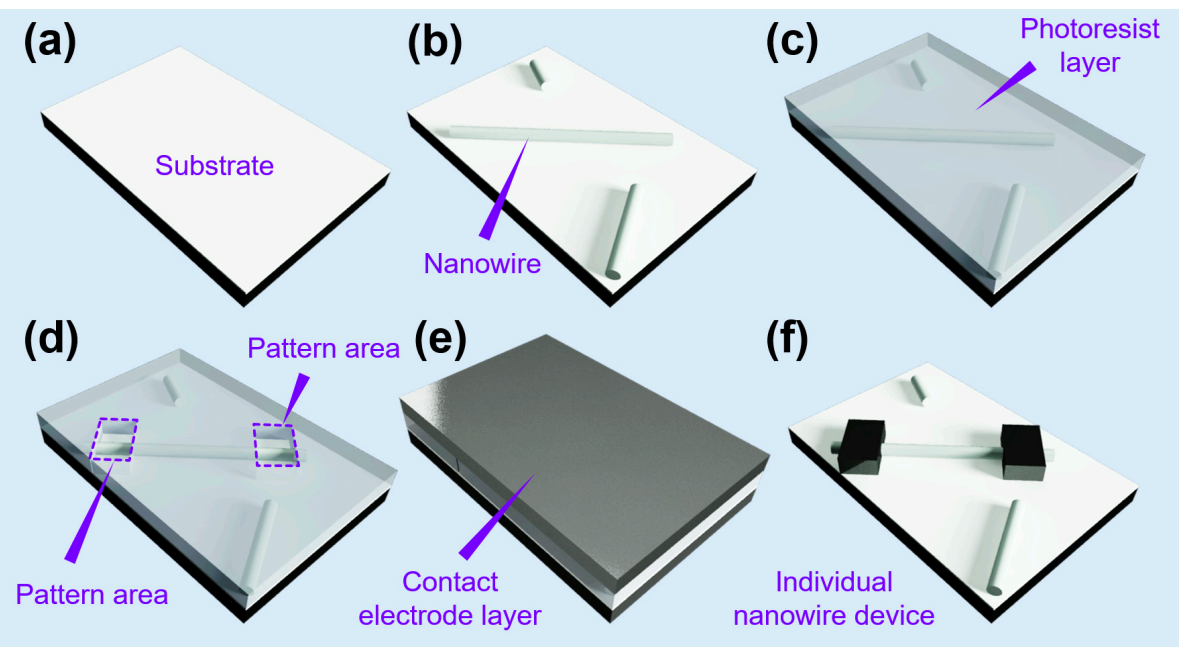

Figure 12. A schematic diagram illustrating the fabrication processes of individual nanowire devices: (a) substrate; (b) transferring nanowires onto the substrate; (c) photoresist coating (sacrificial layer); (d) sacrificial layer patterning; (e) contact electrode deposition; (f) individual nanowire device after lift-off process.

\subsubsection{Device with Suspended Structure}

Due to the sensor heating, the hot air near the sensor surface will form a layer which is likely to support convective processes leading to the concentration gradients of reactive analyte gases, termed as stagnant layer [212]. Such a layer can measure up to several tens of nanometers, and it is comparable with the nanowire size, which will cause insufficient exposure to the target molecules [213,214]. To prevent this problem, a suspended structure has been developed to improve sensor performance. The suspended structure is a highly favorable configuration because the nanowires are surrounded by the gas atmosphere. As shown in Figure 13, the fabrication process of a suspended nanowire device is similar to that of a flat nanowire device. However, it requires one more sacrificial layer (inorganic $\mathrm{MgO}$ /organic PMMA) before the drop of nanowire solvent (Figure 13b). The overall 
enhancement in the performance of the nanodevice is benefited from the suspended structure. For example, Nima et al. fabricated a stable, reproducible $\mathrm{ZnO}$ nanowire humidity sensor with a suspended structure [215]. It is observed that the suspended nanowire device presented an exponential change (over five orders) of resistance in response to relative humidity from $0 \%$ (dry air) to $60 \%$ at room temperature. This improvement is strongly associated with a subthreshold carrier modulation in the nanowire core, the high surface-to-volume ratio of the nanowire, and most importantly, complete exposure of the nanowire surface to air. Owing to the gigantic enhancement in gas sensing response, the development of metal-oxide nanowire gas sensors with the suspended structure has been extensively studied [214,216-220].

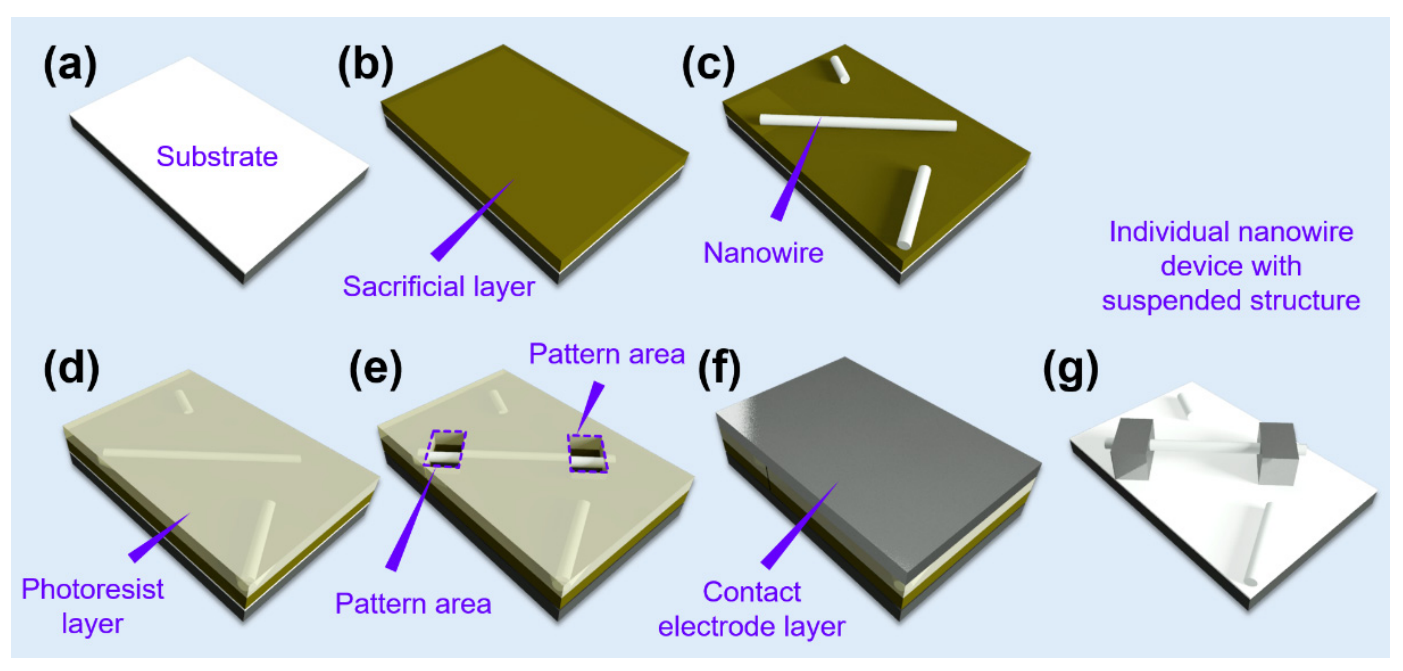

Figure 13. A schematic diagram of the individual suspended nanowire device fabrication process: (a) substrate; (b) photoresist coating (sacrificial layer); (c) transferring nanowires onto the substrate; (d) photoresist coating (sacrificial layer); (e) sacrificial layer patterning; (f) contact electrode deposition; and (g) individual nanowire device with suspended structure after the lift-off process.

\subsubsection{Device with Vertical Structure}

Similar to the suspended nanowire device, sensors with a vertical structure have also been considered a promising design for gas detection due to their 3D architecture. Unfortunately, the conventional "pick and place" technique cannot obtain individual nanowire devices with vertical structures due to the current limitation in nanotechnology. To date, a few papers reported the individual nanowire sensor devices with a vertical structure [221,222]. Offermans et al. offered a potential way to achieve the individual nanowire gas sensor with vertical structure [223,224]. As shown in Figure 14, vertical indium arsenide (InAs) nanowires are firstly grown on an $\operatorname{InP}(111) \mathrm{B}$ wafer. Then, the nanowires were patterned into arrays ranging in size from $30 \mu \mathrm{m} \times 30 \mu \mathrm{m}$ to $100 \mu \mathrm{m} \times 100 \mu \mathrm{m}$ via combining the sacrificial resist layer and etching process. Finally, using the sacrificial resist layer with sputtering deposition, air bridges were formed to make electrical connections. In view of their device structure, it is possible to achieve a device with fewer nanowire connections or even a single nanowire connection by shrinking the size of the patterned array. Meanwhile, it was shown that this vertical structure of the sensor device presents a very high sensitivity to $100 \mathrm{ppb}$ of $\mathrm{NO}_{2}$ at room temperature. However, due to the uncertainty and complexity of this process, it is impossible to massively fabricate such a device with individual vertical nanowires. To the best of our knowledge, to date, there has been no report using individual metal-oxide nanowires with vertical structure as the gas sensor. 

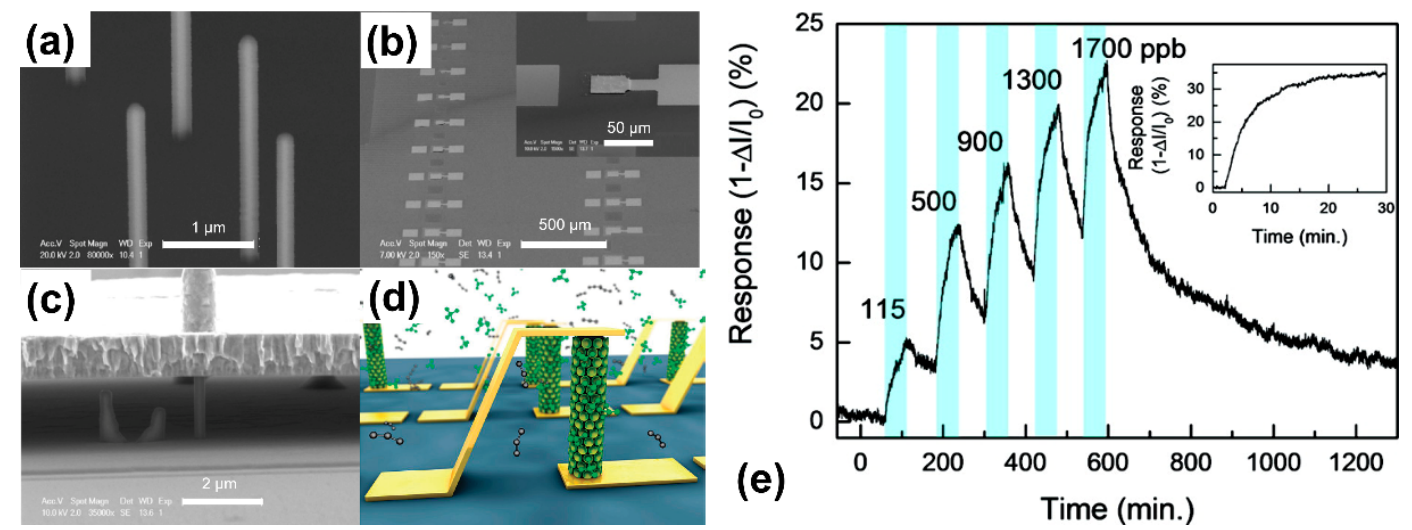

Figure 14. The fabrication process of the individual vertical nanowire device: (a) as-grown nanowires; (b) patterned nanowire arrays with air bridging contact; (c) a side view of an air bridge contact; (d) schematic image of the individual nanowire with a vertical structure; (e) the gas sensing performance of vertical aligned indium arsenide (InAs) nanowires sensor. Reprinted from reference [223] with permission from the American Chemical Society.

\subsection{Metal-Oxide Multiple Nanowire Device}

Due to the requirement of precise alignment between the single nanowire and predeposited patterned electrodes, the overall fabrication process of the individual nanowire device is complicated, time-consuming, and expensive [225-229]. Furthermore, high accuracy and stable electrical measurement systems are needed to obtain the electrical sensing signals of the single nanowire sensor devices [75]. To simplify the fabrication process and electrical signal measurement, multiple nanowire devices become the most widely accepted device design in practical sensor device applications.

\subsubsection{Device with Flat Structure}

A mat-like nanowire structure is similar to the single nanowire device with a flat structure, while the fabrication process is much easier than that of the single nanowire device. In a typical mat-like structure, the device can be loaded easily via two steps. As shown in Figure 15, nanowires can be firstly transferred from the growth substrate onto a platform, and then the contact electrodes are deposited by utilizing a mask with sputtering. Alternatively, the electrodes can be firstly pre-deposited on the platform, and finally nanowires are transferred on the surface of electrodes. Both of the two methods are simple, costless, and unnecessary pre/post-process. Due to its convenience in terms of fabrication process, various metal-oxide nanowire gas sensors, including $\mathrm{SnO}_{2}, \mathrm{ZnO}$, $\mathrm{WO}_{3}, \mathrm{TiO}_{2}, \mathrm{NiO}, \mathrm{CuO}$ [230-235], are successfully obtained by this method. Moreover, this technique is in favor of flexible sensor electronics integration.

\subsubsection{Device with Bridging Structure}

Due to the easy fabrication, in situ controllable nanowire growth position, and 3D architecture, bridging structure is another promising design for nanowire gas sensors $[43,177,191-193,236-267]$. In the typical fabrication process of the device with a bridging structure, bottom electrodes should be firstly deposited on the substrate, then a seed/catalyst layer will be deposited on the top of the bottom electrodes. Finally, nanowire will be grown in situ only on the seed/catalyst layer, as shown in Figure 16. With the increase in the growth time, nanowires will incline and contact other nanowires, forming nanowire-nanowire junctions, which can be utilized as a sensing channel for gas detection. Such on-chip growth nanowire sensors can prevent nanowire-electrode contact issues encountered by the flat nanowire sensor devices, and these kind of sensors show a more stable physical and electrical performance than the sensors fabricated by spinning, dropping, or spray coating technique. Park et al. firstly reported a comparison study of $\mathrm{NO}_{2}$ sensing between air-bridged nanowire sensors and conventional nanoparticle sensors [251]. 
Owing to a higher exposed area to the surroundings, the bridging structure shows a faster response and recovery rates as compared with that of nanoparticle sensors. Meanwhile, Kim et al., Jung et al., and Hung et al. systematically studied the effect of nanowire junction density on the device sensing performance $[245,253,260]$. Through the controlling of nanowire growth time, the number of nanowire-nanowire junctions within the bridging sensor structures can be quantitatively manipulated. Furthermore, it was found that the bridged structures with a high density of junctions show a high sensing performance to $\mathrm{NO}_{2}$. However, the response and recovery time of the bridging nanowire device with a high density of junctions are slower than that of the low-density nanowire device, because a long time is needed for the molecules' diffusion in the high density of nanowire network.

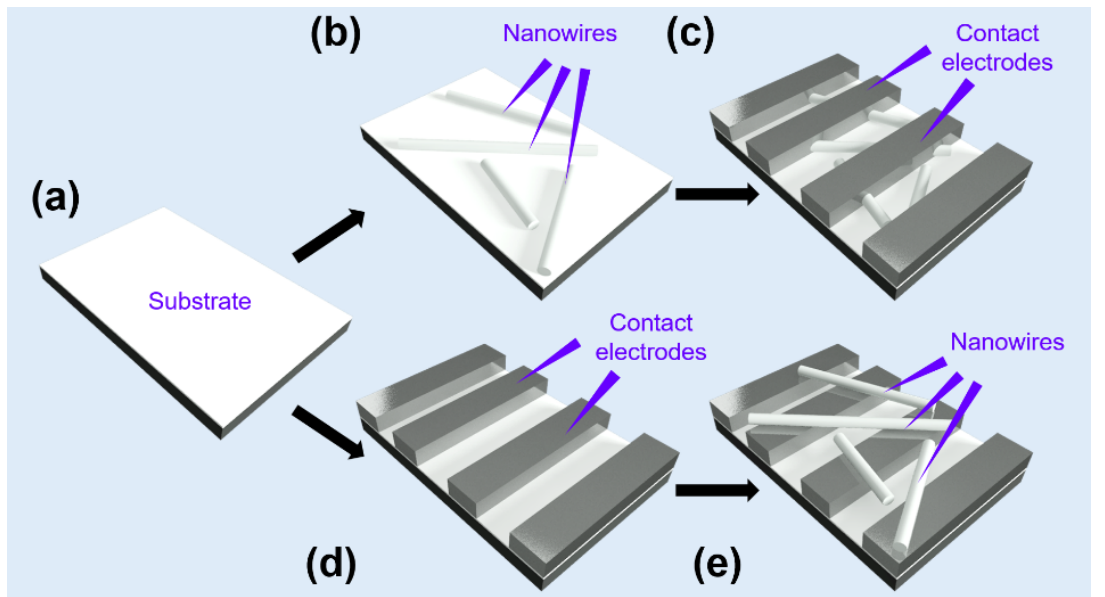

Figure 15. Two typical methods for making a mat-like metal-oxide nanowires device: (a) platform; (b) nanowires transferred onto the platform; (c) contact electrode deposition; (d) contact electrode deposition; and (e) nanowires transferred onto the platform.

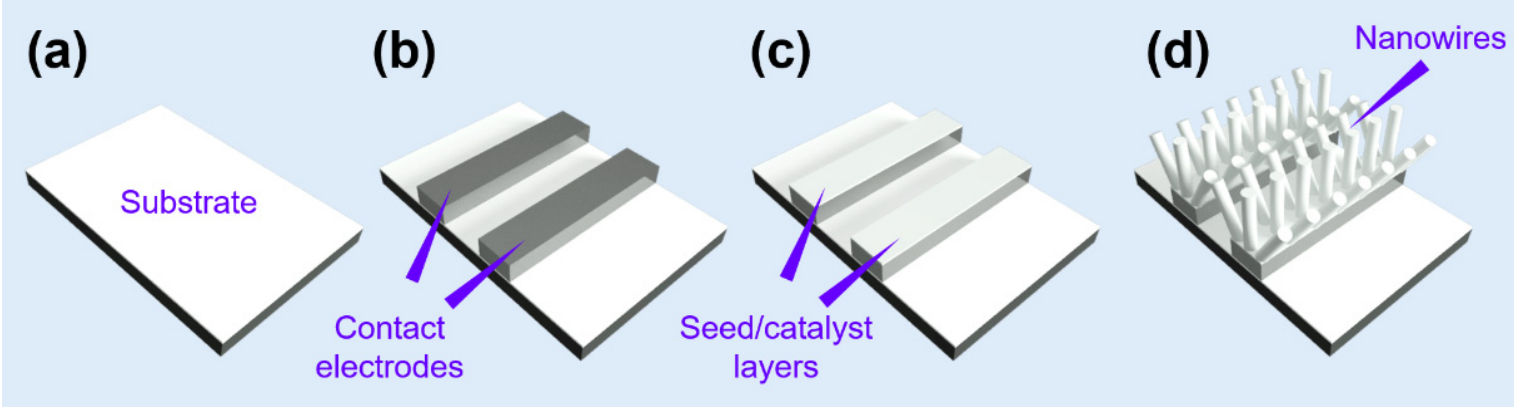

Figure 16. A typical method for making bridging metal-oxide nanowires device: (a) substrate; (b) bottom electrode deposition; (c) seed/catalyst layer deposition; and (d) in situ growth of metal-oxide nanowire on electrodes.

\subsubsection{Device with Vertical Structure}

Recently, the nanowire array sensors with the vertical structure are promising due to their porosity structure and reliable electrical performance [268-270]. To obtain a vertical nanowire sensor, three steps are typically needed, as shown in Figure 17. First, nanowires are grown vertically on the substrate through solution-phase/vapor-phase methods. Then, the nanowires are covered by spin coating a layer of organic photoresist. By precisely controlling the thickness of photoresist on a nanowire array via etching process, the tips of nanowires will be exposed. Afterwards, a metal contact layer is deposited onto the photoresist and connected with all the tips of the nanowires. Finally, a vertical structure of the sensor device can be achieved by removing the unnecessary photoresist. Cao et al. has demonstrated the integration of a vertical $\mathrm{WO}_{3}$ nanowire sensor with high sensitivity 
to $\mathrm{NO}_{2}$ [268]. It is shown that the vertical device exhibited the capability to detect $\mathrm{NO}_{2}$ concentrations down to the $50 \mathrm{ppb}$ level, which shows a promising future in the field of low concentration gas detection. In addition, Chen et al. has proposed a sensor array composed of vertical device structures with different noble metal decorations ( $\mathrm{Pd}, \mathrm{Pt}$, and $\mathrm{Au}$ ) for selective gases detection [48]. Several different types of sensors are fabricated via altering the selection of decorating materials.

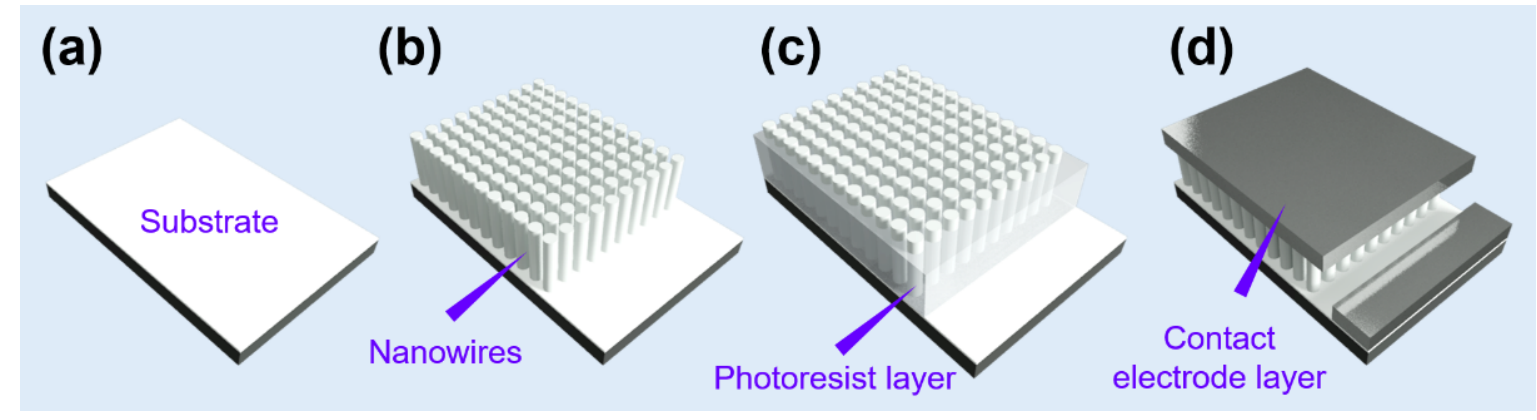

Figure 17. A typical method for making a vertical metal-oxide nanowires device: (a) the substrate with the seed/catalyst layer; (b) nanowires are grown vertically; (c) photoresist coating with the further etching process; and (d) top contact electrode deposition and the removal of photoresist.

\section{Current Progress in Performance Tailoring of Metal-Oxide Nanowire-Based Gas Sensors}

Although metal-oxide nanowires have already shown great potential as gas sensing materials, further efforts are still encouraged to enhance the sensing performance of nanowire-based sensor electronics, such as gas species discrimination from mixtures, low concentration, and room temperature detection. To achieve such goals, introducing additives on the nanowire surface has been proved to be an easy and effective approach.

\subsection{Nanoparticles Decoration (NPs Decoration)}

The loading of noble metal/oxide nanoparticles with a nanometer size onto a metaloxide nanowire surface has been widely employed for functionalizing the nanowire-based sensors due to their low cost and simplicity in the fabrication process. Here, we introduce one common method (not least) to load nanoparticles on nanowires. For noble metal nanoparticle decoration as an example, a noble metal (M) precursor solution was firstly prepared by dissolving appropriated $\mathrm{HMCl}_{\mathrm{x}} \cdot \mathrm{H}_{2} \mathrm{O}$ into $\mathrm{H}_{2} \mathrm{O}$ (ethanol, etc.). Then, by simply immersing nanowires in the above solution for a proper time and calcined at high temperature, M-loaded nanowires can be obtained. This method can also be used for metal-oxide nanoparticle decoration, despite using different precursors. Currently, there are two coexisting mechanisms to understand the sensing performance of decorated nanowires: (1) chemical sensitization (spillover effect): noble metal nanoparticles can promote the dissociation of molecules and oxygen on nanowire surface, leading to an efficient chemical reaction. Moreover, owing to the noble metal-induced lower energy barrier for gas adsorption and desorption, the response and recovery rates can be accelerated [271]; (2) electronic sensitization: the interface between oxidized noble metals (or oxide nanoparticles) and nanowires usually form a thicker electron depletion layer with a narrow channel. During exposure to the target molecules, the concentration of charge carriers can be efficiently modulated [272]. To date, researchers have made significant progress in fabricating nanoparticles decorated nanowire sensors. Through optimizing the decorated material selection/combination, the size of nanoparticles, and the surface coverage of nanowires, it is accessible to realize the fabrication of functionalized nanowire sensors with high sensitivity, high selectivity, and low working temperature. A detailed overview of the sensing performance of noble metal-decorated metal-oxide nanowire gas sensors is summarized in Table 1. 
As for sensitivity, Kolmakov et al. firstly reported the use of noble metal (Pd) functionalized with metal-oxide nanowire $\left(\mathrm{SnO}_{2}\right)$ device for the sensitivity enhancement [273]. As shown in Figure $18 \mathrm{~d}$, due to (1) oxygen dissociation on Pd nanoparticles by spillover effect, and (2) the diffusion of weakly adsorbed oxygen on nanowire surface to Pd nanoparticles, it is found that the Pd nanoparticles decoration can dramatically enhance the device sensing performance to $\mathrm{O}_{2}$ and $\mathrm{H}_{2}$. Motivated by this encouraging result, to date, tremendous efforts via noble metal/oxide nanoparticles decoration are being intensively investigated for enhancing device sensitivity [87,273-277].

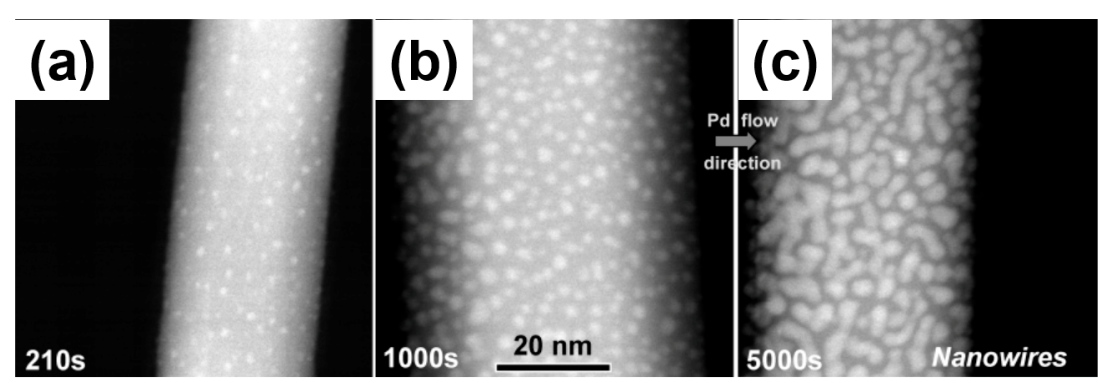

(d)

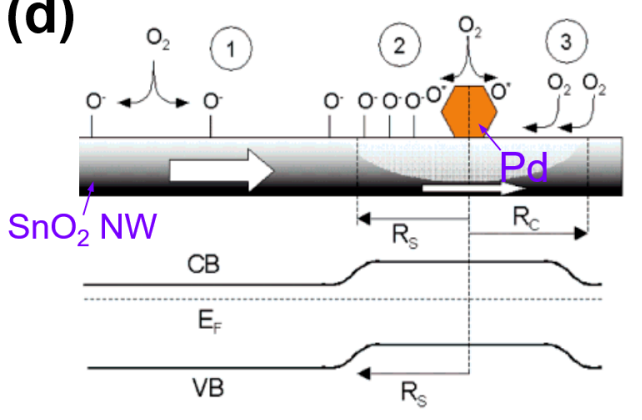

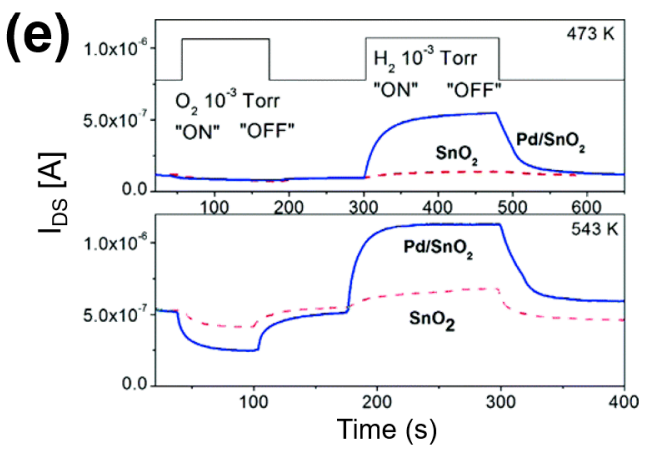

Figure 18. (a-c) Nanoparticles decorated metal-oxide nanowire with different coverage; (d) schematic depiction of the three major processes taking place at $\mathrm{SnO}_{2}$ nanowire surface and their band diagram; and (e) compared studies of the sensing performance of $\mathrm{SnO}_{2}$ and $\mathrm{SnO}_{2} / \mathrm{Pd}$ nanowire sensor devices. Reprinted from reference [273] with permission from the American Chemical Society.

Nanoparticle decoration is also an alternative way to dramatically improve the selectivity of the nanowire-based sensors [174,272,274-286]. For example, Kim et al. reported a $\mathrm{ZnO}$ nanowire sensor with high sensitivity and selectivity toward $\mathrm{H}_{2}$ via $\mathrm{Pd}$ nanoparticle decoration [274]. Due to the synergistic effect of chemical sensitization of Pd nanoparticles and metallization effect of $\mathrm{ZnO}$, the sensing response to $\mathrm{H}_{2}, \mathrm{O}_{2}, \mathrm{NO}_{2}, \mathrm{C}_{6} \mathrm{H}_{6}$, and $\mathrm{C}_{7} \mathrm{H}_{8}$ are increased by 3214.1, 1.6, 7.8, 17.2, and $166.9 \%$, respectively. Moreover, compared with pristine nanowire, the Pd-decorated $\mathrm{ZnO}$ nanowire shows a capability to detect $0.1 \mathrm{ppm}_{2}$ with a wide temperature range from 150 to $350{ }^{\circ} \mathrm{C}$. Byoun et al. reported a $\mathrm{TeO}_{2}$ nanowires gas sensor by surface decoration with oxide nanoparticles [280]. Due to the formation of $\mathrm{p}-\mathrm{n}$ heterojunctions between $\mathrm{p}$-type $\mathrm{TeO}_{2}$ nanowire and n-type $\mathrm{ZnO}$ nanoparticles, the $\mathrm{TeO}_{2}$ nanowires become more resistant and suitable for sensing oxidizing gas, especially since it shows an excellent $\mathrm{NO}_{2}$ selectivity in comparison with interfering gases such as $\mathrm{SO}_{2}, \mathrm{CO}$, and $\mathrm{C}_{2} \mathrm{H}_{5} \mathrm{OH}$.

Furthermore, surface decoration with noble metal/oxide nanoparticles has been regarded as an effective way in lowering down the sensor operation temperature [280,287-295]. For example, as reported by Liang et al., due to the spillover effect and the change in depletion layer caused by $\mathrm{Au}$ nanoparticles, the $\mathrm{Au}$ decorated $\mathrm{VO}_{2}$ nanowires sensor exhibits an excellent sensing performance to $\mathrm{NO}_{2}$ at $0.5-5 \mathrm{ppm}$ at room temperature [285]. Lupan et al. have reported that $\mathrm{Au}$ nanoparticle decoration on $\mathrm{ZnO}$ nanowire surface can realize the $\mathrm{H}_{2}$ room temperature detection [289], Choi et al. found that $\mathrm{Pd}$ nanoparticles decoration on 
$\mathrm{ZnO}$ nanowires enables the $\mathrm{CO}$ sensing at room temperature [287] and Hong et al. have reported the $\mathrm{Cu}_{2} \mathrm{O}$ nanoparticles-decorated $\mathrm{ZnO}$ nanowire sensor could realize the room temperature sensing of NO [296].

In addition, the effects of decorated nanoparticle size and density have also been intensively investigated $[192,271,282,296,297]$. For example, Lee et al. have studied the size effect of Au nanoparticles on the $\mathrm{CuO}$ nanowire sensor [192]. As the diameter of $\mathrm{Au}$ nanoparticles decreases, the sensing responses of the nanowire sensor present an increase to $\mathrm{NO}_{2}$ and $\mathrm{CO}$, and a maximum performance appears when $60 \mathrm{~nm}$ of Au nanoparticles are decorated on the $\mathrm{CuO}$ nanowire surface. Meanwhile, they have pointed out that the size of nanoparticles should be carefully optimized to prevent sufficient surface coverage, since excessive surface coverage would cause the steric hindrance on the nanowire surface, which is harmful to gas sensing.

Table 1. A detailed overview of sensing performance of noble metal-decorated metal-oxide nanowire gas sensors.

\begin{tabular}{|c|c|c|c|c|c|c|c|}
\hline NWs & NPs & Target Gas & $\begin{array}{l}\mathrm{T}_{\text {oper }} \\
\left({ }^{\circ} \mathrm{C}\right)\end{array}$ & $\begin{array}{l}\text { LOD } \\
(\mathrm{ppm})\end{array}$ & Response & $\begin{array}{c}\text { Response } \\
\text { Time(s) }\end{array}$ & Ref. \\
\hline \multirow{15}{*}{$\mathrm{SnO}_{2}$} & $\mathrm{Ag}$ & $\mathrm{NH}_{3}$ & 450 & 0.05 & $300 @ 100$ ppm & 45 & [298] \\
\hline & $\mathrm{Au}$ & $\mathrm{NO}_{2}$ & 200 & 0.1 & $2 @ 0.1$ ppm & $\mathrm{N} / \mathrm{A}$ & [299] \\
\hline & $\mathrm{Au} / \mathrm{ZnO}$-branching & $\mathrm{NO}_{2}$ & 300 & 2 & $13 @ 10$ ppm & 118 & [300] \\
\hline & $\mathrm{Au} / \mathrm{ZnO}$-shell & $\mathrm{CO}$ & 300 & 0.0026 & $26.6 @ 0.1$ ppm & 75 & [301] \\
\hline & $\mathrm{Pd}$ & $\mathrm{H}_{2}$ & 300 & 1 & $55.72 @ 100$ ppm & 22 & [302] \\
\hline & $\mathrm{Pd}$ & $\mathrm{NO}_{2}$ & 300 & 0.1 & $505 @ 0.1$ ppm & 20 & [271] \\
\hline & $\mathrm{Pd}$ & $\mathrm{H}_{2}$ & 300 & 1 & $16.95 @ 1$ ppm & $\mathrm{N} / \mathrm{A}$ & [88] \\
\hline & $\mathrm{Pd}$ & $\mathrm{H}_{2}$ & 150 & 10 & $4.5 @ 100$ ppm & $\mathrm{N} / \mathrm{A}$ & [303] \\
\hline & $\mathrm{Pt}$ & $\mathrm{NO}_{2}$ & 300 & 0.1 & $700 @ 0.1$ ppm & 10 & [271] \\
\hline & $\mathrm{Pt}$ & $\mathrm{H}_{2}$ & 25 & $\mathrm{~N} / \mathrm{A}$ & $1.87 @ 1000$ ppm & 0.33 & [288] \\
\hline & $\mathrm{Pt}$ & Ethanol & 300 & 0.1 & $6.5 @ 100$ ppm & $\mathrm{N} / \mathrm{A}$ & [304] \\
\hline & $\mathrm{Pt}$ & Benzene & 350 & 0.1 & $18 @ 100$ ppm & $\mathrm{N} / \mathrm{A}$ & [304] \\
\hline & $\mathrm{Pt}$ & Acetone & 300 & 0.1 & $5.8 @ 100$ ppm & $\mathrm{N} / \mathrm{A}$ & [304] \\
\hline & $\mathrm{Pt}$ & $\mathrm{H}_{2}$ & 350 & 0.1 & $4 @ 100$ ppm & $\mathrm{N} / \mathrm{A}$ & [304] \\
\hline & $\mathrm{Pt}$ & Toluene & 300 & 0.1 & $58 @ 100$ ppm & $\mathrm{N} / \mathrm{A}$ & [304] \\
\hline \multirow{15}{*}{$\mathrm{ZnO}$} & $\mathrm{Pd}$ & Ethanol & 260 & - & $5 @ 500$ ppm & 6 & [305] \\
\hline & $\mathrm{Ag}$ & Ethanol & 450 & 5 & $228.1 @ 100$ ppm & $40-80$ & [306] \\
\hline & $\mathrm{Au}$ & $\mathrm{NO}_{2}$ & 150 & 1 & $31.4 @ 1$ ppm & 29 & [284] \\
\hline & $\mathrm{Au}$ & $\mathrm{NO}_{2}$ & 25(UV) & 1 & $2.6 @ 1$ ppm & 39.5 & [292] \\
\hline & $\mathrm{Au}$ & $\mathrm{H}_{2}$ & 25 & $<1 \mathrm{ppm}$ & $40 @ 100$ ppm & $\mathrm{N} / \mathrm{A}$ & [289] \\
\hline & $\mathrm{Au}$ & Acetone & 172 & 15 & $50.5 @ 100$ ppm & 1 & [307] \\
\hline & $\mathrm{Au}$ & $\mathrm{H}_{2}$ & 25 & 20 & $32.9 @ 1000$ ppm & $\mathrm{N} / \mathrm{A}$ & [282] \\
\hline & $\mathrm{Au} / \mathrm{Fe}_{2} \mathrm{O}_{3}$ & $\mathrm{NO}_{2}$ & 400 & 150 & $247 @ 250$ ppm & $\mathrm{N} / \mathrm{A}$ & [308] \\
\hline & $\mathrm{Au} / \mathrm{Pd}$ & $\mathrm{NO}_{2}$ & 100 & 1 & $94.2 @ 1$ ppm & 35 & [309] \\
\hline & $\mathrm{Pd}$ & Benzene & 25(UV) & 0.0067 & $2.2 @ 50$ ppm & $\mathrm{N} / \mathrm{A}$ & [310] \\
\hline & $\mathrm{Pd}$ & $\mathrm{H}_{2}$ & 350 & 1 & $87 @ 100$ ppm & $\mathrm{N} / \mathrm{A}$ & [274] \\
\hline & $\mathrm{Pd}$ & $\mathrm{H}_{2} \mathrm{~S}$ & 300 & 10 & $20 @ 500$ ppm & 720 & [311] \\
\hline & $\mathrm{Pd} / \mathrm{BN}$ & $\mathrm{H}_{2}$ & 200 & 0.1 & $12.3 @ 50$ ppm & 240 & [307] \\
\hline & $\mathrm{Pt}$ & $\mathrm{H}_{2} \mathrm{~S}$ & 260 & 0.0011 & $65 @ 0.3$ ppm & 40 & [312] \\
\hline & $\mathrm{Pt}$ & Toluene & 25(UV) & 0.0003 & $2.86 @ 50$ ppm & $\mathrm{N} / \mathrm{A}$ & [310] \\
\hline \multirow{6}{*}{$\mathrm{WO}_{3}$} & $\mathrm{Au}$ & n-butanol & 250 & 5 & $147 @ 100$ ppm & 16.5 & [313] \\
\hline & $\mathrm{Au}$ & Acetone & 250 & 5 & $72 @ 200$ ppm & 17.5 & [313] \\
\hline & $\mathrm{Pd} / \mathrm{Au}$ & Acetone & 300 & 200 & $152.4 @ 200$ ppm & 96 & [314] \\
\hline & $\mathrm{Pd} / \mathrm{Au}$ & n-butanol & 200 & 5 & $93 @ 50$ ppm & 12 & [315] \\
\hline & $\mathrm{Rh}$ & Acetone & 300 & 0.2 & $75 @ 5$ ppm & 11 & [316] \\
\hline & $\mathrm{Ru}$ & Acetone & 350 & 0.05 & $78 @ 5$ ppm & 11.7 & [202] \\
\hline $\mathrm{W}_{18} \mathrm{O}_{49}$ & $\mathrm{Ag} / \mathrm{Pt}$ & Trimethylamine & 240 & 0.071 & $22 @ 2$ ppm & 15 & [277] \\
\hline \multirow{3}{*}{$\mathrm{In}_{2} \mathrm{O}_{3}$} & $\mathrm{Ag}$ & Ethanol & 25 & 0.5 & $1900 @ 100$ ppm & $\mathrm{N} / \mathrm{A}$ & [317] \\
\hline & $\mathrm{Au}$ & $\mathrm{CO}$ & 25 & 0.5 & $2200 @ 100$ ppm & $\mathrm{N} / \mathrm{A}$ & [317] \\
\hline & $\mathrm{Pt}$ & $\mathrm{H}_{2}$ & 25 & 0.5 & $1400 @ 100$ ppm & $\mathrm{N} / \mathrm{A}$ & [317] \\
\hline
\end{tabular}


Table 1. Cont

\begin{tabular}{|c|c|c|c|c|c|c|c|}
\hline NWs & NPs & Target Gas & $\begin{array}{l}\mathrm{T}_{\text {oper }} \\
\left({ }^{\circ} \mathrm{C}\right)\end{array}$ & $\begin{array}{c}\text { LOD } \\
\text { (ppm) }\end{array}$ & Response & $\begin{array}{c}\text { Response } \\
\text { Time(s) }\end{array}$ & Ref. \\
\hline \multirow{5}{*}{$\mathrm{CuO}$} & $\mathrm{Au}$ & $\mathrm{NO}_{2}$ & 300 & 1 & $2.2 @ 50$ ppm & $\mathrm{N} / \mathrm{A}$ & [192] \\
\hline & $\mathrm{Au}$ & $\mathrm{CO}$ & 350 & 1 & $1.25 @ 50$ ppm & $\mathrm{N} / \mathrm{A}$ & [192] \\
\hline & $\mathrm{Pt}$ & Ethanol & 200 & 1000 & $3.8 @ 1000$ ppm & 480 & [318] \\
\hline & $\mathrm{Pd}$ & $\mathrm{H}_{2}$ & 200 & 1000 & $4.5 @ 1000$ ppm & 600 & [318] \\
\hline & $\mathrm{Pd}$ & $\mathrm{H}_{2} \mathrm{~S}$ & 100 & & $1.9 @ 100$ ppm & $\mathrm{N} / \mathrm{A}$ & [319] \\
\hline $\mathrm{PdO}$ & $\mathrm{Pt}$ & $\mathrm{H}_{2}$ & 25 & 10 & $1.2 @ 100$ ppm & 166 & [290] \\
\hline $\mathrm{VO}_{2}$ & $\mathrm{Au}$ & $\mathrm{NO}_{2}$ & 25 & 0.5 & $3.22 @ 5$ ppm & $\mathrm{N} / \mathrm{A}$ & [285] \\
\hline
\end{tabular}

NWs: nanowires; NPs: nanoparticles; $\mathrm{T}_{\text {oper }}$ : operation temperature of sensor; LOD: limit of detection); Response: Rg/Ra (Oxidizing gas) or $\mathrm{Ra} / \operatorname{Rg}$ (Reducing gas).

\subsection{Branched Nanowire}

In addition to surface decoration, branched nanowires (nanowire hierarchical nanostructures) offer a high specific surface area for gas diffusion and adsorption, which are beneficial for molecular sensing. Khoang et al. reported a controllable and scalable route for preparing n-type $\mathrm{ZnO}$ branched n-type $\mathrm{SnO}_{2}$ nanowire hierarchical nanostructures via a combination of thermal evaporation method $\left(\mathrm{SnO}_{2}\right.$ nanowires) and hydrothermal method ( $\mathrm{ZnO}$ nanowires). As shown in Figure 19, compared with pure $\mathrm{SnO}_{2}$ nanowires, the branched nanowires sensor shows three-five-fold sensitivity enhancement to 25-500 ppm ethanol. Kaur et al. demonstrated an n-type $\mathrm{ZnO}$ branched p-type $\mathrm{NiO}$ nanowire hierarchical structures for sensing performance enhancement [233]. In such a kind of sensor, the surface of $\mathrm{NiO}$ nanowires is fully covered by $\mathrm{ZnO}$ nanowires, leading to a response mode transformation from the p-type to n-type. In addition, the lowest detection limits of these sensors to ethanol and acetone can be down to 7 and $11 \mathrm{ppm}$, respectively.

Moreover, to further improve the device sensing performance, Choi et al. attempted to decorate $\mathrm{Au}$ nanoparticles on the $\mathrm{ZnO}$ branched $\mathrm{SnO}_{2}$ nanowire surface [300]. It was indicated that the sensing response of the $\mathrm{ZnO}$-branched $\mathrm{SnO}_{2}$ nanowire sensor is dramatically enhanced after Au nanoparticle decoration due to the spillover effect of noble metal. Meanwhile, the sensor shows an excellent selectivity toward $\mathrm{NO}_{2}$. Similar results have also been reported recently by Bang et al. [320]. They realized the low temperature and selective $\mathrm{NO}_{2}$ sensing via using synergistic effects of $\mathrm{Pt}$ decoration and $\mathrm{Bi}_{2} \mathrm{O}_{3}$ branching.
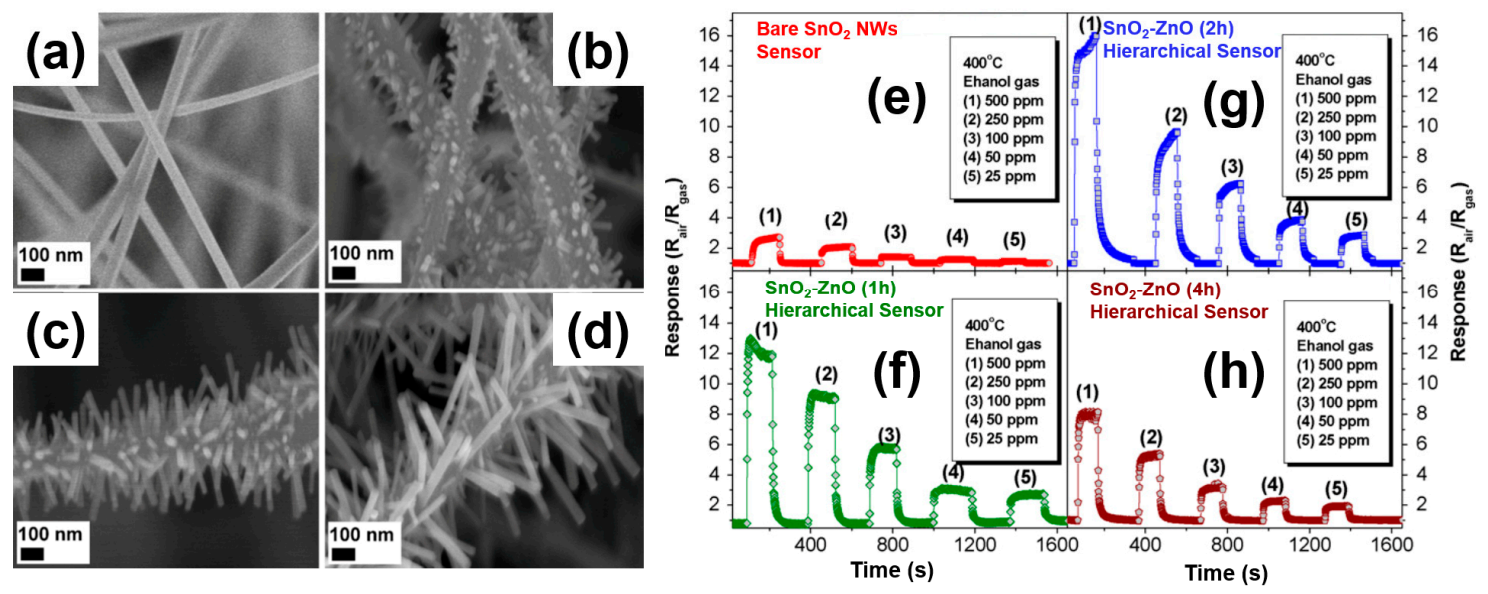

Figure 19. Left figure: branches nanowire with different length on $\mathrm{ZnO}$ nanowires: (a) as fabricated $\mathrm{ZnO}$ nanowires; (b) $1 \mathrm{~h}$ growth $\mathrm{SnO}_{2}$ branched $\mathrm{ZnO}$ nanowire; (c) $2 \mathrm{~h}$ growth; (d) $4 \mathrm{~h}$ growth. Right figure: $\mathrm{SnO}_{2}$ nanowire and $\mathrm{SnO}_{2}-\mathrm{ZnO}$ hierarchical structure sensing performance; (e) as fabricated $\mathrm{ZnO}$ nanowires; (f) $1 \mathrm{~h}$ growth $\mathrm{SnO}_{2}$ branched $\mathrm{ZnO}$ nanowire; (g) $2 \mathrm{~h}$ growth; and (h) $4 \mathrm{~h}$ growth. Reprinted from reference [321] with permission from the American Chemical Society. 


\subsection{Core-Shell Structure (C-S Structure)}

Core-shell (C-S) metal-oxide nanowire sensors have also been extensively studied due to their ability to detect an extremely low concentration of chemical species and mitigate the poor selectivity $[322,323]$. The C-S structure is similar to the nanoparticle-decorated structure but with a continuous layer and higher stability [271]. Such a shell layer can serve as a catalytic layer to promote the molecular oxidizing [324], narrow the conduction core part of nanowire [325], facilitate the adsorption of gas molecules to increase the sensing activity [326], and work as a main conductive channel for sensing [327]. Currently, various C-S nanowires with a combination like n-n (n-type core/n-type shell) [323,327-330], n-p (n-type core/p-type shell) [256,331], and p-n (p-type core/n-type shell) [252,324,332] have been employed as gas sensors. According to recent C-S nanowire gas sensors, the shell layer selection and its deposition thickness are crucially important to tailor the performance of the nanowire-based gas sensors [332,333].

Park et al. firstly demonstrated an exciting model to understand the sensitivity enhancement in $\mathrm{SnO}_{2}-\mathrm{ZnO} \mathrm{C}-\mathrm{S}$ nanofibers [328]. As the deposition shell thickness is comparably shorter than or equivalent to the Debye length of the shell materials, the conducting channel can be fully depleted during the exposure to target molecules. As a result, the conductance variation is favorably considerable compared with that of the non-C-S structure. Katoch et al. also reported a similar result via systematically studying the impact of shell thickness on the sensing performance of core/shell structures [330]. By gradually changing the thickness of $\mathrm{ZnO}$ on $\mathrm{SnO}_{2}$ nanofibers, it was observed that the nanofiber sensor device has the highest sensing response towards $\mathrm{CO}$ when $20 \mathrm{~nm}$ of $\mathrm{ZnO}$ shell is loaded on the $\mathrm{SnO}_{2}$ nanofiber surface. Such thickness is identically close to the Debye length of $\mathrm{ZnO}$.

As shown in Figure 20a-c, by controlling the ALD growth time of the shell layer, Choi et al. proposed a dual functional sensing mechanism in the $\mathrm{SnO}_{2} / \mathrm{ZnO} \mathrm{C}-\mathrm{S}$ nanowires [327]. First, as the shell layer is thinner than its Debye length, the shell layer will experience a large resistance modulation during the sensor exposure to reducing gas. As a result, a substantial portion of electron transport occurs through the inner core nanowire, which would weaken its sensing performance. Second, as the shell layer is slightly larger than its Debye length, electrical transport will be mostly confined within the shell layer, leading to a high modulation/response in sensing performance.
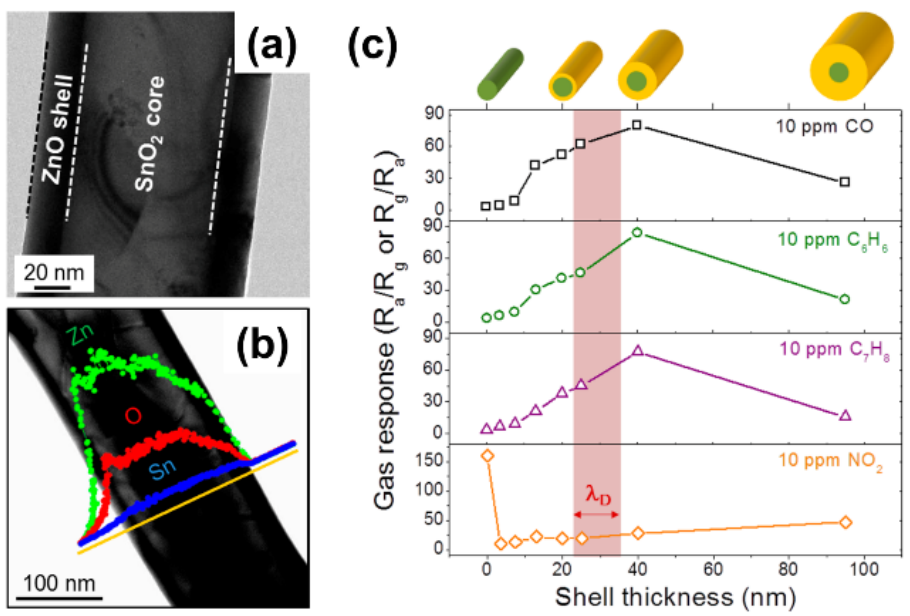

(d)

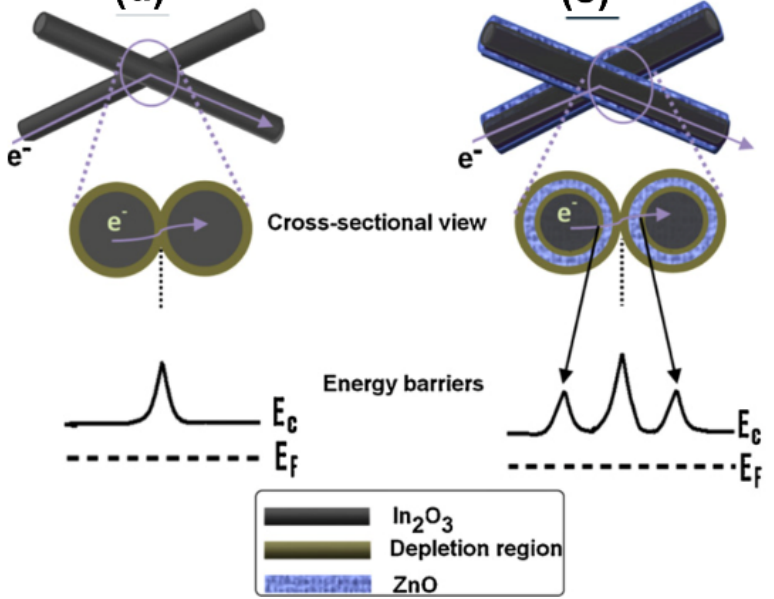

Figure 20. (a) Nanowire with $\mathrm{SnO}_{2}$ core and $\mathrm{ZnO}$ shell structure; (b) EDS of core-shell nanowire; (c) shell thicknessdependent sensing performance towards $\mathrm{CO}$, benzene, toluene, and $\mathrm{NO}_{2}$. Reprinted from reference [327] with permission from the American Chemical Society. (d,e) Schematics of the hydrogen-sensing mechanism for $\operatorname{In}_{2} \mathrm{O}_{3}$ nanowires and $\mathrm{In}_{2} \mathrm{O}_{3} / \mathrm{ZnO}$ C-S nanowires sensors. Reprinted from reference [334] Copyright 2011 Elsevier. 
Singh et al. have discussed carrier transport based on $\operatorname{In}_{2} \mathrm{O}_{3}$ nanowires and $\operatorname{In}_{2} \mathrm{O}_{3} / \mathrm{ZnO}$ core-shell nanowires network devices [334]. Due to the large resistance of the polycrystalline $\mathrm{ZnO}$ shell, carriers mainly flow through the single crystalline $\operatorname{In}_{2} \mathrm{O}_{3}$ core. To achieve electron transportation from nanowire to nanowire, only one potential barrier (core-core, $\mathrm{C} / \mathrm{C}$ ) has to be overcome in the $\mathrm{In}_{2} \mathrm{O}_{3}$ nanowires device (Figure 20d), while the electrons are essentially to overcome three potential barriers (core to shell (C/S), shell to shell $(\mathrm{S} / \mathrm{S})$, and shell to core $(\mathrm{S} / \mathrm{C})$ ) in the core-shell nanowire devices (Figure 20e). Owing to the modulation of potential barriers, significant enhancements in sensor response for the reducing gases have been achieved. This mechanism also can be used to explain the sensing performance enhancement in other $\mathrm{p} / \mathrm{n}$ and $\mathrm{n} / \mathrm{p}$ types of core/shell nanowire sensors $[256,325,329,331,335]$.

\subsection{Impurities Doping}

Introducing dopants have a significant impact on the electrical and chemical properties of semiconductor metal-oxides [336-338]. Experimental studies have proved that small amounts of impurity additives $(<0.1$ at $\%$ or lower) can significantly alter the electronic and chemical properties of metal-oxide nanowires due to the modulation of the Fermi level and introducing additional adsorption sites [339]. For example, Zhang et al. have studied the oxygen vacancies doping effect in $\mathrm{In}_{2} \mathrm{O}_{3}$ nanowires for $\mathrm{NH}_{3}$ sensing [340]. According to their report, via varying the concentration of oxygen vacancies in $\operatorname{In}_{2} \mathrm{O}_{3}$ nanowires, the Fermi level $\left(\mathrm{E}_{\mathrm{F}}\right)$ of the $\operatorname{In}_{2} \mathrm{O}_{3}$ nanowires can be controlled close to the conduction band and above the energy level of $\mathrm{NH}_{3}\left(\mathrm{E}_{\mathrm{NH} 3}\right)$ in a heavily doped condition, or the Fermi level $\left(\mathrm{E}_{\mathrm{F}}\right)$ can be below $\mathrm{E}_{\mathrm{NH} 3}$ in a relatively low doping concentration. As shown in Figure 18a, when the $\mathrm{E}_{\mathrm{F}}$ of nanowires is higher than $\mathrm{E}_{\mathrm{NH} 3}$, electrons should transfer from the nanowire to the adsorbed $\mathrm{NH}_{3}$ and result in a reduction in the nanowire carrier concentration. When the $\mathrm{E}_{\mathrm{F}}$ of nanowires is lower than $\mathrm{E}_{\mathrm{NH} 3}$, electrons should migrate from adsorbed $\mathrm{NH}_{3}$ to the nanowire and result in an enhanced conductance, as shown in Figure 21a,b. This work indicates that the density of dopants can determine the signal and amplitude of the nanowire sensor response. Moreover, Singh et al. have reported an approach to tune the Fermi level of $\operatorname{In}_{2} \mathrm{O}_{3}$ nanowires via $\mathrm{Zn}$ doping and achieving the room temperature detection of $\mathrm{CO}$ [341]. As shown in Figure 21c,d, due to the small chemical potential gradient between the adsorbed $\mathrm{CO}$ molecule and Fermi level of undoped $\operatorname{In}_{2} \mathrm{O}_{3}$ nanowires, there is less electron transfer (to reach equilibrium) and the nanowire-based sensor shows a poor sensitivity to $\mathrm{CO}$ at room temperature. In contrast, as shown in Figure 21e,f, a big difference of the chemical potential between the Fermi level of nanowire and $\mathrm{CO}$ molecule is presented after $\operatorname{In}_{2} \mathrm{O}_{3}$ nanowires are doped with $\mathrm{Zn}$, as a result, the $\mathrm{Zn}$ doped $\mathrm{In}_{2} \mathrm{O}_{3}$ nanowire sensor device offers a fast (response time 20s and recovery time $10 \mathrm{~s}$ ) and large transfer of electrons (1-5 ppm CO detection). However, due to the difficulties in introducing impurities into single-crystalline nanowires, impurities doping is less popular than nanoparticles decoration, branched structures, and core-shell structures for achieving high-performance device. 

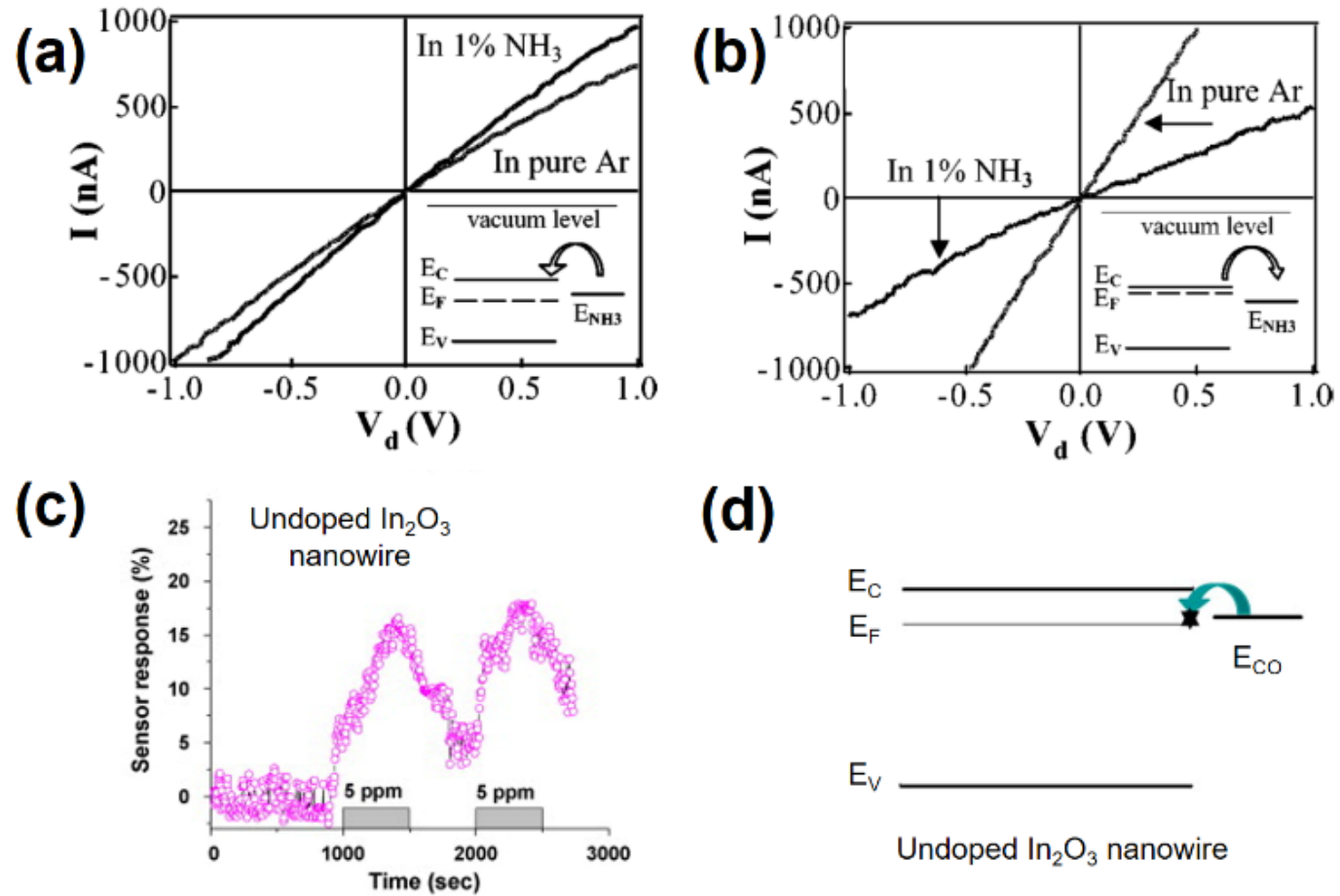

(d)
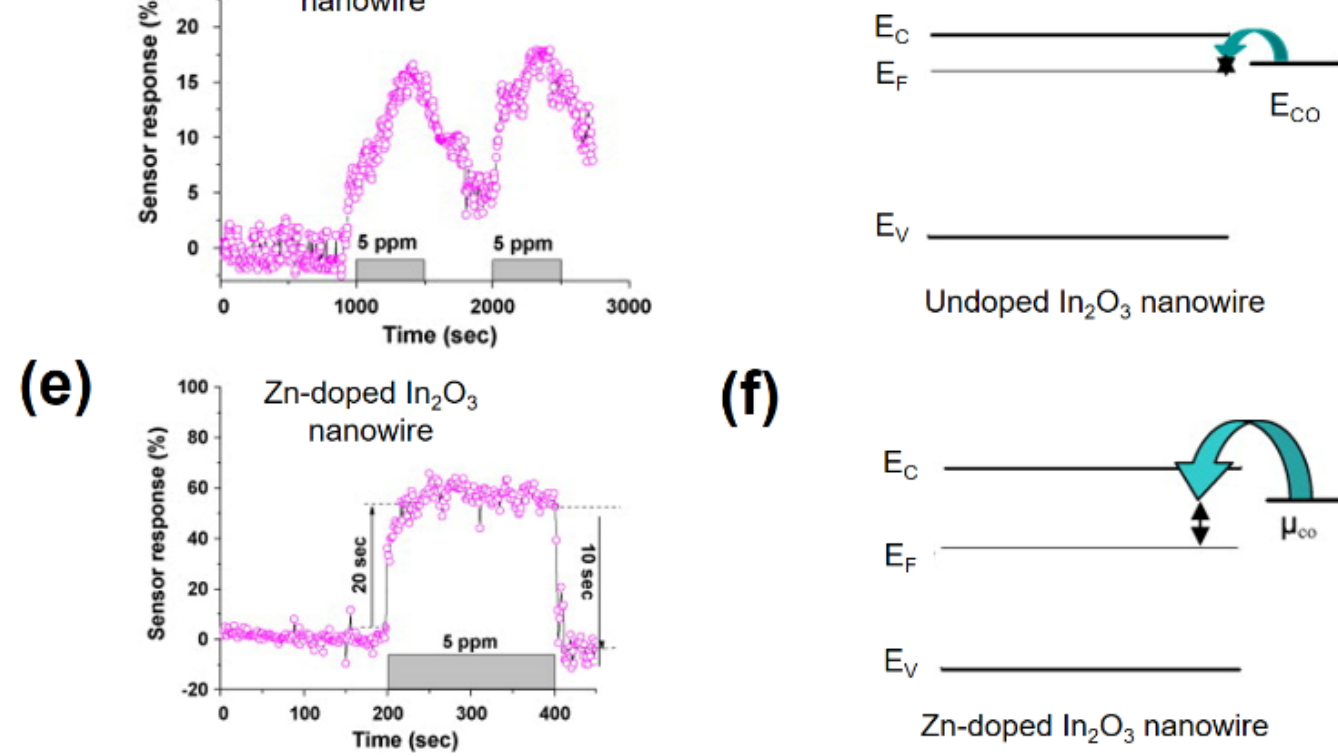

(f)

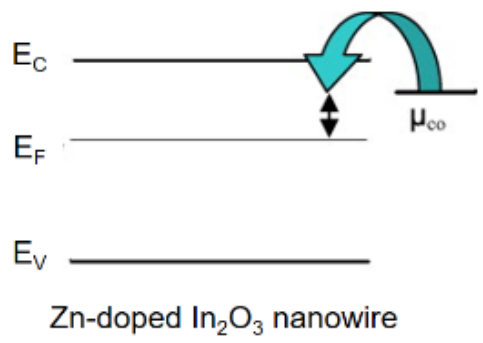

Figure 21. (a) $I-V$ curves of heavily doped $\mathrm{In}_{2} \mathrm{O}_{3}$ nanowires device before and after exposure to $1 \%$ NH3. Inset shows the energy band diagrams of heavily doped $\mathrm{In}_{2} \mathrm{O}_{3}$ and $\mathrm{NH}_{3}$ molecules; (b) $I-V$ curves of lightly doped $\mathrm{In}_{2} \mathrm{O}_{3}$ nanowires device before and after exposure to $1 \% \mathrm{NH}_{3}$. Inset shows the energy band diagrams of lightly doped $\operatorname{In}_{2} \mathrm{O}_{3}$ and $\mathrm{NH}_{3} \mathrm{molecules}$ Reprinted from reference [340] with permission from the American Institute of Physics (AIP) Publishing; (c) sensing response of Undoped $\operatorname{In}_{2} \mathrm{O}_{3}$ nanowires (d) Energy band diagrams of undoped $\operatorname{In}_{2} \mathrm{O}_{3}$ and CO molecules; (e) sensing the response of $\mathrm{Zn}$-doped $\mathrm{In}_{2} \mathrm{O}_{3}$ nanowires; (f) energy band diagrams of $\mathrm{Zn}$-doped $\operatorname{In}_{2} \mathrm{O}_{3}$ and $\mathrm{CO}$ molecules. Reprinted from reference [341] Copyright 2010 Elsevier.

\section{Gas Sensing Mechanism}

Today, nanowire chemiresistors are being widely investigated due to their convenience in data analysis, high accuracy, low cost, and their ability to dynamically monitor the channel resistance/conductance variation during the exposure to the target molecules. Generally, the sensing mechanism of chemiresistors can be divided into three types.

\subsection{Ohmic-Contacted Sensing}

In a traditional chemiresistor sensor, Ohmic contact is highly preferred to study the intrinsic properties of nanowires. Generally, the classical D-L model is responsible for the sensitivity of nanowire gas sensors, where $D$ represents nanowire diameter $(D)$, and $L$ represents the depth of the surface depletion layer (L) [342,343]. Considering the n-type oxide case, when a sensor is exposed to the atmosphere, oxygen can be adsorbed on the surface of metal-oxide nanowire and becomes negatively charged by the following equations [22]:

$$
\mathrm{O}_{2} \text { (gas) } \leftrightarrow \mathrm{O}_{2} \text { (ads) }
$$




$$
\begin{gathered}
\mathrm{O}_{2} \text { (ads) }+\mathrm{e}^{-} \leftrightarrow \mathrm{O}_{2}{ }^{-} \text {(ads) }\left(<100^{\circ} \mathrm{C}\right) \\
\left.\mathrm{O}_{2}{ }^{-} \text {(ads }\right)+\mathrm{e}^{-} \leftrightarrow 2 \mathrm{O}^{-} \text {(ads) }\left(100-300^{\circ} \mathrm{C}\right) \\
\left.\mathrm{O}^{-} \text {(ads }\right)+\mathrm{e}^{-} \leftrightarrow \mathrm{O}^{2-} \text { (ads) }\left(>300^{\circ} \mathrm{C}\right)
\end{gathered}
$$

Such oxygen-charged behavior would extract electrons and create a shell-like surface depletion layer on the nanowire surface (Figure 22a), which can effectively modulate channel conductivity. Moreover, due to the adsorbed oxygen ions $\left(\mathrm{O}^{-}\right.$and $\left.\mathrm{O}^{2-}\right)$, highly active towards reducing gas, high temperatures $\left(>100^{\circ} \mathrm{C}\right)$ are usually required to generate oxygen ions and enhance chemical reaction. For example, when the sensor is exposed to the gases (such as toluene, ethanol, $\mathrm{CO}, \mathrm{NH}_{3}, \mathrm{H}_{2}$, methanol, shown in Equations (5)-(7) [22]), the charged oxygen $\left(\mathrm{O}^{-}\right)$can react with these gases, and release electrons back to the nanowire bulk. As a result, the thickness of the depletion layer is shrunk, leading to an increase in conductance (Figure 22b). In contrast, when the sensor is exposed to the oxidizing gases (such as $\mathrm{NO}_{2}, \mathrm{O}_{3}$, Equations (8) and (9) [22]), these gases can extract more electrons from the nanowire surface. Then, the depletion layer thickness increases and results in a reduction in nanowire conductance (Figure 22c):

$$
\begin{gathered}
\mathrm{CO}(\text { ads })+\mathrm{O}^{-} \text {(ads) } \rightarrow \mathrm{CO}_{2} \text { (gas) }+\mathrm{e}^{-} \\
\mathrm{CH}_{3} \mathrm{CH}_{2} \mathrm{OH}(\text { ads })+6 \mathrm{O}^{-} \text {(ads) } \rightarrow 2 \mathrm{CO}_{2} \text { (gas) }+3 \mathrm{H}_{2} \mathrm{O} \text { (gas) }+6 \mathrm{e}^{-} \\
\mathrm{H}_{2} \text { (ads) }+\mathrm{O}^{-} \text {(ads) } \rightarrow \mathrm{H}_{2} \mathrm{O} \text { (gas) }+\mathrm{e}^{-} \\
\mathrm{e}^{-}+\mathrm{NO}_{2} \text { (ads) } \leftrightarrow \mathrm{NO}_{2}^{-} \text {(ads) } \\
2 \mathrm{e}^{-}+\mathrm{O}_{3} \text { (ads) } \leftrightarrow \mathrm{O}_{2}^{-} \text {(ads) }+\mathrm{O}^{-} \text {(ads) }
\end{gathered}
$$

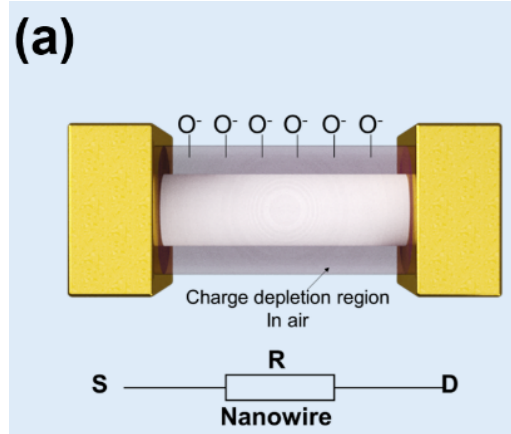

(b)

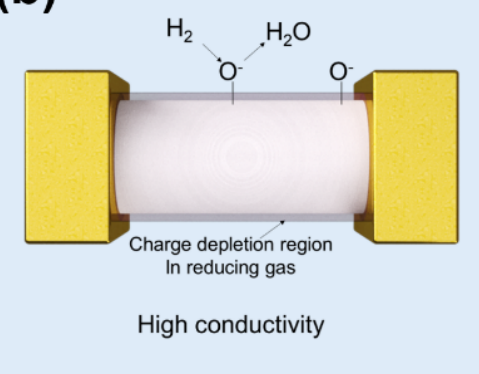

(c)
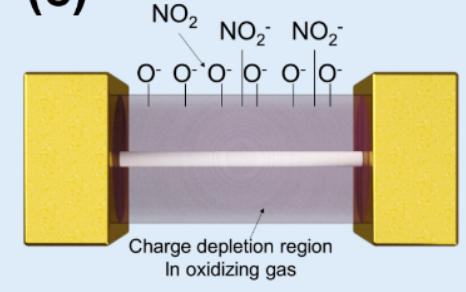

Low conductivity

Figure 22. A schematic diagram of conventional chemiresistor sensors: (a) nanowire conducting channel exposed to ambient; (b) nanowire conducting channel exposed to reducing gases; and (c) nanowire conducting channel exposed to oxidizing gases.

Due to its convenience in data analysis, tremendous works have used the Ohmic contacted device as a platform for fundamental studies to improve the device sensing performance.

\subsection{Schottky-Contacted Sensing}

Recently, the Schottky-contacted nanowire sensors have attracted considerable attention due to the higher sensitivity, faster sensing response, shorter recovery time, and lower cost as compared with the conventional Ohmic-contacted nanowire sensors. In a typical Schottky-contacted sensor (Figure 23a), the overall resistance/conductance of the device is dominated by the Schottky barrier height $(\mathrm{SBH})$, and its value is susceptible to external stimulus. Wei et al. firstly reported a Schottky-contacted nanowire sensor for gas molecules detection [344]. The device contains one $\mathrm{Pt} / \mathrm{ZnO}$ junction (Schottky contact) and one $\mathrm{Pt}-\mathrm{Ga} / \mathrm{ZnO}$ junction (Ohmic contact). By comparing the sensing performance of the Schottky-contacted device and the conventional Ohmic-contacted device, it is shown that the Schottky-contacted sensor device presents 1085 times and 8776 times sensitivity 
improvement to oxidizing gas $\left(\mathrm{O}_{2}\right)$ and reducing gas $(\mathrm{CO})$, respectively. Furthermore, the Schottky contacted sensor device exhibited a faster response and shorter reset time, improved by a factor of 7 . This new sensing concept has been extensively applied to other metal-oxide nanowire systems such as the well-known $\mathrm{SnO}_{2}$ [345] and $\mathrm{In}_{2} \mathrm{O}_{3}$ [346] nanowire-based sensors. Here, the author recommends the latest comprehensive review of Schottky-contacted nanowire sensors presented by Meng et al. [21].

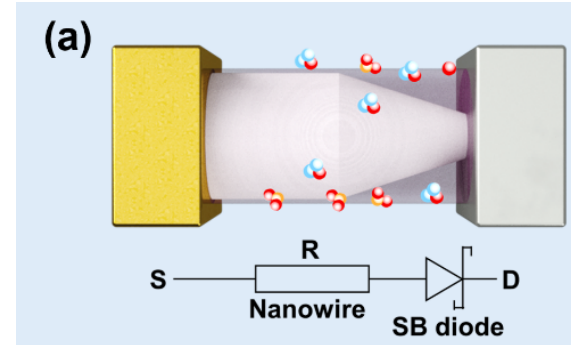

(b)

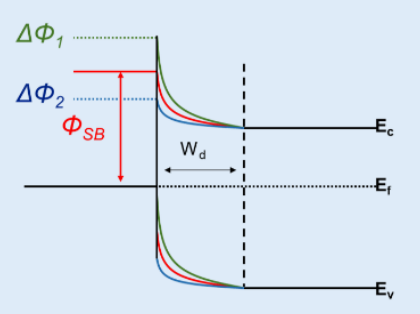

Figure 23. A schematic diagram of Schottky-contacted sensors: (a) structure of a Schottky-contacted sensor; and (b) change of Schottky barrier height and depletion region under the external stimulation.

\subsection{Nanowire-Nanowire Junctions Sensing}

In the case of an n-type nanowire-nanowire junction sensor, as shown in Figure 24a, both the thickness of the electron depletion layer and the potential barrier height of the nanowire-nanowire interface dominates the overall conductance of the device. Furthermore, if the electron depletion layer is smaller than the nanowire diameter, the potential barrier heights of nanowire-nanowire junctions will play a crucial role in the gas sensing performance of nanowire sensors. Similar to the Schottky-contacted nanowire devices, the nanowire-nanowire barrier height can be decreased/increased when devices are exposed to a reducing/oxidizing atmosphere.
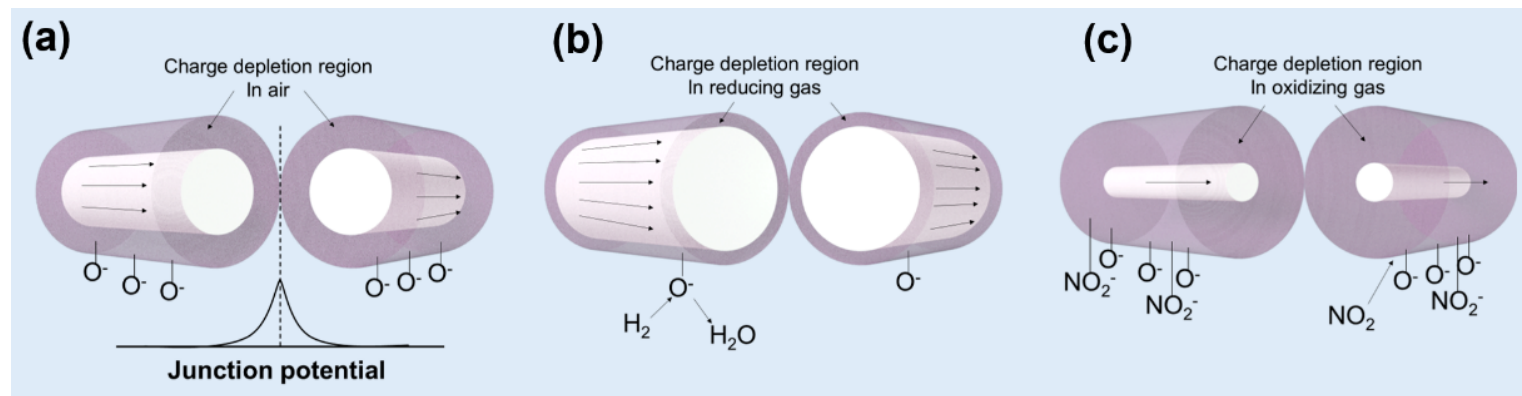

Figure 24. A schematic diagram of conventional nanowire-nanowire junction sensors: (a) nanowire conducting channel exposed to ambient; (b) nanowire conducting channel exposed to oxidization gas; and (c) nanowire conducting channel exposed to reducing gas.

Many works have been performed using the interfacial sensing concept, not only for the simplicity in device fabrication but also for higher sensitivity. Most importantly, this concept also shows strong integration capability onto a sensing platform due to the development of nanowire devices with bridging structures [246]. Park et al. firstly reported a metal-oxide nanowire sensor with a bridging structure for $\mathrm{NO}_{2}$ detection [251]. As reported in their work, $\mathrm{SnO}_{2}$ nanowires are in situ grown at the pre-deposited electrode onchip without using any arduous and individual lithography process. Due to self-connection with other nanowires, multiple nanowire-nanowire junctions are naturally formed as sensing channels. Consistent gas sensing characteristics can be seen due to the averaging effect of multi nanowire connections, and high sensitivity to $\mathrm{NO}_{2}$ is obtained $\left(\mathrm{R}_{\mathrm{g}} / \mathrm{R}_{\mathrm{a}}=230\right)$. Inspired by their encouraging work, other metal-oxide nanowires $\left(\mathrm{ZnO}, \mathrm{TiO}_{2}\right.$, and $\left.\mathrm{CuO}\right)$ 
have also been applied to fabricate bridging structure sensors to combine the merits of in situ growth and nanowire-nanowire junctions sensing [177,191,250,263,347].

\section{Critical Issues for Metal-Oxide Nanowire-Based Gas Sensor Devices}

Despite all the extraordinary achievements of 1D nanowire-based sensors, some critical problems are still encouraged to be studied and investigated further to advance the nanowire sensor from the lab to the market. Here, we mainly discuss four critical issues: reproducibility, selectivity, stability, and energy consumption.

\subsection{Reproducibility of Devices}

Integrating a nanowire with contact electrodes on a platform allows us to study the intrinsic properties of the nanowire. However, a tiny variation in the size or shape of nanostructures will powerfully alter their physical and chemical properties. Thus, the nanowire-based electronics would inevitably suffer from poor reproducibility. To prevent the reproducibility issue, one easy method is to use a multiple nanowire sensor to eliminate the individual differences among nanowires. Currently, a commercially available fabrication process for the thin film sensor is used for the mat-like nanowire network sensor fabrication. Zhang et al. have compared the difference in electrical properties between single and multiple nanowire sensors [75]. It was found that all the multiple nanowire devices possess similar and consistent characteristics such as conductance, threshold gate voltage, and sensitivity to gas species. The fabrication of multiple nanowire gas sensors with the bridging structure is also an alternative approach to obtain molecular sensors with high uniformity [247]. The fabrication process in detail was described in Section 3.2.2. Unfortunately, those sensors did not really face/solve the reproducibility issues in the single nanowire devices. In fact, there is no difference between using multiple nanowire devices and conventional nanoparticle devices for gas sensing despite the porous structure.

\subsection{Selectivity of Device}

Another critical issue is the selectivity of the sensor device. Metal-oxide nanowire sensors generally have high sensitivity to the gas analytes, but they are also suffering from poor selectivity. To enhance the selectivity of sensors, a widely accepted method is introducing recognition elements on the sensing materials, for example, impurity elements doping, nanoparticle surface decorating, core/shell heterostructure construction. In addition, operational temperature modulation and nanowire architecture altering are also served as effective methods to improve the selectivity of the metal-oxide nanowire-based molecular sensors toward the target gas molecules. However, the results are usually far from prospects due to the low operational stability.

In addition, an alternative way to selectively detect the target gas molecules is to use the sensor array, because sensor arrays combined by a number of non-selective sensors which can acquire more information on a specific analyte than an individual sensor [348]. Subsequently, molecule information can be extracted from sensor arrays by appropriate pattern recognition techniques, such as principal component analysis (PCA) and backpropagation artificial neural network (BP-ANN) [349]. However, according to the research from Chen et al., multi-component sensing combined with PCA cannot work well if the reactions have no big difference between a specific target species and different metal-oxide surfaces [350]. Thus, enhancing the overall sensing performance of functional materials is the priority rather than data extraction and process. Unfortunately, this is usually not an easy task.

\subsection{Long-Term Stability of the Device}

Stability, including chemical stability and physical stability, is the essential key to open the gate for sensor practical applications. Sysoev et al. firstly pointed out that using the nanowire network sensor can obtain long-term stable sensing performance compared with the conventional nanoparticle sensors because nanowires can prevent nanostructure 
aggregation [351]. However, although numerous efforts are devoted to improving the long-term stability of metal-oxide nanowire sensors, the influence of humidity, poisoning, and new contact issues still exist to prevent such a kind of sensors from the practical applications [47]. Steinhauer et al. reported that the sensing performance of $\mathrm{CuO}$ nanowirebased gas sensors is strongly weakened with the increase in surrounding $\mathrm{H}_{2} \mathrm{O}$ [47]. This is because the formation of the surface hydroxyl groups induced by $\mathrm{H}_{2} \mathrm{O}$ adsorption prevents the oxygen chemisorption from the surface active sites. Meanwhile, Nakamura et al. have noticed that a ppm-level $\mathrm{CO}_{2}$ in the air can react substantially with $\mathrm{ZnO}$ nanowire surfaces even at room temperature [74]. Such a reaction will form an electrically insulating zinc carbonate thin layer, which can critically determine the electrical stability of hydrothermally grown single-crystalline $\mathrm{ZnO}$ nanowires. In addition, Zeng et al. reported a contact issue in the conventional metal-oxide nanowire device [73]. Titanium has been most widely used to contact typical metal-oxide (e.g., $\mathrm{SnO}_{2}, \mathrm{ZnO}$ ) by counting the energy level matching and good adhesion to the substrate, while the Ti contact can be oxidized easily, which causes an increase in contact resistance and further degradation in sensor performance after long-time operations under high temperature. Up to now, only a few papers have mentioned how to achieve long-term stability for metal-oxide nanowire sensors, and it is still remains a crucial challenge for commercialization.

\subsection{Energy Consumption}

An external heater is usually needed to elevate the temperature of metal-oxide gas sensors for effective gas sensing, which inevitably increases the power consumption and sensor size. There are currently two methods to solve this problem: (1) developing room temperature sensing materials; (2) using the self-Joule-heat technique. As for low-temperature sensors, tremendous progress has been made to reduce the operating temperature of the metal-oxide nanowire sensors, such as surface modification, additives doping, UV/visiblelight irradiation. For example, Lupan et al. reported that the Pd-modified $\mathrm{ZnO}$ nanowires sensor could achieve room temperature sensing for $\mathrm{H}_{2}$. However, it appears to have other annoying troubles such as lower sensing response, longer response time, and slow recovery rate [352]. Self-Joule-heating is a nearly ideal strategy for operating nanowire gas sensors at ultralow power consumption, without additional heaters. Currently, it has been reported that conducting self-Joule-heat for nanowire sensors and remarkably decrease power consumption. Prades et al. have reported that the energy consumption of individual $\mathrm{SnO}_{2}$ nanowire sensor devices can be down to $20 \mu \mathrm{J} / \mathrm{s}$ as self-Joule-heat is performed [218]. In addition, the power consumption of the nanowire sensor device could be further decreased via the pulsed self-heating technique [353]. However, recent studies on the self-Joule-heat technique only focused on controlling the spatial thermal properties of nanowires rather than tailoring the sensing performance of these sensors.

\section{Prospective towards Metal-Oxide Nanowire Gas Sensor Electronics}

As for the reproducibility of nanowire devices, we should carefully consider how to synthesize nanowires with high uniformity. Template-assisted nanowire growth is considered an alternative approach to achieve a highly ordered nanowire array. However, the complexity of template fabrication, low density of nanowires, and the extensive distribution of nanowire diameter have limited the wide application of such method [354]. Recently, Zhao et al. reported a two-step method to fabricate $\mathrm{ZnO}$ nanowires with uniformly shaped structures, as shown in Figure 25 [355]. Firstly, $\mathrm{ZnO}$ nanowires of random size are etched by $\mathrm{NH}_{4}{ }^{+}$as the seed layer, and then, a very similar diameter (average about $17 \mathrm{~nm}$ with $\sigma 1.3 \mathrm{~nm}$, shown in Figure 25c) of $\mathrm{ZnO}$ nanowires are grown in the second step, which significantly increases the reproducibility of metal-oxide nanowire. This unique finding paves the way for the fabrication of nanowires-integrated nanodevices with reliable performance. 
(a)

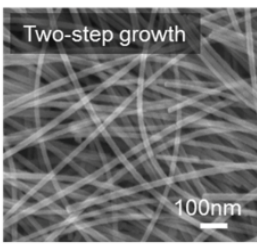

(b)

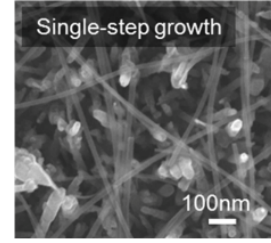

(d)

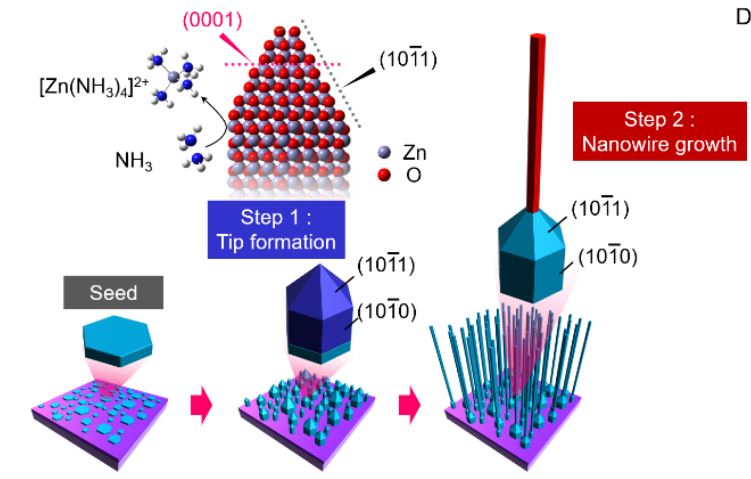

(c)

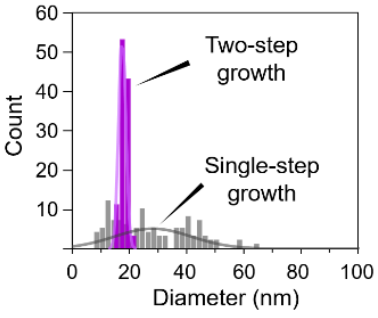

Figure 25. (a) SEM image of two-step growth $\mathrm{ZnO}$ nanowire; (b) SEM image of conventional single-step growth $\mathrm{ZnO}$ nanowire; (c) comparison of $\mathrm{ZnO}$ nanowire diameter distribution grown by single-step and two-step method; (d) the mechanism of the synthesis of monodispersed sized $\mathrm{ZnO}$ nanowires from randomly sized seeds. Reprinted from reference [355] with permission from the American Chemical Society.

Poor selectivity is a perpetually perplexing problem that limits the wide application of the MOS gas sensor, including the metal-oxide nanowire-based sensors. Inspired by the catalytical chemistry, it is worth considering combining porous materials such as zeolites, metal-organic frameworks, and mesostructured oxides with a metal-oxide nanowire [356-358]. Canlas et al. reported a novel method to fabricate molecules imprinted oxide catalyst, and the fabrication process is shown in Figure 26 [359]. Using this structure, the nanocavities can preferentially react with nitrobenzene rather than nitroxylene in the photoreduction model and react with benzyl alcohol rather than 2,4,6-trimethylbenzyl alcohol in the photo-oxidation model. This technique can be applied to the metal-oxide nanowire sensor to gigantically improve selectivity due to their preferential interactions with specific VOC molecules, even with a chemically similar structure.

(a)

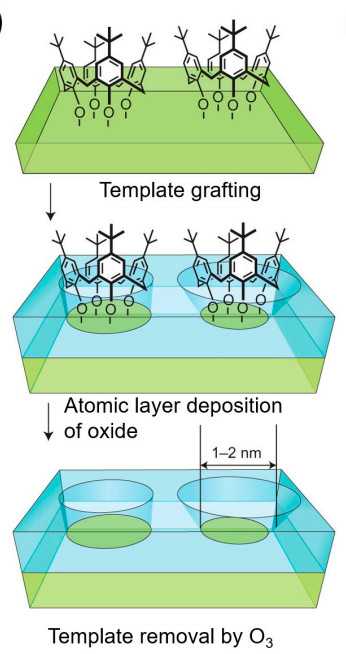

(b)

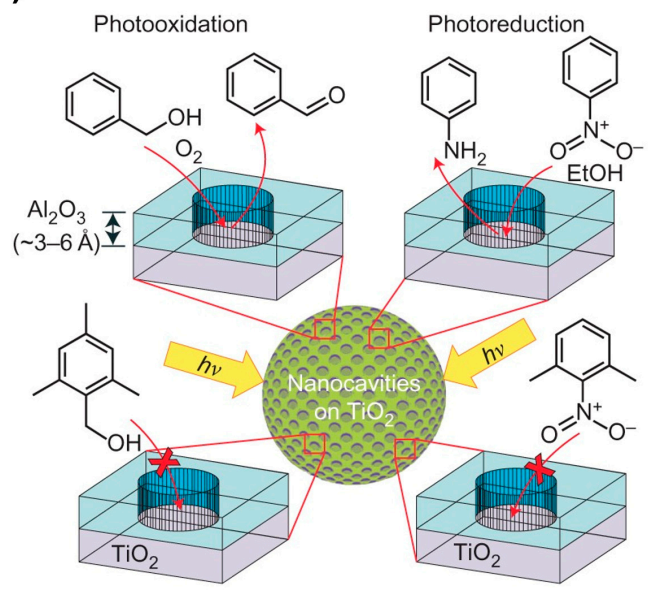

Figure 26. (a) The fabrication process of molecules imprinted oxide; and (b) the preferential reaction with gas species. Reprinted from reference [359] with permission from the Nature publishing group. 
Solving the degradation issues, including nanowire degradation, contact degradation, and electrode degradation, is the only way to achieve long-term stability in nanowire devices. As shown in Figure 27a, Nakamura et al. demonstrated a strategy for achieving the atmospheric electrical stability of $\mathrm{ZnO}$ nanowires [74]. Via using a thermal annealing treatment in vacuum/air, the insulating layer induced by the unstable -OH layer on as fabricated $\mathrm{ZnO}$ nanowire surface is efficiently eliminated. Such a simple and lowcost method can enhance nanowire atmospheric stability for at least 40 days with stable electrical properties. Meanwhile, Zeng et al. offered a way to overcome the degradation in conventional sensor contact, as shown in Figure 27b [73]. It is found that the nanowire device can obtain good stability for at least over 2000 hours by replacing the easily oxidized contact metal (Ti) with heavily doped metal-oxide (antimony doped tin oxide). Moreover, Yan et al. reported an unusual annealing process on oxide thin films for highly thermal and chemical stability shown in Figure 27c [360,361]. It was indicated that Al-doped ZnO (AZO) nano-thin films could efficiently suppress the inevitable crystal defect formation in the as-fabricated thin film via sequential annealing process under air and Zn vapor atmosphere, resulting in a stable electrical resistivity $\left(\sim 10^{-4} \Omega \cdot \mathrm{cm}\right)$ in air, even at high temperature (up to $500{ }^{\circ} \mathrm{C}$ ). This thermally stable thin film can be utilized as electrodes for gas sensors, which obtain stable performance over 250 hours compared to the conventional $\mathrm{Ti} / \mathrm{Pt}$ contact sensor. Meanwhile, the sequential annealed AZO nano-thin films also show highly chemical stability in buffer solution ( $\mathrm{pH}$ : 3 11) compared with non-annealed AZO nano-thin films and $\mathrm{ZnO}$ thin films. These proposed strategies can successfully suppress the electrical performance degradation of the nanowire devices and have a great potential to be applied to various oxide nanostructures, which would give a foundation for the designing and fabrication of oxide nanomaterial-based IoT sensors with long-term stability.

\section{(a)}

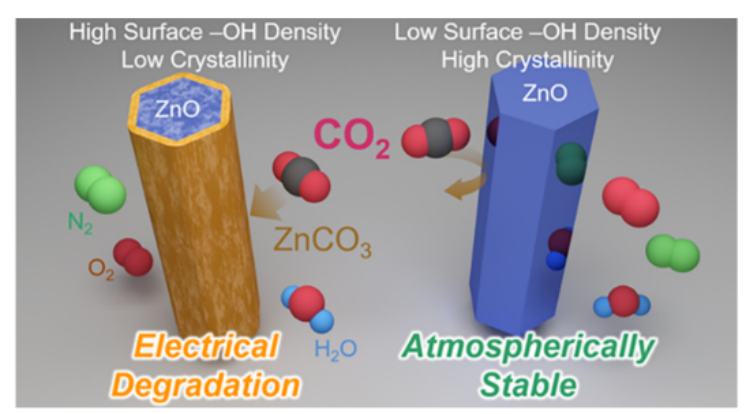

Oxide Nanowire Sensor

(b)

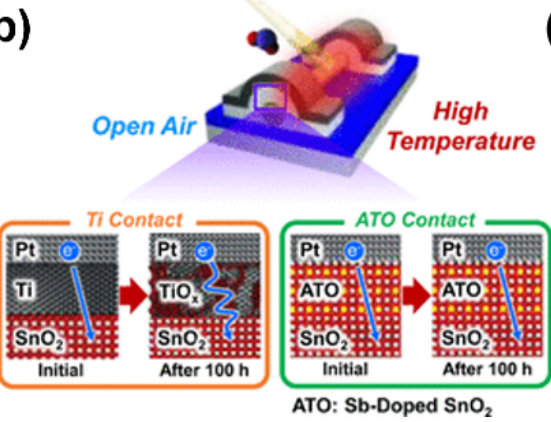

(c)

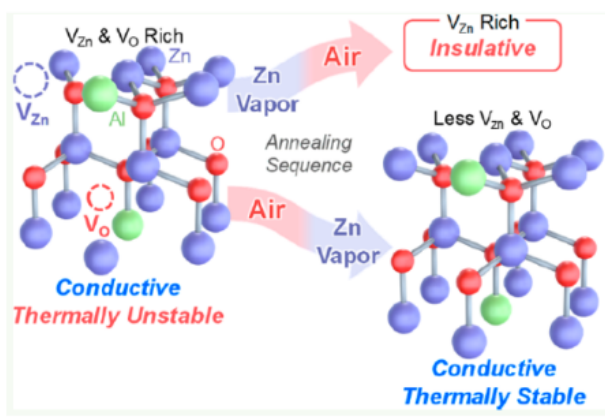

Figure 27. (a) Atmospherically stable $\mathrm{ZnO}$ nanowires via using the annealing process. Reprinted from reference [74] with permission from the American Chemical Society; (b) gas sensor with longterm stability via using heavily doped oxide as the contact. ATO, Sb-doped $\mathrm{SnO}_{2}$. Reprinted from reference [73] with permission from the American Chemical Society; (c) Al-doped ZnO thin film with thermal stability via using sequential annealing. Reprinted from reference [360] with permission from the American Chemical Society. 
With regard to the low power consumption, Meng et al. recently reported an excellent thermal management approach in metal-oxide nanowire sensors via a pulsed self-Jouleheating technique, as shown in Figure 28 [220]. It was found that the thermal conductivity of the device was reduced due to the prohibition of heat dissipation from nanowire to surroundings, and its thermal relaxation times can be decreased down to a microsecond range, while several tens of seconds are needed for conventional MEMS gas sensors. This method enables the reduction in energy consumption down to $\sim 10^{2} \mathrm{pJ} / \mathrm{s}$ and the enhancement of sensitivity for electrical sensing of $\mathrm{NO}_{2}(100 \mathrm{ppb})$. This proposed thermal management concept of nanowires in both spatial and time domains offers a strategy for exploring novel functionalities of nanowire-based sensors with high performance.

(a)

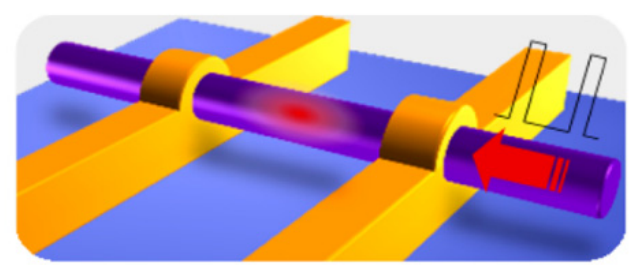

(b)
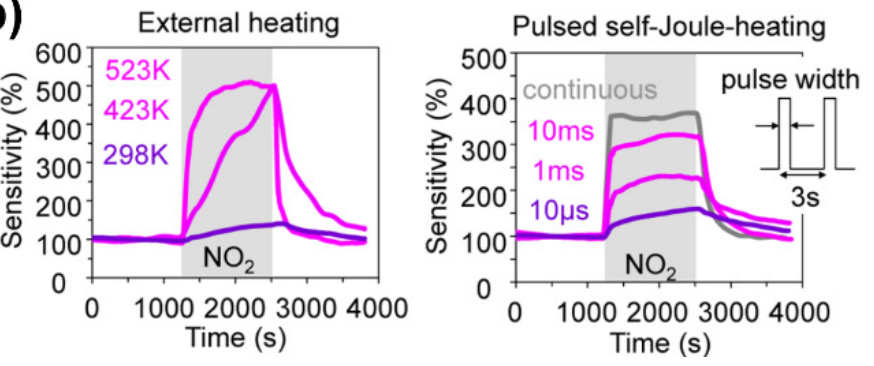

Figure 28. (a) Suspended nanowire device; and (b) comparison between the conventional external heating device and pulsed self-joule-heating device. Reprinted from reference [220] with permission from the American Chemical Society.

With the improvement of the metal-oxide nanowire synthesis and device fabrication processes with high uniformity, the integrated nanowire sensor electronics would have a high reproducibility, selectivity, and long-term stability. This would promote the nanowire sensor electronics to be widely used in the IoT applications, such as medicine, food industry, security, and environment protection.

Author Contributions: Writing—original draft preparation, H.Z.; writing—review and editing, G.Z., H.Z., K.N., T.T., T.H. and T.Y.; supervision, T.Y. All authors have read and agreed to the published version of the manuscript.

Funding: This research was funded by KAKENHI, grant number JP17H04927, JP18H01831, JP18H05243, and JP18KK0112. T.T. was supported by JST PRESTO Grant Number JPMJPR19M6, K.N. was supported by JST PRESTO Grant Number JPMJPR19J7, T.H. was supported by JST PRESTO Grant Number JPMJPR19T8, Japan. T.T., G.Z., K.N., and T.Y. were supported by JST CREST Grant Number JPMJCR19I2, Japan. T.Y. and K.N. were supported by CAS-JSPS Joint Research Projects (Grant Number JPJSBP120187207) and by Mirai R\&D of JST.

Institutional Review Board Statement: Not applicable.

Informed Consent Statement: Not applicable.

Data Availability Statement: Data sharing not applicable.

Acknowledgments: This work was performed under the Cooperative Research Program of "Network Joint Research Center for Materials and Devices" and the MEXT Project of "Integrated Research Consortium on Chemical Sciences".

Conflicts of Interest: The authors declare no conflict of interest. 


\section{References}

1. Lim, H.; Kim, H.S.; Qazi, R.; Kwon, Y.; Jeong, J.; Yeo, W. Wearable Flexible Hybrid Electronics: Advanced Soft Materials, Sensor Integrations, and Applications of Wearable Flexible Hybrid Electronics in Healthcare, Energy, and Environment. Adv. Mater. 2020, 32, 1-43.

2. Güntner, A.T.; Abegg, S.; Königstein, K.; Gerber, P.A.; Schmidt-Trucksäss, A.; Pratsinis, S.E. Breath Sensors for Health Monitoring. ACS Sens. 2019, 4, 268-280. [CrossRef]

3. Wang, T.; Ramnarayanan, A.; Cheng, H. Real Time Analysis of Bioanalytes in Healthcare, Food, Zoology and Botany. Sensors 2017, 18, 5. [CrossRef]

4. Dincer, C.; Bruch, R.; Costa-Rama, E.; Fernández-Abedul, M.T.; Merkoçi, A.; Manz, A.; Urban, G.A.; Güder, F. Disposable Sensors in Diagnostics, Food, and Environmental Monitoring. Adv. Mater. 2019, 31, 1806739. [CrossRef]

5. Fang, X.; Zong, B.; Mao, S. Metal-Organic Framework-Based Sensors for Environmental Contaminant Sensing. Nano-Micro Lett. 2018, 10, 1-19. [CrossRef]

6. Wang, D.; Chen, A.; Jen, A.K.-Y. Reducing cross-sensitivity of $\mathrm{TiO}_{2}-(\mathrm{B})$ nanowires to humidity using ultraviolet illumination for trace explosive detection. Phys. Chem. Chem. Phys. 2013, 15, 5017-5021. [CrossRef] [PubMed]

7. Cao, A.; Zhu, W.; Shang, J.; Klootwijk, J.H.; Sudhölter, E.J.R.; Huskens, J.; De Smet, L.C.P.M. Metal-Organic Polyhedra-Coated Si Nanowires for the Sensitive Detection of Trace Explosives. Nano Lett. 2016, 17, 1-7. [CrossRef] [PubMed]

8. Engel, Y.; Elnathan, R.; Pevzner, A.; Davidi, G.; Flaxer, E.; Patolsky, F. Supersensitive Detection of Explosives by Silicon Nanowire Arrays. Angew. Chem. Int. Ed. 2010, 49, 6830-6835. [CrossRef] [PubMed]

9. Lan, A.; Li, K.; Wu, H.; Olson, D.H.; Emge, T.J.; Ki, W.; Hong, M.; Li, J. A Luminescent Microporous Metal-Organic Framework for the Fast And reversible Detection of High Explosives. Angew. Chem. Int. Ed. 2009, 48, 2334-2338. [CrossRef] [PubMed]

10. Zappa, D. Low-Power Detection of Food Preservatives by a Novel Nanowire-Based Sensor Array. Foods 2019, 8, 226. [CrossRef] [PubMed]

11. Carmona, E.N.; Sberveglieri, V.; Ponzoni, A.; Galstyan, V.; Zappa, D.; Pulvirenti, A.; Comini, E. Detection of food and skin pathogen microbiota by means of an electronic nose based on metal oxide chemiresistors. Sens. Actuators B Chem. 2017, 238, 1224-1230. [CrossRef]

12. Mirzaei, A.; Lee, J.-H.; Majhi, S.M.; Weber, M.; Bechelany, M.; Kim, H.W.; Kim, S.S. Resistive gas sensors based on metal-oxide nanowires. J. Appl. Phys. 2019, 126, 241102. [CrossRef]

13. Karnati, P.; Akbar, S.; Morris, P.A. Conduction mechanisms in one dimensional core-shell nanostructures for gas sensing: A review. Sens. Actuators B Chem. 2019, 295, 127-143. [CrossRef]

14. Korotcenkov, G. Current Trends in Nanomaterials for Metal Oxide-Based Conductometric Gas Sensors: Advantages and Limitations. Part 1: 1D and 2D Nanostructures. Nanomaterials 2020, 10, 1392. [CrossRef] [PubMed]

15. Majhi, S.M.; Mirzaei, A.; WooKimab, H.; Kim, S.S.; Kim, T.W. Recent advances in energy-saving chemiresistive gas sensors: A review. Nano Energy 2021, 79, 105369. [CrossRef]

16. Joshi, N.; Hayasaka, T.; Liu, Y.; Liu, H.; Oliveira, O.N.; Lin, L. A review on chemiresistive room temperature gas sensors based on metal oxide nanostructures, graphene and 2D transition metal dichalcogenides. Microchim. Acta 2018, 185, 1-16. [CrossRef]

17. Mounasamy, V.; Mani, G.K.; Madanagurusamy, S. Vanadium oxide nanostructures for chemiresistive gas and vapour sensing: A review on state of the art. Microchim. Acta 2020, 187, 1-29. [CrossRef]

18. Wang, J.; Zhou, Q.; Peng, S.; Xu, L.; Zeng, W. Volatile Organic Compounds Gas Sensors Based on Molybdenum Oxides: A Mini Review. Front. Chem. 2020, 8, 1-7. [CrossRef]

19. Comini, E. Metal oxides nanowires chemical/gas sensors: Recent advances. Mater. Today Adv. 2020, 7, 100099. [CrossRef]

20. Wang, Y.; Duan, L.; Deng, Z.; Liao, J. Electrically Transduced Gas Sensors Based on Semiconducting Metal Oxide Nanowires. Sensors 2020, 20, 6781. [CrossRef]

21. Meng, J.; Li, Z. Schottky-Contacted Nanowire Sensors. Adv. Mater. 2020, 32, 1-16. [CrossRef] [PubMed]

22. Kaur, N.; Singh, M.; Comini, E. One-Dimensional Nanostructured Oxide Chemoresistive Sensors. Langmuir 2020, 36, 6326-6344. [CrossRef] [PubMed]

23. Choi, P.G.; Izu, N.; Shirahata, N.; Masuda, Y. $\mathrm{SnO}_{2}$ Nanosheets for Selective Alkene Gas Sensing. ACS Appl. Nano Mater. 2019, 2, 1820-1827. [CrossRef]

24. Miao, J.; Chen, C.; Meng, L.; Lin, J.Y. Self-Assembled Monolayer of Metal Oxide Nanosheet and Structure and Gas-Sensing Property Relationship. ACS Sens. 2019, 4, 1279-1290. [CrossRef]

25. Kim, K.; Choi, P.G.; Itoh, T.; Masuda, Y. Catalyst-free Highly Sensitive $\mathrm{SnO}_{2}$ Nanosheet Gas Sensors for Parts per Billion-Level Detection of Acetone. ACS Appl. Mater. Interfaces 2020, 12, 51637-51644. [CrossRef]

26. Govindhan, M.; Sidhureddy, B.; Chen, A. High-Temperature Hydrogen Gas Sensor Based on Three-Dimensional HierarchicalNanostructured Nickel-Cobalt Oxide. ACS Appl. Nano Mater. 2018, 1, 6005-6014. [CrossRef]

27. Zhang, H.; Chen, W.-G.; Li, Y.-Q.; Song, Z.-H. Gas Sensing Performances of ZnO Hierarchical Structures for Detecting Dissolved Gases in Transformer Oil: A Mini Review. Front. Chem. 2018, 6, 1-7. [CrossRef]

28. Li, N.; Fan, Y.; Shi, Y.; Xiang, Q.; Wang, X.; Xu, J. A low temperature formaldehyde gas sensor based on hierarchical $\mathrm{SnO} / \mathrm{SnO} 2$ nano-flowers assembled from ultrathin nanosheets: Synthesis, sensing performance and mechanism. Sens. Actuators B Chem. 2019, 294, 106-115. [CrossRef] 
29. Kolmakov, A.; Zhang, Y.; Cheng, G.; Moskovits, M. Detection of $\mathrm{CO}$ and $\mathrm{O}_{2}$ Using Tin Oxide Nanowire Sensors. Adv. Mater. 2003, 15, 997-1000. [CrossRef]

30. Huang, M.H.; Mao, S.; Feick, H.; Yan, H.Q.; Wu, Y.Y.; Kind, H.; Weber, E.; Russo, R.; Yang, P.D. Room-Temperature Ultraviolet Nanowire Nanolasers. Science 2001, 292, 1897-1899. [CrossRef] [PubMed]

31. Li, J.Y.; Qiao, Z.Y.; Chen, X.L.; Chen, L.; Cao, Y.G.; He, M.; Li, H.; Cao, Z.M.; Zhang, Z. Synthesis of $\beta$-Ga $2 \mathrm{O}_{3} \mathrm{Nanorods}$ J. Alloys Compd. 2000, 306, 300-302. [CrossRef]

32. Comini, E.; Faglia, G.; Sberveglieri, G.; Pan, Z.; Wang, Z.L. Stable and highly sensitive gas sensors based on semiconducting oxide nanobelts. Appl. Phys. Lett. 2002, 81, 1869-1871. [CrossRef]

33. Vomiero, A.; Bianchi, S.; Comini, E.; Faglia, G.; Ferroni, M.; Sberveglieri, G. Controlled Growth and Sensing Properties of $\mathrm{In}_{2} \mathrm{O}_{3}$ Nanowires. Cryst. Growth Des. 2007, 7, 2500-2504. [CrossRef]

34. Lupan, O.; Postica, V.; Wolff, N.; Polonskyi, O.; Duppel, V.; Kaidas, V.; Lazari, E.; Ababii, N.; Faupel, F.; Kienle, L.; et al. Localized Synthesis of Iron Oxide Nanowires and Fabrication of High Performance Nanosensors Based on a Single $\mathrm{Fe}_{2} \mathrm{O}_{3} \mathrm{Nanowire}_{\text {. Small }}$ 2017, 13, 1-10.

35. Jin, W.; Yan, S.; An, L.; Chen, W.; Yang, S.; Zhao, C.; Dai, Y. Enhancement of ethanol gas sensing response based on ordered $\mathrm{V}_{2} \mathrm{O}_{5}$ nanowire microyarns. Sens. Actuators B Chem. 2015, 206, 284-290. [CrossRef]

36. Fu, X.Q.; Wang, C.; Yu, H.C.; Wang, Y.G.; Wang, T.H. Fast humidity sensors based on $\mathrm{CeO}_{2}$ nanowires. Nanotechnology 2007, 18, 145503. [CrossRef]

37. Baratto, C.; Kumar, R.; Comini, E.; Faglia, G.; Sberveglieri, G. Gas Sensing Study of ZnO Nanowire Heterostructured with NiO for Detection of Pollutant Gases. Procedia Eng. 2014, 87, 1091-1094. [CrossRef]

38. Kaur, N.; Zappa, D.; Poli, N.; Comini, E. Integration of VLS-Grown $\mathrm{WO}_{3}$ Nanowires into Sensing Devices for the Detection of $\mathrm{H}_{2} \mathrm{~S}$ and $\mathrm{O}_{3}$. ACS Omega 2019, 4, 16336-16343. [CrossRef]

39. Kaur, N.; Comini, E.; Zappa, D.; Poli, N.; Sberveglieri, G. Nickel oxide nanowires: Vapor liquid solid synthesis and integration into a gas sensing device. Nanotechnology 2016, 27, 205701. [CrossRef]

40. Lupan, O.; Cretu, V.; Postica, V.; Ahmadi, M.; Cuenya, B.R.; Chow, L.; Tiginyanu, I.; Viana, B.; Pauporté, T.; Adelung, R. Silver-Doped Zinc Oxide Single Nanowire Multifunctional Nanosensor with a Significant Enhancement in Response. Sens. Actuators B Chem. 2016, 223, 893-903. [CrossRef]

41. Gu, L.; Zhou, D.; Cao, J.C. Piezoelectric Active Humidity Sensors Based on Lead-Free $\mathrm{NaNbO}_{3}$ Piezoelectric Nanofibers. Sensors 2016, 16, 833. [CrossRef]

42. Zhou, T.; Liu, X.; Zhang, R.; Wang, Y.; Zhang, T. Shape control and selective decoration of $\mathrm{Zn}_{2} \mathrm{SnO}_{4}$ nanostructures on $1 \mathrm{D}$ nanowires: Boosting chemical-sensing performances. Sens. Actuators B Chem. 2019, 290, 210-216. [CrossRef]

43. Thanh, H.X.; Trung, D.D.; Trung, K.Q.; Van Dam, K.; Van Duy, N.; Hung, C.M.; Hoa, N.D.; Van Hieu, N. On-chip growth of single phase $\mathrm{Zn}_{2} \mathrm{SnO}_{4}$ nanowires by thermal evaporation method for gas sensor application. J. Alloys Compd. 2017, 708, 470-475. [CrossRef]

44. Cheng, Z.; Huang, C.; Song, L.; Wang, Y.; Ding, Y.; Xu, J.; Zhang, Y. Electrospinning synthesis of CdIn ${ }_{2} \mathrm{O}_{4}$ nanofibers for ethanol detection. Sens. Actuators B Chem. 2015, 209, 530-535. [CrossRef]

45. Gu, G.; Zheng, B.; Han, W.Q.; Roth, S.; Liu, J. Tungsten Oxide Nanowires on Tungsten Substrates. Nano Lett. 2002,2 , 849-851. [CrossRef]

46. Baek, D.-H.; Choi, J.; Kim, J. Fabrication of suspended nanowires for highly sensitive gas sensing. Sens. Actuators B Chem. 2019, 284, 362-368. [CrossRef]

47. Steinhauer, S.; Chapelle, A.; Menini, P.; Sowwan, M. Local CuO Nanowire Growth on Microhotplates: In Situ Electrical Measurements and Gas Sensing Application. ACS Sens. 2016, 1, 503-507. [CrossRef]

48. Chen, J.; Wang, K.; Zhou, W. Vertically Aligned ZnO Nanorod Arrays Coated with $\mathrm{SnO}_{2} / \mathrm{Noble}$ Metal Nanoparticles for Highly Sensitive and Selective Gas Detection. IEEE Trans. Nanotechnol. 2010, 10, 968-974. [CrossRef]

49. Ford, A.C.; Ho, J.C.; Chueh, Y.-L.; Tseng, Y.-C.; Fan, Z.; Guo, J.; Bokor, J.; Javey, A. Diameter-Dependent Electron Mobility of InAs Nanowires. Nano Lett. 2009, 9, 360-365. [CrossRef]

50. Duan, J.-L.; Liu, J.; Yao, H.-J.; Mo, D.; Hou, M.-D.; Sun, Y.-M.; Chen, Y.-F.; Zhang, L. Controlled synthesis and diameter-dependent optical properties of Cu nanowire arrays. Mater. Sci. Eng. B 2008, 147, 57-62. [CrossRef]

51. Li, D.; Wu, Y.; Kim, P.; Shi, L.; Yang, P.; Majumdar, A. Thermal conductivity of individual silicon nanowires. Appl. Phys. Lett. 2003, 83, 2934-2936. [CrossRef]

52. Tonezzer, M.; Hieu, N. Size-dependent response of single-nanowire gas sensors. Sens. Actuators B Chem. 2012, 163, 146-152. [CrossRef]

53. Xia, Y.; Yang, P.; Sun, Y.; Wu, Y.; Mayers, B.; Gates, B.; Yin, Y.; Kim, F.; Yan, H. One-Dimensional Nanostructures: Synthesis, Characterization, and Applications. Adv. Mater. 2003, 15, 353-389. [CrossRef]

54. Gröttrup, J.; Postica, V.; Ababii, N.; Lupan, O.; Zamponi, C.; Meyners, D.; Mishra, Y.K.; Sontea, V.; Tiginyanu, I.; Adelung, R. Size-Dependent UV and Gas Sensing Response of Individual $\mathrm{Fe}_{2} \mathrm{O}_{3}-\mathrm{ZnO}$ :Fe Micro- and Nanowire Based Devices. J. Alloys Compd. 2017, 701, 920-925. [CrossRef]

55. Kim, K.; Kwak, H.-T.; Cho, H.; Meyyappan, M.; Baek, C.-K. Design Guidelines for High Sensitivity ZnO Nanowire Gas Sensors with Schottky Contact. IEEE Sens. J. 2019, 19, 976-981. [CrossRef] 
56. Walker, J.M.; Akbar, S.A.; Morris, P.A. Synergistic effects in gas sensing semiconducting oxide nano-heterostructures: A review. Sens. Actuators B Chem. 2019, 286, 624-640. [CrossRef]

57. Zappa, D.; Galstyan, V.; Kaur, N.; Munasinghe Arachchige, H.M.M.; Sisman, O.; Comini, E. “Metal Oxide -Based Heterostructures for Gas Sensors"- A Review. Anal. Chim. Acta 2018, 1039, 1-23. [CrossRef]

58. Simakov, V.; Sinev, I.; Shikunov, D.; Tymoshenko, D.; Smirnov, A.; Zaitsev, B. Experimental investigation and modeling of temperature influence on vertical and radial growth rate of tin dioxide nanowires synthesized by catalyst-free thermal evaporation method. Mater. Chem. Phys. 2020, 242, 122502. [CrossRef]

59. Singh, N.; Ponzoni, A.; Comini, E.; Lee, P.S. Chemical sensing investigations on $\mathrm{Zn}-\mathrm{In}_{2} \mathrm{O}_{3}$ nanowires. Sens. Actuators B Chem. 2012, 171, 244-248. [CrossRef]

60. Liu, Z.; Zhang, D.; Han, S.; Li, C.; Tang, T.; Jin, W.; Liu, X.; Lei, B.; Zhou, C. Laser Ablation Synthesis and Electron Transport Studies of Tin Oxide Nanowires. Adv. Mater. 2003, 15, 1754-1757. [CrossRef]

61. Shkurmanov, A.; Sturm, C.; Franke, H.; Lenzner, J.; Grundmann, M. Low-Temperature PLD-Growth of Ultrathin ZnO Nanowires by Using $\mathrm{Zn}_{\mathrm{x}} \mathrm{Al}_{1-\mathrm{x}} \mathrm{O}$ and $\mathrm{Zn}_{\mathrm{x}} \mathrm{Ga}_{1-\mathrm{x}} \mathrm{O}$ Seed Layers. Nanoscale Res. Lett. 2017, 12, 1-7. [CrossRef]

62. Liang, J.; Zhao, Y.; Zhu, K.; Guo, J.; Zhou, L. Synthesis and room temperature $\mathrm{NO}_{2}$ gas sensitivity of vanadium dioxide nanowire structures by chemical vapor deposition. Thin Solid Films 2019, 669, 537-543. [CrossRef]

63. Vallejos, S.; Gràcia, I.; Lednický, T.; Vojkuvka, L.; Figueras, E.; Hubálek, J.; Cané, C. Highly Hydrogen Sensitive Micromachined Sensors Based on Aerosol-Assisted Chemical Vapor Deposited ZnO Rods. Sens. Actuators B Chem. 2018, 268, 15-21. [CrossRef]

64. Nekita, S.; Nagashima, K.; Zhang, G.; Wang, Q.; Kanai, M.; Takahashi, T.; Hosomi, T.; Nakamura, K.; Okuyama, T.; Yanagida, T. Face-Selective Crystal Growth of Hydrothermal Tungsten Oxide Nanowires for Sensing Volatile Molecules. ACS Appl. Nano Mater. 2020, 3, 10252-10260. [CrossRef]

65. Liu, Q.; Yasui, T.; Nagashima, K.; Yanagida, T.; Hara, M.; Horiuchi, M.; Zhu, Z.; Takahashi, H.; Shimada, T.; Arima, A.; et al Ammonia-Induced Seed Layer Transformations in a Hydrothermal Growth Process of Zinc Oxide Nanowires. J. Phys. Chem. C 2020, 124, 20563-20568. [CrossRef]

66. Wang, Q.; Huang, J.; Zhou, J.; Liu, Z.; Geng, Y.; Liang, Z.; Du, Y.; Tian, X. Different nanostructured tungsten oxides synthesized by facile solvothermal route for chlorine gas sensing. Sens. Actuators B Chem. 2018, 275, 306-311. [CrossRef]

67. Qin, Y.; Li, X.; Wang, F.; Hu, M. Solvothermally synthesized tungsten oxide nanowires/nanorods for $\mathrm{NO}_{2}$ gas sensor applications. J. Alloys Compd. 2011, 509, 8401-8406. [CrossRef]

68. Dasgupta, N.P.; Sun, J.; Liu, C.; Brittman, S.; Andrews, S.C.; Lim, J.; Gao, H.; Yan, R.; Yang, P. 25th Anniversary Article: Semiconductor Nanowires-Synthesis, Characterization, and Applications. Adv. Mater. 2014, 26, 2137-2184. [CrossRef] [PubMed]

69. Asadzadeh, M.Z.; Köck, A.; Popov, M.; Steinhauer, S.; Spitaler, J.; Romaner, L. Response modeling of single $\mathrm{SnO}_{2}$ nanowire gas sensors. Sens. Actuators B Chem. 2019, 295, 22-29. [CrossRef]

70. Gall, O.Z.; Zhong, X.; Schulman, D.S.; Kang, M.; Razavieh, A.; Mayer, T.S. Titanium dioxide nanowire sensor array integration on CMOS platform using deterministic assembly. Nanotechnology 2017, 28, 265501. [CrossRef] [PubMed]

71. Jeong, S.; Kim, J.; Lee, J. Rational Design of Semiconductor-Based Chemiresistors and their Libraries for Next-Generation Artificial Olfaction. Adv. Mater. 2020, 32, 1-47. [CrossRef]

72. Zhou, Z.; Lan, C.; Wei, R.; Ho, J.C. Transparent metal-oxide nanowires and their applications in harsh electronics. J. Mater. Chem. C 2018, 7, 202-217. [CrossRef]

73. Zeng, H.; Takahashi, T.; Kanai, M.; Zhang, G.; He, Y.; Nagashima, K.; Yanagida, T. Long-Term Stability of Oxide Nanowire Sensors via Heavily Doped Oxide Contact. ACS Sens. 2017, 2, 1854-1859. [CrossRef]

74. Nakamura, K.; Takahashi, T.; Hosomi, T.; Seki, T.; Kanai, M.; Zhang, G.; Nagashima, K.; Shibata, N.; Yanagida, T. Redox-Inactive $\mathrm{CO}_{2}$ Determines Atmospheric Stability of Electrical Properties of ZnO Nanowire Devices through a Room-Temperature Surface Reaction. ACS Appl. Mater. Interfaces 2019, 11, 40260-40266. [CrossRef]

75. Zhang, D.; Liu, Z.; Li, C.; Tang, T.; Liu, X.; Han, S.; Lei, A.B.; Zhou, C. Detection of $\mathrm{NO}_{2}$ down to ppb Levels Using Individual and Multiple $\mathrm{In}_{2} \mathrm{O}_{3}$ Nanowire Devices. Nano Lett. 2004, 4, 1919-1924. [CrossRef]

76. Verma, V.P.; Das, S.; Hwang, S.; Choi, H.; Jeon, M.; Choi, W. Nitric oxide gas sensing at room temperature by functionalized single zinc oxide nanowire. Mater. Sci. Eng. B 2010, 171, 45-49. [CrossRef]

77. Johnson, M.C.; Aloni, S.; McCready, D.E.; Bourret-Courchesne, E.D. Controlled Vapor-Liquid-Solid Growth of Indium, Gallium, and Tin Oxide Nanowires via Chemical Vapor Transport. Cryst. Growth Des. 2006, 6, 1936-1941. [CrossRef]

78. Anzai, H.; Suzuki, M.; Nagashima, K.; Kanai, M.; Guozhu, Z.; He, Y.; Boudot, M.; Zhang, G.; Takahashi, T.; Kanemoto, K.; et al. True Vapor-Liquid-Solid Process Suppresses Unintentional Carrier Doping of Single Crystalline Metal Oxide Nanowires. Nano Lett. 2017, 17, 4698-4705. [CrossRef] [PubMed]

79. Bang, J.H.; Choi, M.S.; Mirzaei, A.; Kwon, Y.J.; Kim, S.S.; Kim, T.W.; Kim, H.W. Selective $\mathrm{NO}_{2}$ sensor based on Bi ${ }_{2} \mathrm{O}_{3}$ branched $\mathrm{SnO}_{2}$ nanowires. Sens. Actuators B Chem. 2018, 274, 356-369. [CrossRef]

80. Kim, J.-H.; Mirzaei, A.; Kim, J.-Y.; Lee, J.-H.; Kim, H.W.; Hishita, S.; Kim, S.S. Enhancement of gas sensing by implantation of Sb-ions in $\mathrm{SnO}_{2}$ nanowires. Sens. Actuators B Chem. 2020, 304, 127307. [CrossRef]

81. Morales, A.M.; Lieber, C.M. A Laser Ablation Method for the Synthesis of Crystalline Semiconductor Nanowires. Science 1998, 279, 208-211. [CrossRef] 
82. Zervos, M.; Mihailescu, C.N.; Giapintzakis, J.; Luculescu, C.R.; Florini, N.; Komninou, P.; Kioseoglou, J.; Othonos, A. Broad compositional tunability of indium tin oxide nanowires grown by the vapor-liquid-solid mechanism. APL Mater. 2014, $2,056104$. [CrossRef]

83. Zhu, Z.; Suzuki, M.; Nagashima, K.; Yoshida, H.; Kanai, M.; Meng, G.; Anzai, H.; Zhuge, F.; He, Y.; Boudot, M.; et al. Rational Concept for Reducing Growth Temperature in Vapor-Liquid-Solid Process of Metal Oxide Nanowires. Nano Lett. 2016, 16, 7495-7502. [CrossRef] [PubMed]

84. Meng, G.; Yanagida, T.; Nagashima, K.; Yoshida, H.; Kanai, M.; Klamchuen, A.; Zhuge, F.; He, Y.; Rahong, S.; Fang, X.; et al. Impact of Preferential Indium Nucleation on Electrical Conductivity of Vapor-Liquid-Solid Grown Indium-Tin Oxide Nanowires. J. Am. Chem. Soc. 2013, 135, 7033-7038. [CrossRef] [PubMed]

85. Klamchuen, A.; Suzuki, M.; Nagashima, K.; Yoshida, H.; Kanai, M.; Zhuge, F.; He, Y.; Meng, G.; Kai, S.; Takeda, S.; et al. Rational Concept for Designing Vapor-Liquid-Solid Growth of Single Crystalline Metal Oxide Nanowires. Nano Lett. 2015, 15, 6406-6412. [CrossRef] [PubMed]

86. Meng, G.; Yanagida, T.; Yoshida, H.; Nagashima, K.; Kanai, M.; Zhuge, F.; He, Y.; Klamchuen, A.; Rahong, S.; Fang, X.; et al. A flux induced crystal phase transition in the vapor-liquid-solid growth of indium-tin oxide nanowires. Nanoscale 2014, 6, 7033-7038. [CrossRef]

87. Jeongseok, L.; Se-Hyeong, L.; So-Young, B.; Yoojong, K.; Kyoungwan, W.; Sanghyun, L.; Yooseong, L.; Moonsuk, Y. Improved Sensitivity of $\alpha-\mathrm{Fe}_{2} \mathrm{O}_{3}$ Nanoparticle-Decorated ZnO Nanowire Gas Sensor for CO. Sensors 2019, 19, 1903.

88. Kim, J.-H.; Mirzaei, A.; Kim, H.W.; Kim, S.S. Improving the hydrogen sensing properties of $\mathrm{SnO}_{2}$ nanowire-based conductometric sensors by Pd-decoration. Sens. Actuators B Chem. 2019, 285, 358-367. [CrossRef]

89. Woo, H.-S.; Kwak, C.-H.; Chung, J.-H.; Lee, J.-H. Highly selective and sensitive xylene sensors using Ni-doped branched ZnO nanowire networks. Sens. Actuators B Chem. 2015, 216, 358-366. [CrossRef]

90. Afshar, M.; Preiß, E.M.; Sauerwald, T.; Rodner, M.; FeiLi, D.; Straub, M.; König, K.; Schütze, A.; Seidel, H.; Preiss, E. Indium-tinoxide single-nanowire gas sensor fabricated via laser writing and subsequent etching. Sens. Actuators B Chem. 2015, 215, 525-535. [CrossRef]

91. Nguyen, P.; Ng, H.T.; Kong, J.; Cassell, A.M.; Quinn, R.; Li, J.; Han, J.; McNeil, M.; Meyyappan, M. Epitaxial Directional Growth of Indium-Doped Tin Oxide Nanowire Arrays. Nano Lett. 2003, 3, 925-928. [CrossRef]

92. Xue, X.Y.; Chen, Y.J.; Liu, Y.G.; Shi, S.L.; Wang, Y.G.; Wang, T.H. Synthesis and ethanol sensing properties of indium-doped tin oxide nanowires. Appl. Phys. Lett. 2006, 88, 201907. [CrossRef]

93. Kaur, N.; Comini, E.; Poli, N.; Zappa, D.; Sberveglieri, G. Nickel Oxide Nanowires Growth by VLS Technique for Gas Sensing Application. Procedia Eng. 2015, 120, 760-763. [CrossRef]

94. Nagashima, K.; Yoshida, H.; Klamchuen, A.; Kanai, M.; Meng, G.; Zhuge, F.; He, Y.; Anzai, H.; Zhu, Z.; Suzuki, M.; et al. Tailoring Nucleation at Two Interfaces Enables Single Crystalline NiO Nanowires via Vapor-Liquid-Solid Route. ACS Appl. Mater. Interfaces 2016, 8, 27892-27899. [CrossRef] [PubMed]

95. Oka, K.; Yanagida, T.; Nagashima, K.; Kawai, T.; Kim, J.-S.; Park, B.H. Resistive-Switching Memory Effects of NiO Nanowire/Metal Junctions. J. Am. Chem. Soc. 2010, 132, 6634-6635. [CrossRef] [PubMed]

96. Chang, P.-C.; Fan, Z.; Wang, D.; Tseng, W.-Y.; Chiou, W.-A.; Hong, J.; Lu, J.G. ZnO Nanowires Synthesized by Vapor Trapping CVD Method. Chem. Mater. 2004, 16, 5133-5137. [CrossRef]

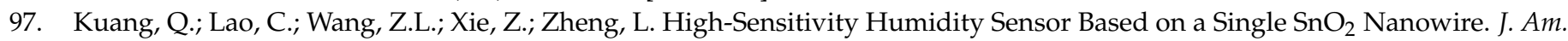
Chem. Soc. 2007, 129, 6070-6071. [CrossRef]

98. Klamchuen, A.; Yanagida, T.; Kanai, M.; Nagashima, K.; Oka, K.; Seki, S.; Suzuki, M.; Hidaka, Y.; Kai, S.; Kawai, T. Dopant homogeneity and transport properties of impurity-doped oxide nanowires. Appl. Phys. Lett. 2011, 98, 053107. [CrossRef]

99. Zhuge, F.; Yanagida, T.; Nagashima, K.; Yoshida, H.; Kanai, M.; Xu, B.; Klamchuen, A.; Meng, G.; He, Y.; Rahong, S.; et al. Fundamental Strategy for Creating VLS Grown $\mathrm{TiO}_{2}$ Single Crystalline Nanowires. J. Phys. Chem. C 2012, 116, 24367-24372. [CrossRef]

100. Kim, M.H.; Baik, J.M.; Zhang, J.; Larson, C.; Li, Y.; Stucky, G.D.; Moskovits, M.; Wodtke, A.M. TiO 2 Nanowire Growth Driven by Phosphorus-Doped Nanocatalysis. J. Phys. Chem. C 2010, 114, 10697-10702. [CrossRef]

101. Li, C.; Zhang, D.; Han, S.; Liu, X.; Tang, T.; Zhou, C. Diameter-Controlled Growth of Single-Crystalline $\mathrm{In}_{2} \mathrm{O}_{3} \mathrm{Nanowires}$ and Their Electronic Properties. Adv. Mater. 2003, 15, 143-146. [CrossRef]

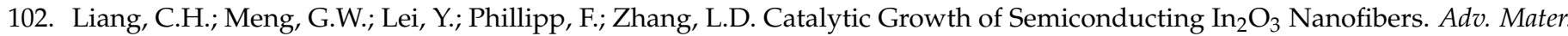
2001, 13, 1330-1333. [CrossRef]

103. Dang, H.Y.; Wang, J.; Fan, S.S. The synthesis of metal oxide nanowires by directly heating metal samples in appropriate oxygen atmospheres. Nanotechnology 2003, 14, 738-741. [CrossRef]

104. Yan, Y.; Zhou, L.; Zhang, J.; Zeng, H.; Zhang, Y.; Zhang, L. Synthesis and Growth Discussion of One-Dimensional MgO Nanostructures: Nanowires, Nanobelts, and Nanotubes in VLS Mechanism. J. Phys. Chem. C 2008, 112, 10412-10417. [CrossRef]

105. Yanagida, T.; Nagashima, K.; Tanaka, H.; Kawai, T. Mechanism of critical catalyst size effect on MgO nanowire growth by pulsed laser deposition. J. Appl. Phys. 2008, 104, 016101. [CrossRef]

106. A Fortuna, S.; Li, X. Metal-catalyzed semiconductor nanowires: A review on the control of growth directions. Semicond. Sci. Technol. 2010, 25, 024005. [CrossRef] 
107. Weng, T.-F.; Ho, M.-S.; Sivakumar, C.; Balraj, B.; Chung, P.-F. VLS growth of pure and Au decorated $\beta$-Ga $\mathrm{O}_{3}$ nanowires for room temperature CO gas sensor and resistive memory applications. Appl. Surf. Sci. 2020, 533, 147476. [CrossRef]

108. Klamchuen, A.; Yanagida, T.; Nagashima, K.; Seki, S.; Oka, K.; Taniguchi, M.; Kawai, T. Crucial Role of Doping Dynamics on Transport Properties of Sb-Doped $\mathrm{SnO}_{2}$ Nanowires. Appl. Phys. Lett. 2009, 95, 7-9. [CrossRef]

109. Marcu, A.; Yanagida, T.; Nagashima, K.; Oka, K.; Tanaka, H.; Kawai, T. Crucial Role of Interdiffusion on Magnetic Properties of in Situ Formed $\mathrm{MgO} \mathrm{Fe}_{3-\Delta} \mathrm{O}_{4}$ Heterostructured Nanowires. Appl. Phys. Lett. 2008, 92, 3-5. [CrossRef]

110. Marcu, A.; Yanagida, T.; Nagashima, K.; Tanaka, H.; Kawai, T. Effect of ablated particle flux on MgO nanowire growth by pulsed laser deposition. J. Appl. Phys. 2007, 102, 016102. [CrossRef]

111. He, Y.; Yanagida, T.; Nagashima, K.; Zhuge, F.; Meng, G.; Xu, B.; Klamchuen, A.; Rahong, S.; Kanai, M.; Li, X.; et al. Crystal-Plane Dependence of Critical Concentration for Nucleation on Hydrothermal ZnO Nanowires. J. Phys. Chem. C 2013, 117, 1197-1203. [CrossRef]

112. Nagashima, K.; Yanagida, T.; Kanai, M.; Oka, K.; Klamchuen, A.; Rahong, S.; Meng, G.; Horprathum, M.; Xu, B.; Zhuge, F.; et al. Switching Properties of Titanium Dioxide Nanowire Memristor. Jpn. J. Appl. Phys. 2012, 51, 9-12. [CrossRef]

113. Nagashima, K.; Yanagida, T.; Klamchuen, A.; Kanai, M.; Oka, K.; Seki, S.; Kawai, T.; Lee, Y.-H.; Lee, J.-H. Interfacial effect on metal/oxide nanowire junctions. Appl. Phys. Lett. 2010, 96, 073110. [CrossRef]

114. Nagashima, K.; Yanagida, T.; Oka, K.; Kanai, M.; Klamchuen, A.; Kim, J.-S.; Park, B.H.; Kawai, T. Intrinsic Mechanisms of Memristive Switching. Nano Lett. 2011, 11, 2114-2118. [CrossRef]

115. Nagashima, K.; Yanagida, T.; Oka, K.; Kanai, M.; Klamchuen, A.; Rahong, S.; Meng, G.; Horprathum, M.; Xu, B.; Zhuge, F.; et al. Prominent Thermodynamical Interaction with Surroundings on Nanoscale Memristive Switching of Metal Oxides. Nano Lett. 2012, 12, 5684-5690. [CrossRef]

116. Nagashima, K.; Yanagida, T.; Oka, K.; Tanaka, H.; Kawai, T. Mechanism and control of sidewall growth and catalyst diffusion on oxide nanowire vapor-liquid-solid growth. Appl. Phys. Lett. 2008, 93, 153103. [CrossRef]

117. Nagashima, K.; Yanagida, T.; Oka, K.; Taniguchi, M.; Kawai, T.; Kim, J.-S.; Park, B.H. Resistive Switching Multistate Nonvolatile Memory Effects in a Single Cobalt Oxide Nanowire. Nano Lett. 2010, 10, 1359-1363. [CrossRef]

118. Nagashima, K.; Yanagida, T.; Tanaka, H.; Kawai, T. Control of magnesium oxide nanowire morphologies by ambient temperature. Appl. Phys. Lett. 2007, 90, 233103. [CrossRef]

119. Nagashima, K.; Yanagida, T.; Tanaka, H.; Kawai, T. Epitaxial growth of MgO nanowires by pulsed laser deposition. J. Appl. Phys. 2007, 101, 124304. [CrossRef]

120. Oka, K.; Yanagida, T.; Nagashima, K.; Kanai, M.; Kawai, T.; Kim, J.-S.; Park, B.H. Spatial Nonuniformity in Resistive-Switching Memory Effects of NiO. J. Am. Chem. Soc. 2011, 133, 12482-12485. [CrossRef]

121. Oka, K.; Yanagida, T.; Nagashima, K.; Kanai, M.; Xu, B.; Park, B.H.; Katayama-Yoshida, H.; Kawai, T. Dual Defects of Cation and Anion in Memristive Nonvolatile Memory of Metal Oxides. J. Am. Chem. Soc. 2012, 134, 2535-2538. [CrossRef]

122. Oka, K.; Yanagida, T.; Nagashima, K.; Tanaka, H.; Kawai, T. Nonvolatile Bipolar Resistive Memory Switching in Single Crystalline NiO Heterostructured Nanowires. J. Am. Chem. Soc. 2009, 131, 3434-3435. [CrossRef]

123. Oka, K.; Yanagida, T.; Nagashima, K.; Tanaka, H.; Seki, S.; Honsho, Y.; Ishimaru, M.; Hirata, A.; Kawai, T. Specific surface effect on transport properties of $\mathrm{NiO} / \mathrm{MgO}$ heterostructured nanowires. Appl. Phys. Lett. 2009, 95, 133110. [CrossRef]

124. Yanagida, T.; Marcu, A.; Matsui, H.; Nagashima, K.; Oka, K.; Yokota, K.; Taniguchi, M.; Kawai, T. Enhancement of Oxide VLS Growth by Carbon on Substrate Surface. J. Phys. Chem. C 2008, 112, 18923-18926. [CrossRef]

125. Yanagida, T.; Nagashima, K.; Tanaka, H.; Kawai, T. Mechanism of catalyst diffusion on magnesium oxide nanowire growth. Appl. Phys. Lett. 2007, 91, 061502. [CrossRef]

126. Yanase, T.; Ogihara, U.; Awashima, Y.; Yanagida, T.; Nagashima, K.; Nagahama, T.; Shimada, T. Growth Kinetics and Magnetic Property of Single-Crystal Fe Nanowires Grown via Vapor-Solid Mechanism Using Chemically Synthesized FeO Nanoparticle Catalysts. Cryst. Growth Des. 2019, 19, 7257-7263. [CrossRef]

127. Zeng, H.; Takahashi, T.; Seki, T.; Kanai, M.; Zhang, G.; Hosomi, T.; Nagashima, K.; Shibata, N.; Yanagida, T. Oxygen-Induced Reversible Sn-Dopant Deactivation between Indium Tin Oxide and Single-Crystalline Oxide Nanowire Leading to Interfacial Switching. ACS Appl. Mater. Interfaces 2020, 12, 52929-52936. [CrossRef]

128. Klamchuen, A.; Tanaka, H.; Tanaka, D.; Toyama, H.; Meng, G.; Rahong, S.; Nagashima, K.; Kanai, M.; Yanagida, T.; Kawai, T.; et al. Advanced Photoassisted Atomic Switches Produced Using ITO Nanowire Electrodes and Molten Photoconductive Organic Semiconductors. Adv. Mater. 2013, 25, 5893-5897. [CrossRef]

129. Klamchuen, A.; Yanagida, T.; Kanai, M.; Nagashima, K.; Oka, K.; Kawai, T.; Suzuki, M.; Hidaka, Y.; Kai, S. Impurity induced periodic mesostructures in Sb-doped $\mathrm{SnO}_{2}$ nanowires. J. Cryst. Growth 2010, 312, 3251-3256. [CrossRef]

130. Klamchuen, A.; Yanagida, T.; Kanai, M.; Nagashima, K.; Oka, K.; Kawai, T.; Suzuki, M.; Hidaka, Y.; Kai, S. Role of surrounding oxygen on oxide nanowire growth. Appl. Phys. Lett. 2010, 97, 073114. [CrossRef]

131. Klamchuen, A.; Yanagida, T.; Kanai, M.; Nagashima, K.; Oka, K.; Rahong, S.; Gang, M.; Horprathum, M.; Suzuki, M.; Hidaka, Y.; et al. Study on transport pathway in oxide nanowire growth by using spacing-controlled regular array. Appl. Phys. Lett. 2011, 99, 193105. [CrossRef]

132. Zhang, Z.; Wang, S.J.; Yu, T.; Wu, T. Controlling the Growth Mechanism of ZnO Nanowires by Selecting Catalysts. J. Phys. Chem. C 2007, 111, 17500-17505. [CrossRef] 
133. Deng, S.; Tjoa, V.; Fan, H.M.; Tan, H.R.; Sayle, D.C.; Olivo, M.; Mhaisalkar, S.; Wei, J.; Sow, C.H. Reduced Graphene Oxide Conjugated $\mathrm{Cu} 2 \mathrm{O}$ Nanowire Mesocrystals for High-Performance $\mathrm{NO}_{2}$ Gas Sensor. J. Am. Chem. Soc. 2012, 134, $4905-4917$. [CrossRef]

134. Smith, A.M.; Kast, M.G.; Nail, B.A.; Aloni, S.; Boettcher, S.W. A planar-defect-driven growth mechanism of oxygen deficient tungsten oxide nanowires. J. Mater. Chem. A 2014, 2, 6121-6129. [CrossRef]

135. Zhou, S.; Feng, Y.; Zhang, L. A physical evaporation synthetic route to large-scale GaN nanowires and their dielectric properties. Chem. Phys. Lett. 2003, 369, 610-614. [CrossRef]

136. Bierman, M.J.; Lau, Y.K.A.; Kvit, A.V.; Schmitt, A.L.; Jin, S. Dislocation-Driven Nanowire Growth and Eshelby Twist. Science 2008, 320, 1060-1063. [CrossRef] [PubMed]

137. Zhang, H.; Kong, Y.; Wang, Y.; Du, X.; Bai, Z.; Wang, J.; Yu, D.; Ding, Y.; Hang, Q.; Feng, S. Ga ${ }_{2} \mathrm{O}_{3}$ nanowires prepared by physical evaporation. Solid State Commun. 1999, 109, 677-682. [CrossRef]

138. Meng, F.; Morin, S.A.; Forticaux, A.; Jin, S. Screw Dislocation Driven Growth of Nanomaterials. Accounts Chem. Res. 2013, 46, 1616-1626. [CrossRef]

139. Morin, S.A.; Bierman, M.J.; Tong, J.; Jin, S. Mechanism and Kinetics of Spontaneous Nanotube Growth Driven by Screw Dislocations. Science 2010, 328, 476-480. [CrossRef]

140. Fan, H.J.; Bertram, F.; Dadgar, A.; Christen, J.; Krost, A.; Zacharias, M. Self-assembly of ZnO nanowires and the spatial resolved characterization of their luminescence. Nanotechnology 2004, 15, 1401-1404. [CrossRef]

141. Yao, B.D.; Chan, Y.F.; Wang, N. Formation of ZnO nanostructures by a simple way of thermal evaporation. Appl. Phys. Lett. 2002, 81, 757-759. [CrossRef]

142. Zhou, J.; Gong, L.; Deng, S.Z.; Chen, J.; She, J.C.; Xu, N.S.; Yang, R.; Wang, Z.L. Growth and field-emission property of tungsten oxide nanotip arrays. Appl. Phys. Lett. 2005, 87, 223108. [CrossRef]

143. Thabethe, B.S.; Malgas, G.F.; Motaung, D.E.; Malwela, T.; Arendse, C.J. Self-Catalytic Growth of Tin Oxide Nanowires by Chemical Vapor Deposition Process. J. Nanomater. 2013, 2013, 1-7. [CrossRef]

144. Yang, Z.; Zhu, F.; Zhou, W.; Zhang, Y. Novel nanostructures of $\beta-\mathrm{Ga}_{2} \mathrm{O}_{3}$ synthesized by thermal evaporation. Phys. E Low-Dimens. Syst. Nanostruct. 2005, 30, 93-95. [CrossRef]

145. Wang, Z.L.; Kong, X.Y.; Zuo, J.M. Induced Growth of Asymmetric Nanocantilever Arrays on Polar Surfaces. Phys. Rev. Lett. 2003, 91, 185502. [CrossRef]

146. Sinha, G.; Datta, A.; Panda, S.K.; Chavan, P.G.; A More, M.; Joag, D.S.; Patra, A. Self-catalytic growth and field-emission properties of $\mathrm{Ga}_{2} \mathrm{O}_{3}$ nanowires. J. Phys. D Appl. Phys. 2009, 42, 42. [CrossRef]

147. Luo, S.; Chu, P.K.; Liu, W.; Zhang, M.; Lin, C. Origin of low-temperature photoluminescence from $\mathrm{SnO}_{2}$ nanowires fabricated by thermal evaporation and annealed in different ambients. Appl. Phys. Lett. 2006, 88, 183112. [CrossRef]

148. Wang, Z.L.; Kong, X.Y.; Ding, Y.; Gao, P.; Hughes, W.L.; Yang, R.; Zhang, Y. Semiconducting and Piezoelectric Oxide Nanostructures Induced by Polar Surfaces. Adv. Funct. Mater. 2004, 14, 943-956. [CrossRef]

149. Kong, X.Y.; Ding, Y.; Wang, Z.L. Metal-Semiconductor Zn-ZnO Core-Shell Nanobelts and Nanotubes. J. Phys. Chem. B 2004, 108, 570-574. [CrossRef]

150. Wang, X.; Ding, Y.; Summers, C.J.; Wang, Z.L. Large-Scale Synthesis of Six-Nanometer-Wide ZnO Nanobelts. J. Phys. Chem. B 2004, 108, 8773-8777. [CrossRef]

151. Youn, S.K.; Ramgir, N.; Wang, C.; Subannajui, K.; Cimalla, V.; Zacharias, M. Catalyst-Free Growth of ZnO Nanowires Based on Topographical Confinement and Preferential Chemisorption and Their Use for Room Temperature CO Detection. J. Phys. Chem. C 2010, 114, 10092-10100. [CrossRef]

152. Pallister, P.J.; Buttera, S.C.; Barry, S.T. Self-seeding gallium oxide nanowire growth by pulsed chemical vapor deposition. Phys. Status Solidi (a) 2015, 212, 1514-1518. [CrossRef]

153. Xiang, B.; Zhang, Y.; Wang, Z.; Luo, X.H.; Zhu, Y.W.; Zhang, H.Z.; Yu, D.P. Field-emission properties of TiO 2 nanowire arrays. J. Phys. D Appl. Phys. 2005, 38, 1152-1155. [CrossRef]

154. Ho, S.-T.; Wang, C.-Y.; Liu, H.-L.; Lin, H.-N. Catalyst-free selective-area growth of vertically aligned zinc oxide nanowires. Chem. Phys. Lett. 2008, 463, 141-144. [CrossRef]

155. Xu, L.; Li, X.; Zhan, Z.; Wang, L.; Feng, S.; Chai, X.; Lu, W.; Shen, J.; Weng, Z.; Sun, J. Catalyst-Free, Selective Growth of ZnO Nanowires on $\mathrm{SiO}_{2}$ by Chemical Vapor Deposition for Transfer-Free Fabrication of UV Photodetectors. ACS Appl. Mater. Interfaces 2015, 7, 20264-20271. [CrossRef]

156. Chung, T.F.; Luo, L.B.; He, Z.B.; Leung, Y.H.; Shafiq, I.; Yao, Z.Q.; Lee, S.T. Selective growth of catalyst-free ZnO nanowire arrays on Al:ZnO for device application. Appl. Phys. Lett. 2007, 91, 233112. [CrossRef]

157. Anzai, H.; Takahashi, T.; Suzuki, M.; Kanai, M.; Zhang, G.; Hosomi, T.; Seki, T.; Nagashima, K.; Shibata, N.; Yanagida, T. Unusual Oxygen Partial Pressure Dependence of Electrical Transport of Single-Crystalline Metal Oxide Nanowires Grown by the Vapor-Liquid-Solid Process. Nano Lett. 2019, 19, 1675-1681. [CrossRef]

158. Liu, J.; Nagashima, K.; Yamashita, H.; Mizukami, W.; Uzuhashi, J.; Hosomi, T.; Kanai, M.; Zhao, X.; Miura, Y.; Zhang, G.; et al. Face-selective tungstate ions drive zinc oxide nanowire growth direction and dopant incorporation. Commun. Mater. 2020, 1, 1-10. [CrossRef] 
159. Zhang, G.; Hosomi, T.; Mizukami, W.; Liu, J.; Nagashima, K.; Takahashi, T.; Kanai, M.; Sugiyama, T.; Yasui, T.; Aoki, Y.; et al. A thermally robust and strongly oxidizing surface of $\mathrm{WO}_{3}$ hydrate nanowires for electrical aldehyde sensing with long-term stability. J. Mater. Chem. A 2021. [CrossRef]

160. Zhang, G.; Wang, C.; Mizukami, W.; Hosomi, T.; Nagashima, K.; Yoshida, H.; Nakamura, K.; Takahashi, T.; Kanai, M.; Yasui, T.; et al. Monovalent sulfur oxoanions enable millimeter-long single-crystalline $h$ - $\mathrm{WO}_{3}$ nanowire synthesis. Nanoscale 2020, 12, 9058-9066. [CrossRef]

161. Sakai, D.; Nagashima, K.; Yoshida, H.; Kanai, M.; He, Y.; Zhang, G.; Zhao, X.; Takahashi, T.; Yasui, T.; Hosomi, T.; et al. Substantial Narrowing on the Width of "Concentration Window" of Hydrothermal ZnO Nanowires via Ammonia Addition. Sci. Rep. 2019, 9, 1-10. [CrossRef]

162. Choi, H.G.; Jung, Y.H.; Kim, D.K. Solvothermal Synthesis of Tungsten Oxide Nanorod/Nanowire/Nanosheet. J. Am. Ceram. Soc. 2005, 88, 1684-1686. [CrossRef]

163. Li, Z.; Niu, X.; Wang, N.; Shen, H.; Liu, W.; Sun, K.; Fu, Y.Q.; Wang, Z. Hydrothermally synthesized $\mathrm{CeO}_{2}$ nanowires for $\mathrm{H}_{2} \mathrm{~S}$ sensing at room temperature. J. Alloys Compd. 2016, 682, 647-653. [CrossRef]

164. Xu, P.; Cheng, Z.; Pan, Q.; Xu, J.; Xiang, Q.; Yu, W.; Chu, Y. High aspect ratio $\operatorname{In}_{2} \mathrm{O}_{3}$ nanowires: Synthesis, mechanism and $\mathrm{NO}_{2}$ gas-sensing properties. Sens. Actuators B Chem. 2008, 130, 802-808. [CrossRef]

165. Zhai, T.; Liu, H.; Li, H.; Fang, X.; Liao, M.; Li, L.; Zhou, H.; Koide, Y.; Bando, Y.; Golberg, D. Centimeter-Long $\mathrm{V}_{2} \mathrm{O}_{5} \mathrm{Nanowires:}$ From Synthesis to Field-Emission, Electrochemical, Electrical Transport, and Photoconductive Properties. Adv. Mater. 2010, 22, 2547-2552. [CrossRef] [PubMed]

166. Al-Hazmi, F.; Alnowaiser, F.; Al-Ghamdi, A.A.; Aly, M.; Al-Tuwirqi, R.M.; El-Tantawy, F. A new large-Scale synthesis of magnesium oxide nanowires: Structural and antibacterial properties. Superlattices Microstruct. 2012, 52, 200-209. [CrossRef]

167. Lupan, O.; Chow, L.; Chai, G.; Schulte, A.; Park, S.; Heinrich, H. A rapid hydrothermal synthesis of rutile $\mathrm{SnO}_{2}$ nanowires. Mater. Sci. Eng. B 2009, 157, 101-104. [CrossRef]

168. Xia, X.-H.; Tu, J.-P.; Zhang, Y.-Q.; Mai, Y.-J.; Wang, X.-L.; Gu, C.-D.; Zhao, X.-B. Freestanding $\mathrm{Co}_{3} \mathrm{O}_{4}$ nanowire array for high performance supercapacitors. RSC Adv. 2012, 2, 1835-1841. [CrossRef]

169. Miao, B.; Zeng, W.; Lin, L.; Xu, S. Characterization and gas-sensing properties of NiO nanowires prepared through hydrothermal method. Phys. E Low-Dimens. Syst. Nanostruct. 2013, 52, 40-45. [CrossRef]

170. Jaggessar, A.; Mathew, A.; Wang, H.; Tesfamichael, T.; Yan, C.; Yarlagadda, P.K. Mechanical, bactericidal and osteogenic behaviours of hydrothermally synthesised $\mathrm{TiO}_{2}$ nanowire arrays. J. Mech. Behav. Biomed. Mater. 2018, 80, 311-319. [CrossRef]

171. Jiang, T.; Wang, Y.; Meng, D.; Wu, X.; Wang, J.; Chen, J. Controllable fabrication of CuO nanostructure by hydrothermal method and its properties. Appl. Surf. Sci. 2014, 311, 602-608. [CrossRef]

172. Wang, X.; Li, Y. Selected-Control Hydrothermal Synthesis of $\alpha$ - and $\beta-\mathrm{MnO}_{2}$ Single Crystal Nanowires. J. Am. Chem. Soc. 2002, 124, 2880-2881. [CrossRef]

173. Bae, H.J.; Yoo, T.H.; Yoon, Y.; Lee, I.G.; Kim, J.P.; Cho, B.J.; Hwang, W.S. High-Aspect Ratio $\beta-\mathrm{Ga}_{2} \mathrm{O}_{3}$ Nanorods via Hydrothermal Synthesis. Nanomaterials 2018, 8, 594. [CrossRef]

174. Yuan, K.; Wang, C.-Y.; Zhu, L.-Y.; Cao, Q.; Yang, J.-H.; Li, X.-X.; Huang, W.; Wang, Y.-Y.; Lu, H.-L.; Zhang, D.W. Fabrication of a Micro-Electromechanical System-Based Acetone Gas Sensor Using $\mathrm{CeO}_{2}$ Nanodot-Decorated $\mathrm{WO}_{3}$ Nanowires. ACS Appl. Mater. Interfaces 2020, 12, 14095-14104. [CrossRef]

175. Hsueh, T.-J.; Peng, C.-H.; Chen, W.-S. A transparent ZnO nanowire MEMS gas sensor prepared by an ITO micro-heater. Sens. Actuators B Chem. 2020, 304, 127319. [CrossRef]

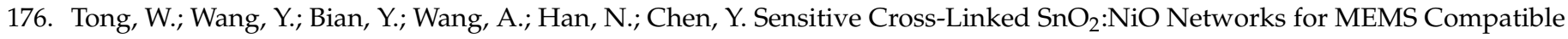
Ethanol Gas Sensors. Nanoscale Res. Lett. 2020, 15, 1-12. [CrossRef] [PubMed]

177. Steinhauer, S.; Brunet, E.; Maier, T.; Mutinati, G.; Köck, A.; Freudenberg, O.; Gspan, C.; Grogger, W.; Neuhold, A.; Resel, R. Gas sensing properties of novel $\mathrm{CuO}$ nanowire devices. Sens. Actuators B Chem. 2013, 187, 50-57. [CrossRef]

178. Hung, P.T.; Hien, V.X.; Lee, J.-H.; Kim, J.-J.; Heo, Y.-W. Fabrication of $\mathrm{SnO}_{2}$ Nanowire Networks on a Spherical Sn Surface by Thermal Oxidation. J. Electron. Mater. 2017, 46, 6070-6077. [CrossRef]

179. Jiang, X.; Herricks, A.T.; Xia, Y. CuO Nanowires Can Be Synthesized by Heating Copper Substrates in Air. Nano Lett. 2002, 2, 1333-1338. [CrossRef]

180. Gonçalves, A.M.B.; Campos, L.C.; Ferlauto, A.S.; Lacerda, R.G. On the growth and electrical characterization of CuO nanowires by thermal oxidation. J. Appl. Phys. 2009, 106, 034303. [CrossRef]

181. Yuan, L.; Wang, Y.; Cai, R.; Jiang, Q.; Wang, J.; Li, B.; Sharma, A.; Zhou, G. The origin of hematite nanowire growth during the thermal oxidation of iron. Mater. Sci. Eng. B 2012, 177, 327-336. [CrossRef]

182. Sun, X.; Zhu, W.; Wu, D.; Liu, Z.; Chen, X.; Yuan, L.; Wang, G.; Sharma, R.; Zhou, G. Atomic-Scale Mechanism of Unidirectional Oxide Growth. Adv. Funct. Mater. 2020, 30,1-12. [CrossRef]

183. Arachchige, H.M.M.M.; Zappa, D.; Poli, N.; Gunawardhana, N.; Attanayake, N.H.; Comini, E. Seed-Assisted Growth of TiO 2 Nanowires by Thermal Oxidation for Chemical Gas Sensing. Nanomaterials 2020, 10, 935. [CrossRef]

184. Qin, Y.; Xie, W.; Liu, Y.; Ye, Z. Thermal-oxidative growth of aligned $\mathrm{W}_{18} \mathrm{O}_{49}$ nanowire arrays for high performance gas sensor. Sens. Actuators B Chem. 2016, 223, 487-495. [CrossRef]

185. Zhou, J.; Xu, N.-S.; Deng, S.-Z.; Chen, J.; She, J.-C.; Wang, Z.L. Large-Area Nanowire Arrays of Molybdenum and Molybdenum Oxides: Synthesis and Field Emission Properties. Adv. Mater. 2003, 15, 1835-1840. [CrossRef] 
186. Ren, S.; Bai, Y.; Chen, J.; Deng, S.; Xu, N.; Wu, Q.; Yang, S. Catalyst-free synthesis of ZnO nanowire arrays on zinc substrate by low temperature thermal oxidation. Mater. Lett. 2007, 61, 666-670. [CrossRef]

187. Zappa, D.; Bertuna, A.; Comini, E.; Molinari, M.; Poli, N.; Sberveglieri, G. Tungsten oxide nanowires for chemical detection. Anal. Methods 2014, 7, 2203-2209. [CrossRef]

188. Avramov, I. Kinetics of growth of nanowhiskers (nanowires and nanotubes). Nanoscale Res. Lett. 2007, 2, 235-239. [CrossRef]

189. Hansen, B.J.; Chan, H.-L.; Lu, J.; Lu, G.; Chen, J. Short-circuit diffusion growth of long bi-crystal CuO nanowires. Chem. Phys. Lett. 2011, 504, 41-45. [CrossRef]

190. Rao, P.M.; Zheng, X. Rapid Catalyst-Free Flame Synthesis of Dense, Aligned $\alpha-\mathrm{Fe}_{2} \mathrm{O}_{3}$ Nanoflake and CuO Nanoneedle Arrays. Nano Lett. 2009, 9, 3001-3006. [CrossRef]

191. Park, W.J.; Choi, K.J.; Kim, M.H.; Koo, B.H.; Lee, J.-L.; Baik, J.M. Self-Assembled and Highly Selective Sensors Based on Air-Bridge-Structured Nanowire Junction Arrays. ACS Appl. Mater. Interfaces 2013, 5, 6802-6807. [CrossRef]

192. Lee, J.S.; Katoch, A.; Kim, J.H.; Kim, S.S. Effect of Au Nanoparticle Size on the Gas-Sensing Performance of p-CuO Nanowires. Sens. Actuators B Chem. 2016, 222, 307-314. [CrossRef]

193. Kim, J.H.; Katoch, A.; Choi, S.W.; Kim, S.S. Growth and Sensing Properties of Networked p-CuO Nanowires. Sens. Actuators B Chem. 2015, 212, 190-195. [CrossRef]

194. Ra, H.-W.; Choi, K.-S.; Kim, J.-H.; Hahn, Y.-B.; Im, Y.-H. Fabrication of ZnO Nanowires Using Nanoscale Spacer Lithography for Gas Sensors. Small 2008, 4, 1105-1109. [CrossRef]

195. Cho, S.-Y.; Yoo, H.-W.; Kim, J.Y.; Jung, W.-B.; Jin, M.L.; Kim, J.-S.; Jeon, H.-J.; Jung, H.-T. High-Resolution p-Type Metal Oxide Semiconductor Nanowire Array as an Ultrasensitive Sensor for Volatile Organic Compounds. Nano Lett. 2016, 16, 4508-4515. [CrossRef]

196. Li, Z.; Zhang, H.; Zheng, W.; Wang, W.; Huang, H.; Wang, C.; MacDiarmid, A.G.; Wei, Y. Highly Sensitive and Stable Humidity Nanosensors Based on $\mathrm{LiCl}$ Doped $\mathrm{TiO}_{2}$ Electrospun Nanofibers. J. Am. Chem. Soc. 2008, 130, 5036-5037. [CrossRef]

197. Qi, Q.; Zhang, T.; Liu, L.; Zheng, X. Synthesis and toluene sensing properties of $\mathrm{SnO}_{2}$ nanofibers. Sens. Actuators B Chem. 2009, 137, 471-475. [CrossRef]

198. León-Brito, N.; Meléndez, A.; Ramos, I.; Pinto, N.J.; Santiago-Avilés, J.J. Electrical Properties of Electrospun Sb-Doped Tin Oxide Nanofibers. J. Physics Conf. Ser. 2007, 61, 683-687. [CrossRef]

199. Li, Z.; Yang, Q.; Wu, Y.; He, Y.; Chen, J.; Wang, J. $\mathrm{La}^{3+}$ doped $\mathrm{SnO}_{2}$ nanofibers for rapid and selective $\mathrm{H}_{2}$ sensor with long range linearity. Int. J. Hydrog. Energy 2019, 44, 8659-8668. [CrossRef]

200. Wang, Y.; Zhang, H.; Sun, X. Electrospun nanowebs of $\mathrm{NiO} / \mathrm{SnO}_{2}$ p-n heterojunctions for enhanced gas sensing. Appl. Surf. Sci. 2016, 389, 514-520. [CrossRef]

201. Kim, I.-D.; Rothschild, A.; Lee, B.H.; Kim, D.Y.; Jo, A.S.M.; Tuller, H.L. Ultrasensitive Chemiresistors Based on Electrospun TiO 2 Nanofibers. Nano Lett. 2006, 6, 2009-2013. [CrossRef]

202. Kim, K.-H.; Kim, S.-J.; Cho, H.-J.; Kim, N.-H.; Jang, J.-S.; Choi, S.-J.; Kim, I.-D. WO $W_{3}$ nanofibers functionalized by protein-templated $\mathrm{RuO}_{2}$ nanoparticles as highly sensitive exhaled breath gas sensing layers. Sens. Actuators B Chem. 2017, 241, 1276-1282. [CrossRef]

203. Lin, D.; Wu, H.; Zhang, R.; Pan, W. Preparation and electrical properties of electrospun tin-doped indium oxide nanowires. Nanotechnology 2007, 18, 465301. [CrossRef]

204. Chen, K.; Lu, H.; Li, G.; Zhang, J.; Tian, Y.; Gao, Y.; Guo, Q.; Lu, H.; Gao, J. Surface functionalization of porous $\mathrm{In}_{2} \mathrm{O}_{3}$ nanofibers with $\mathrm{Zn}$ nanoparticles for enhanced low-temperature $\mathrm{NO}_{2}$ sensing properties. Sens. Actuators B Chem. 2020, 308, 127716. [CrossRef]

205. Foroushani, F.T.; Tavanai, H.; Ranjbar, M.; Bahrami, H. Fabrication of tungsten oxide nanofibers via electrospinning for gasochromic hydrogen detection. Sens. Actuators B Chem. 2018, 268, 319-327. [CrossRef]

206. Liu, L.; Li, S.; Guo, X.; Wang, L.; Liu, L.; Wang, X. The fabrication of $\operatorname{In}_{2} \mathrm{O}_{3}$ nanowire and nanotube by single nozzle electrospinning and their gas sensing property. J. Mater. Sci. Mater. Electron. 2016, 27, 5153-5157. [CrossRef]

207. Formo, E.; Lee, E.; Campbell, D.; Xia, Y. Functionalization of Electrospun $\mathrm{TiO}_{2}$ Nanofibers with Pt Nanoparticles and Nanowires for Catalytic Applications. Nano Lett. 2008, 8, 668-672. [CrossRef] [PubMed]

208. Jiang, Z.; Jiang, T.; Wang, J.; Wang, Z.; Xu, X.; Wang, Z.; Zhaojie, W.; Li, Z.; Wang, C. Ethanol chemiresistor with enhanced discriminative ability from acetone based on Sr-doped $\mathrm{SnO}_{2}$ nanofibers. J. Colloid Interface Sci. 2015, 437, 252-258. [CrossRef]

209. Lee, C.-S.; Li, H.-Y.; Kim, B.-Y.; Jo, Y.-M.; Byun, H.-G.; Hwang, I.-S.; Abdel-Hady, F.; Wazzan, A.A.; Lee, J.-H. Discriminative detection of indoor volatile organic compounds using a sensor array based on pure and Fe-doped $\operatorname{In}_{2} \mathrm{O}_{3}$ nanofibers. Sens. Actuators B Chem. 2019, 285, 193-200. [CrossRef]

210. Zhao, Y.; He, X.; Li, J.; Gao, X.; Jia, J. Porous $\mathrm{CuO} / \mathrm{SnO}_{2}$ composite nanofibers fabricated by electrospinning and their $\mathrm{H}_{2} \mathrm{~S}$ sensing properties. Sens. Actuators B Chem. 2012, 165, 82-87. [CrossRef]

211. Hu, H.; Wang, S.; Feng, X.; Pauly, M.; Decher, G.; Long, Y. In-plane aligned assemblies of 1D-nanoobjects: Recent approaches and applications. Chem. Soc. Rev. 2020, 49, 509-553. [CrossRef]

212. Helwig, A.; Muller, G.; Sberveglieri, G.; Faglia, G. Catalytic enhancement of $\mathrm{SnO}_{2}$ gas sensors as seen by the moving gas outlet method. Sens. Actuators B Chem. 2008, 130, 193-199. [CrossRef]

213. Lim, Y.; Heo, J.-I.; Madou, M.; Shin, H. Monolithic carbon structures including suspended single nanowires and nanomeshes as a sensor platform. Nanoscale Res. Lett. 2013, 8, 492. [CrossRef] 
214. Choi, J.; Kim, J. Highly sensitive hydrogen sensor based on suspended, functionalized single tungsten nanowire bridge. Sens. Actuators B Chem. 2009, 136, 92-98. [CrossRef]

215. Kiasari, N.M.; Soltanian, S.; Gholamkhass, B.; Servati, P. Room temperature ultra-sensitive resistive humidity sensor based on single zinc oxide nanowire. Sens. Actuators A Phys. 2012, 182, 101-105. [CrossRef]

216. Prades, J.D.; Hernandez-Ramirez, F.; Fischer, T.; Hoffmann, M.; Müller, R.; López, N.; Mathur, S.; Morante, J.R. Quantitative analysis of CO-humidity gas mixtures with self-heated nanowires operated in pulsed mode. Appl. Phys. Lett. 2010, 97, 243105. [CrossRef]

217. Helbling, T.; Pohle, R.; Durrer, L.; Stampfer, C.; Roman, C.; Jungen, A.; Fleischer, M.; Hierold, C. Sensing $\mathrm{NO}_{2}$ with individual suspended single-walled carbon nanotubes. Sens. Actuators B Chem. 2008, 132, 491-497. [CrossRef]

218. Prades, J.D.; Jimenez-Diaz, R.; Hernandez-Ramirez, F.; Barth, S.; Cirera, A.; Romano-Rodriguez, A.; Mathur, S.; Morante, J.R. Ultralow power consumption gas sensors based on self-heated individual nanowires. Appl. Phys. Lett. 2008, 93, 123110. [CrossRef]

219. Strelcov, E.; Dmitriev, S.; Button, B.; Cothren, J.; Sysoev, V.; Kolmakov, A. Evidence of the self-heating effect on surface reactivity and gas sensing of metal oxide nanowire chemiresistors. Nanotechnology 2008, 19, 355502. [CrossRef]

220. Meng, G.; Zhuge, F.; Nagashima, K.; Nakao, A.; Kanai, M.; He, Y.; Boudot, M.; Takahashi, T.; Uchida, K.; Yanagida, T. Nanoscale Thermal Management of Single $\mathrm{SnO}_{2}$ Nanowire: Pico-Joule Energy Consumed Molecule Sensor. ACS Sens. 2016, 1, 997-1002. [CrossRef]

221. Yang, B.; Buddharaju, K.D.; Teo, S.H.G.; Singh, N.; Lo, G.Q.; Kwong, D.L. Vertical Silicon-Nanowire Formation and Gate-AllAround MOSFET. IEEE Electron. Device Lett. 2008, 29, 791-794. [CrossRef]

222. Ng, H.T.; Han, J.; Yamada, T.; Nguyen, P.; Chen, A.Y.P.; Meyyappan, M. Single Crystal Nanowire Vertical Surround-Gate Field-Effect Transistor. Nano Lett. 2004, 4, 1247-1252. [CrossRef]

223. Offermans, P.; Crego-Calama, M.; Brongersma, S.H. Gas Detection with Vertical InAs Nanowire Arrays. Nano Lett. 2010, 10, 2412-2415. [CrossRef] [PubMed]

224. Offermans, P.; Crego-Calama, M.; Brongersma, S. Functionalized vertical InAs nanowire arrays for gas sensing. Sens. Actuators B Chem. 2012, 161, 1144-1149. [CrossRef]

225. Du, J.; Xing, J.; Ge, C.; Liu, H.; Liu, P.; Hao, H.; Dong, J.; Zheng, Z.; Gao, H. Highly Sensitive and Ultrafast Deep UV Photodetector Based on a $\beta-\mathrm{Ga}_{2} \mathrm{O}_{3}$ Nanowire Network Grown by CVD. J. Phys. D. Appl. Phys. 2016, 49, 425105. [CrossRef]

226. Zhang, X.; Liu, Q.; Liu, B.; Yang, W.; Li, J.; Niu, P.; Jiang, X. Giant UV photoresponse of a GaN nanowire photodetector through effective Pt nanoparticle coupling. J. Mater. Chem. C 2017, 5, 4319-4326. [CrossRef]

227. Park, S.H.; Kim, S.H.; Lee, C. Synthesis and $\mathrm{CO}$ gas sensing properties of surface-nitridated $\mathrm{Ga}_{2} \mathrm{O}_{3}$ nanowires. RSC Adv. 2014, 4, 63402-63407. [CrossRef]

228. Cui, Y.; Lieber, C.M. Functional Nanoscale Electronic Devices Assembled Using Silicon Nanowire Building Blocks. Science 2001, 291, 851-853. [CrossRef]

229. Zhao, D.; Huang, H.; Chen, S.; Li, Z.; Li, S.; Wang, M.; Zhu, H.; Chen, X. In Situ Growth of Leakage-Free Direct-Bridging GaN Nanowires: Application to Gas Sensors for Long-Term Stability, Low Power Consumption, and Sub-ppb Detection Limit. Nano Lett. 2019, 19, 3448-3456. [CrossRef]

230. Ponzoni, A.; Comini, E.; Sberveglieri, G.; Zhou, J.; Deng, S.Z.; Xu, N.S.; Ding, Y.; Wang, Z.L. Ultrasensitive and highly selective gas sensors using three-dimensional tungsten oxide nanowire networks. Appl. Phys. Lett. 2006, 88, 203101. [CrossRef]

231. Xue, X.Y.; Chen, Y.J.; Wang, Y.G.; Wang, T.H. Synthesis and ethanol sensing properties of $\mathrm{ZnSnO}_{3}$ nanowires. Appl. Phys. Lett. 2005, 86, 233101. [CrossRef]

232. Deb, B.; Desai, S.; Sumanasekera, G.U.; Sunkara, M.K. Gas sensing behaviour of mat-like networked tungsten oxide nanowire thin films. Nanotechnology 2007, 18, 18. [CrossRef]

233. Kaur, N.; Zappa, D.; Ferroni, M.; Poli, N.; Campanini, M.; Negrea, R.; Comini, E. Branch-like NiO/ZnO heterostructures for VOC sensing. Sens. Actuators B Chem. 2018, 262, 477-485. [CrossRef]

234. Kim, Y.-S.; Hwang, I.-S.; Kim, S.-J.; Lee, C.-Y.; Lee, J.-H. CuO nanowire gas sensors for air quality control in automotive cabin. Sens. Actuators B Chem. 2008, 135, 298-303. [CrossRef]

235. Yu, W.; Zeng, W.; Li, Y. A nest-like $\mathrm{TiO}_{2}$ nanostructures for excellent performance ethanol sensor. Mater. Lett. 2019, $248,82-85$. [CrossRef]

236. Ahn, M.W.; Park, K.S.; Heo, J.H.; Park, J.G.; Kim, D.W.; Choi, K.J.; Lee, J.H.; Hong, S.H. Gas Sensing Properties of Defect-Controlled ZnO-Nanowire Gas Sensor. Appl. Phys. Lett. 2008, 93, 2006-2009. [CrossRef]

237. Arnold, S.P.; Prokes, S.M.; Perkins, F.K.; E Zaghloul, M. Design and performance of a simple, room-temperature $\mathrm{Ga}_{2} \mathrm{O}_{3} \mathrm{nanowire}$ gas sensor. Appl. Phys. Lett. 2009, 95, 103102. [CrossRef]

238. Thong, L.V.; Hoa, N.D.; Le, D.T.T.; Viet, D.T.; Tam, P.D.; Le, A.T.; Hieu, N. Van On-Chip Fabrication of SnO 2 -Nanowire Gas Sensor: The Effect of Growth Time on Sensor Performance. Sens. Actuators B Chem. 2010, 146, 361-367. [CrossRef]

239. Luo, L.; Sosnowchik, B.D.; Lin, L. Local vapor transport synthesis of zinc oxide nanowires for ultraviolet-enhanced gas sensing. Nanotechnology 2010, 21, 495502. [CrossRef] [PubMed]

240. Ngoc, T.M.; Van Duy, N.; Hung, C.M.; Hoa, N.D.; Trung, N.N.; Nguyen, H.; Van Hieu, N. Ultralow power consumption gas sensor based on a self-heated nanojunction of $\mathrm{SnO}_{2}$ nanowires. RSC Adv. 2018, 8, 36323-36330. [CrossRef] 
241. Tan, H.M.; Manh Hung, C.; Ngoc, T.M.; Nguyen, H.; Duc Hoa, N.; Van Duy, N.; Hieu, N. Van Novel Self-Heated Gas Sensors Using on-Chip Networked Nanowires with Ultralow Power Consumption. ACS Appl. Mater. Interfaces 2017, 9, 6153-6162. [CrossRef] [PubMed]

242. Chou, C.-Y.; Tseng, S.-F.; Chang, T.-L.; Tu, C.-T.; Han, H.-C. Controlled bridge growth of ZnO nanowires on laser-scribed graphene-based devices for NO gas detection. Appl. Surf. Sci. 2020, 508, 145204. [CrossRef]

243. Wang, B.; Zhu, L.F.; Yang, Y.H.; Xu, N.S.; Yang, G.W. Fabrication of a $\mathrm{SnO}_{2}$ Nanowire Gas Sensor and Sensor Performance for Hydrogen. J. Phys. Chem. C 2008, 112, 6643-6647. [CrossRef]

244. Lee, K.; Baek, D.-H.; Na, H.; Choi, J.; Kim, J. Simple fabrication method of silicon/tungsten oxide nanowires heterojunction for NO2 gas sensors. Sens. Actuators B Chem. 2018, 265, 522-528. [CrossRef]

245. Jung, T.-H.; Kwon, S.-I.; Park, J.-H.; Lim, D.-G.; Choi, Y.-J.; Park, J.-G. $\mathrm{SnO}_{2}$ nanowires bridged across trenched electrodes and their gas-sensing characteristics. Appl. Phys. A 2008, 91, 707-710. [CrossRef]

246. Hung, C.M.; Le, D.T.T.; Van Hieu, N. On-chip growth of semiconductor metal oxide nanowires for gas sensors: A review. J. Sci. Adv. Mater. Devices 2017, 2, 263-285. [CrossRef]

247. Choi, K.J.; Hwang, I.-S.; Park, J.-G.; Lee, J.-H. Novel fabrication of an $\mathrm{SnO}_{2}$ nanowire gas sensor with high sensitivity. Nanotechnology 2008, 19, 095508. [CrossRef] [PubMed]

248. Van Dang, T.; Hoa, N.D.; Van Duy, N.; Van Hieu, N. Chlorine Gas Sensing Performance of On-Chip Grown $\mathrm{ZnO} \mathrm{WO}_{3}$, and $\mathrm{SnO} 2$ Nanowire Sensors. ACS Appl. Mater. Interfaces 2016, 8, 4828-4837. [CrossRef]

249. Wongchoosuk, C.; Subannajui, K.; Wang, C.; Yang, Y.; Güder, F.; Kerdcharoen, T.; Cimalla, V.; Zacharias, M. Electronic nose for toxic gas detection based on photostimulated core-shell nanowires. RSC Adv. 2014, 4, 35084-35088. [CrossRef]

250. Lee, J.-S.; Katoch, A.; Kim, J.-H.; Kim, S.S. Growth of Networked $\mathrm{TiO}_{2}$ Nanowires for Gas-Sensing Applications. J. Nanosci. Nanotechnol. 2016, 16, 11580-11585. [CrossRef]

251. Park, J.-H.; Lim, D.-G.; Choi, Y.-J.; Kim, N.-W.; Choi, K.-J.; Park, J.-G. Laterally grown $\mathrm{SnO}_{2}$ nanowires and their $\mathrm{NO}_{2}$ gas sensing characteristics. In Proceedings of the 2007 7th IEEE Conference on Nanotechnology (IEEE NANO), Hong Kong, China, 2-5 August 2007; pp. 1054-1057.

252. Sun, G.J.; Choi, S.W.; Katoch, A.; Wu, P.; Kim, S.S. Bi-Functional Mechanism of $\mathrm{H}_{2} \mathrm{~S}$ Detection Using CuO-SnO 2 Nanowires. J. Mater. Chem. C 2013, 1, 5454-5462. [CrossRef]

253. Hung, C.M.; Phuong, H.V.; Van Duy, N.; Hoa, N.D.; Van Hieu, N. Comparative effects of synthesis parameters on the $\mathrm{NO}_{2}$ gas-sensing performance of on-chip grown $\mathrm{ZnO}$ and $\mathrm{Zn}_{2} \mathrm{SnO}_{4}$ nanowire sensors. J. Alloys Compd. 2018, 765, 1237-1242. [CrossRef]

254. Lin, Y.-H.; Hsueh, Y.-C.; Lee, P.-S.; Wang, C.-C.; Chen, J.-R.; Wu, J.-M.; Perng, T.-P.; Shih, H.C. Preparation of Pt/SnO 2 Core-Shell Nanowires with Enhanced Ethanol Gas- and Photon-Sensing Properties. J. Electrochem. Soc. 2010, 157, K206. [CrossRef]

255. Sun, G.-J.; Choi, S.-W.; Jung, S.-H.; Katoch, A.; Kim, S.S. V-groove $\mathrm{SnO}_{2}$ nanowire sensors: Fabrication and Pt-nanoparticle decoration. Nanotechnology 2013, 24, 025504. [CrossRef] [PubMed]

256. Kim, J.H.; Katoch, A.; Kim, S.H.; Kim, S.S. Chemiresistive Sensing Behavior of $\mathrm{SnO}_{2}(\mathrm{n})-\mathrm{Cu}_{2} \mathrm{O}(\mathrm{p})$ Core-Shell Nanowires. ACS Appl. Mater. Interfaces 2015, 7, 15351-15358. [CrossRef] [PubMed]

257. Ngoc, T.M.; Van Duy, N.; Hoa, N.D.; Hung, C.M.; Nguyen, H.; Van Hieu, N. Effective design and fabrication of low-powerconsumption self-heated $\mathrm{SnO}_{2}$ nanowire sensors for reducing gases. Sens. Actuators B Chem. 2019, 295, 144-152. [CrossRef]

258. Choi, S.-W.; Katoch, A.; Sun, G.-J.; Kim, S.S. Bimetallic Pd/Pt nanoparticle-functionalized $\mathrm{SnO}_{2}$ nanowires for fast response and recovery to $\mathrm{NO}_{2}$. Sens. Actuators $B$ Chem. 2013, 181, 446-453. [CrossRef]

259. Ahn, M.W.; Park, K.S.; Heo, J.H.; Kim, D.W.; Choi, K.J.; Park, J.G. On-Chip Fabrication of ZnO-Nanowire Gas Sensor with High Gas Sensitivity. Sens. Actuators B Chem. 2009, 138, 168-173. [CrossRef]

260. Kim, B.-G.; Lim, D.-G.; Park, J.-H.; Choi, Y.-J.; Park, J.-G. In-situ bridging of $\mathrm{SnO}_{2}$ nanowires between the electrodes and their $\mathrm{NO}_{2}$ gas sensing characteristics. Appl. Surf. Sci. 2011, 257, 4715-4718. [CrossRef]

261. Chávez, F.; Pérez-Sánchez, G.; Goiz, O.; Zaca-Morán, P.; Peña-Sierra, R.; Morales-Acevedo, A.; Felipe, C.; Soledad-Priego, M. Sensing performance of palladium-functionalized $\mathrm{WO}_{3}$ nanowires by a drop-casting method. Appl. Surf. Sci. 2013, $275,28-35$. [CrossRef]

262. Chen, J.; Wang, K.; Hartman, L.; Zhou, W. $\mathrm{H}_{2}$ S Detection by Vertically Aligned CuO Nanowire Array Sensors. J. Phys. Chem. C 2008, 112, 16017-16021. [CrossRef]

263. Hsueh, T.-J.; Hsu, C.-L.; Chang, S.-J.; Chen, I.-C. Laterally grown ZnO nanowire ethanol gas sensors. Sens. Actuators B Chem. 2007, 126, 473-477. [CrossRef]

264. Huh, J.; Park, J.; Kim, G.T.; Park, J.Y. Highly Sensitive Hydrogen Detection of Catalyst-Free ZnO Nanorod Networks Suspended by Lithography-Assisted Growth. Nanotechnology 2011, 22, 085502. [CrossRef]

265. Vallejos, S.; Gràcia, I.; Chmela, O.; Figueras, E.; Hubálek, J.; Cane, C. Chemoresistive micromachined gas sensors based on functionalized metal oxide nanowires: Performance and reliability. Sens. Actuators B Chem. 2016, 235, 525-534. [CrossRef]

266. Le, D.T.T.; Van Duy, N.; Tan, H.M.; Trung, D.D.; Trung, N.N.; Van, P.T.H.; Hoa, N.D.; Van Hieu, N. Density-controllable growth of $\mathrm{SnO}_{2}$ nanowire junction-bridging across electrode for low-temperature $\mathrm{NO}_{2}$ gas detection. J. Mater. Sci. 2013, 48, 7253-7259. [CrossRef]

267. Jung, S.-H.; Choi, S.-W.; Kim, S.S. Fabrication and properties of trench-structured networked $\mathrm{SnO}_{2}$ nanowire gas sensors. Sens. Actuators B Chem. 2012, 171, 672-678. [CrossRef] 
268. Cao, B.; Chen, J.; Tang, X.; Zhou, W. Growth of monoclinic $\mathrm{WO}_{3}$ nanowire array for highly sensitive $\mathrm{NO}_{2}$ detection. J. Mater. Chem. 2009, 19, 2323-2327. [CrossRef]

269. Liao, L.; Lu, H.B.; Li, J.C.; He, H.; Wang, D.F.; Fu, D.J.; Liu, C.; Zhang, W.F. Size Dependence of Gas Sensitivity of ZnO Nanorods. J. Phys. Chem. C 2007, 111, 1900-1903. [CrossRef]

270. Samanta, C.; Ghatak, A.; Raychaudhuri, A.K.; Ghosh, B. ZnO/Si nanowires heterojunction array-based nitric oxide (NO) gas sensor with noise-limited detectivity approaching $10 \mathrm{ppb}$. Nanotechnology 2019, 30, 305501. [CrossRef] [PubMed]

271. Lee, J.-H.; Mirzaei, A.; Kim, J.-Y.; Kim, J.-H.; Kim, H.W.; Kim, S.S. Optimization of the surface coverage of metal nanoparticles on nanowires gas sensors to achieve the optimal sensing performance. Sens. Actuators B Chem. 2020, 302, 127196. [CrossRef]

272. Navarrete, E.; Bittencourt, C.; Umek, P.; Llobet, E. AACVD and gas sensing properties of nickel oxide nanoparticle decorated tungsten oxide nanowires. J. Mater. Chem. C 2018, 6, 5181-5192. [CrossRef]

273. Kolmakov, A.; Klenov, D.O.; Lilach, Y.; Stemmer, A.S.; Moskovits, M. Enhanced Gas Sensing by Individual $\mathrm{SnO}_{2} \mathrm{Nanowires}$ and Nanobelts Functionalized with Pd Catalyst Particles. Nano Lett. 2005, 5, 667-673. [CrossRef] [PubMed]

274. Kim, J.-H.; Mirzaei, A.; Kim, H.W.; Kim, S.S. Pd functionalization on ZnO nanowires for enhanced sensitivity and selectivity to hydrogen gas. Sens. Actuators B Chem. 2019, 297, 126693. [CrossRef]

275. Touba, S.; Kimiagar, S. Enhancement of sensitivity and selectivity of $\alpha-\mathrm{Fe}_{2} \mathrm{O}_{3}$ nanorod gas sensors by ZnO nanoparticles decoration. Mater. Sci. Semicond. Process. 2019, 102, 104603. [CrossRef]

276. Weber, M.; Kim, J.-Y.; Lee, J.-H.; Kim, J.-H.; Iatsunskyi, I.; Coy, E.; Miele, P.; Bechelany, M.; Kim, S.S. Highly efficient hydrogen sensors based on Pd nanoparticles supported on boron nitride coated ZnO nanowires. J. Mater. Chem. A 2019, 7, 8107-8116. [CrossRef]

277. Xu, Y.; Ma, T.; Zhao, Y.; Zheng, L.; Liu, X.; Zhang, J. Multi-metal functionalized tungsten oxide nanowires enabling ultra-sensitive detection of triethylamine. Sens. Actuators B Chem. 2019, 300, 127042. [CrossRef]

278. Xue, X.; Xing, L.; Chen, Y.; Shi, S.; Wang, Y.; Wang, T. Synthesis and $\mathrm{H}_{2} \mathrm{~S}$ Sensing Properties of CuO-SnO 2 Core/Shell PN-Junction Nanorods. J. Phys. Chem. C 2008, 112, 12157-12160. [CrossRef]

279. Choi, S.; Jo, J.-W.; Kim, J.; Song, S.; Kim, J.; Park, S.K.; Kim, Y.-H. Static and Dynamic Water Motion-Induced Instability in Oxide Thin-Film Transistors and Its Suppression by Using Low-k Fluoropolymer Passivation. ACS Appl. Mater. Interfaces 2017, 9, 26161-26168. [CrossRef]

280. Byoun, Y.; Jin, C.; Choi, S.-W. Strategy for sensitive and selective $\mathrm{NO}_{2}$ detection at low temperatures utilizing p-type $\mathrm{TeO}$ nanowire-based sensors by formation of discrete n-type ZnO nanoclusters. Ceram. Int. 2020, 46, 19365-19374. [CrossRef]

281. Navarrete, E.; Bittencourt, C.; Umek, P.; Cossement, D.; Güell, F.; Llobet, E. Tungsten trioxide nanowires decorated with iridium oxide nanoparticles as gas sensing material. J. Alloys Compd. 2020, 812, 152156. [CrossRef]

282. Lupan, O.; Postica, V.; Wolff, N.; Su, J.; Labat, F.; Ciofini, I.; Cavers, H.; Adelung, R.; Polonskyi, O.; Faupel, F.; et al. LowTemperature Solution Synthesis of Au-Modified ZnO Nanowires for Highly Efficient Hydrogen Nanosensors. ACS Appl. Mater. Interfaces 2019, 11, 32115-32126. [CrossRef] [PubMed]

283. Cai, Z.; Park, S. Enhancement mechanisms of ethanol-sensing properties based on $\mathrm{Cr}_{2} \mathrm{O}_{3}$ nanoparticle-anchored $\mathrm{SnO}_{2}$ nanowires. J. Mater. Res. Technol. 2020, 9, 271-281. [CrossRef]

284. Chen, X.; Shen, Y.; Zhong, X.; Li, T.; Zhao, S.; Zhou, P.; Han, C.; Wei, D.; Shen, Y. Synthesis of ZnO nanowires / Au nanoparticles hybrid by a facile one-pot method and their enhanced $\mathrm{NO}_{2}$ sensing properties. J. Alloys Compd. 2019, 783, 503-512. [CrossRef]

285. Liang, J.; Zhu, K.; Yang, R.; Hu, M. Room temperature $\mathrm{NO}_{2}$ sensing properties of Au-decorated vanadium oxide nanowires sensor. Ceram. Int. 2018, 44, 2261-2268. [CrossRef]

286. Park, J.W.; Kang, B.H.; Kim, H.J. A Review of Low-Temperature Solution-Processed Metal Oxide Thin-Film Transistors for Flexible Electronics. Adv. Funct. Mater. 2020, 30, 1-40. [CrossRef]

287. Choi, S.-W.; Kim, S.S. Room temperature CO sensing of selectively grown networked ZnO nanowires by Pd nanodot functionalization. Sens. Actuators B Chem. 2012, 168, 8-13. [CrossRef]

288. Chen, Z.; Hu, K.; Yang, P.; Fu, X.; Wang, Z.; Yang, S.; Xiong, J.; Zhang, X.; Hu, Y.; Gu, H. Hydrogen sensors based on Pt-decorated $\mathrm{SnO}_{2}$ nanorods with fast and sensitive room-temperature sensing performance. J. Alloys Compd. 2019, 811, 152086. [CrossRef]

289. Lupan, O.; Postica, V.; Pauporté, T.; Viana, B.; Terasa, M.-I.; Adelung, R. Room Temperature Gas Nanosensors Based on Individual and Multiple Networked Au-Modified ZnO Nanowires. Sens. Actuators B Chem. 2019, 299, 126977. [CrossRef]

290. Cho, H.-J.; Chen, V.T.; Qiao, S.; Koo, W.-T.; Penner, R.M.; Kim, I.-D. Pt-Functionalized PdO Nanowires for Room Temperature Hydrogen Gas Sensors. ACS Sens. 2018, 3, 2152-2158. [CrossRef]

291. Liang, J.; Yang, R.; Zhu, K.; Hu, M. Room Temperature Acetone-Sensing Properties of Branch-like $\mathrm{VO}_{2}$ (B)@ZnO Hierarchical Hetero-Nanostructures. J. Mater. Sci. Mater. Electron. 2018, 29, 3780-3789. [CrossRef]

292. Wan, D.; Park, K.H.; Lee, S.-H.; Fàbrega, C.; Prades, J.D.; Jang, J.-W. Plasmon expedited response time and enhanced response in gold nanoparticles-decorated zinc oxide nanowire-based nitrogen dioxide gas sensor at room temperature. J. Colloid Interface Sci. 2021, 582, 658-668.

293. Liu, M.; Wei, X.; Zhang, Z.; Sun, G.; Chen, C.; Xue, C.; Zhuang, H.; Man, B. Effect of temperature on pulsed laser deposition of ZnO films. Appl. Surf. Sci. 2006, 252, 4321-4326. [CrossRef]

294. Katoch, A.; Choi, S.-W.; Sun, G.-J.; Kim, S.S. Low Temperature Sensing Properties of Pt Nanoparticle-Functionalized Networked ZnO Nanowires. J. Nanosci. Nanotechnol. 2015, 15, 330-333. [CrossRef] [PubMed] 
295. Hong, L.-Y.; Ke, H.-W.; Tsai, C.-E.; Lin, H.-N. Low concentration NO gas sensing under ambient environment using Cu2O nanoparticle modified $\mathrm{ZnO}$ nanowires. Mater. Lett. 2016, 185, 243-246. [CrossRef]

296. Ko, W.C.; Kim, K.M.; Kwon, Y.J.; Choi, H.; Park, J.K.; Jeong, Y.K. ALD-assisted synthesis of $\mathrm{V}_{2} \mathrm{O}_{5}$ nanoislands on SnO 2 nanowires for improving $\mathrm{NO}_{2}$ sensing performance. Appl. Surf. Sci. 2020, 509, 144821. [CrossRef]

297. Abideen, Z.U.; Kim, J.-H.; Kim, S.S. Optimization of metal nanoparticle amount on $\mathrm{SnO}_{2}$ nanowires to achieve superior gas sensing properties. Sens. Actuators B Chem. 2017, 238, 374-380. [CrossRef]

298. Yuan, Z.; Zhang, J.; Meng, F.; Li, Y.; Li, R.; Chang, Y.; Zhao, J.; Han, E.; Wang, S. Highly Sensitive Ammonia Sensors Based on Ag-Decorated $\mathrm{WO}_{3}$ Nanorods. IEEE Trans. Nanotechnol. 2018, 17, 1252-1258. [CrossRef]

299. Choi, S.-W.; Jung, S.-H.; Kim, S.S. Significant enhancement of the $\mathrm{NO}_{2}$ sensing capability in networked $\mathrm{SnO}_{2}$ nanowires by Au nanoparticles synthesized via $\gamma$-ray radiolysis. J. Hazard. Mater. 2011, 193, 243-248. [CrossRef]

300. Choi, M.S.; Bang, J.H.; Mirzaei, A.; Oum, W.; Na, H.G.; Jin, C.; Kim, S.S.; Kim, H.W. Promotional Effects of ZnO-Branching and Au-Functionalization on the Surface of $\mathrm{SnO}_{2}$ Nanowires for $\mathrm{NO}_{2}$ Sensing. J. Alloys Compd. 2019, 786, 27-39. [CrossRef]

301. Kim, J.-H.; Mirzaei, A.; Kim, H.W.; Kim, S.S. Extremely sensitive and selective sub-ppm CO detection by the synergistic effect of Au nanoparticles and core-shell nanowires. Sens. Actuators B Chem. 2017, 249, 177-188. [CrossRef]

302. Cai, Z.; Park, S. Synthesis of Pd nanoparticle-decorated $\mathrm{SnO}_{2}$ nanowires and determination of the optimum quantity of Pd nanoparticles for highly sensitive and selective hydrogen gas sensor. Sens. Actuators B Chem. 2020, 322, 128651. [CrossRef]

303. Nguyen, K.; Hung, C.M.; Ngoc, T.M.; Le, D.T.T.; Nguyen, D.H.; Van, D.N.; Van, H.N. Low-temperature prototype hydrogen sensors using Pd-decorated $\mathrm{SnO}_{2}$ nanowires for exhaled breath applications. Sens. Actuators B Chem. 2017, 253, 156-163. [CrossRef]

304. Tonezzer, M.; Kim, J.H.; Lee, J.H.; Iannotta, S.; Kim, S.S. Predictive Gas Sensor Based on Thermal Fingerprints from Pt-SnO 2 Nanowires. Sens. Actuators B Chem. 2019, 281, 670-678. [CrossRef]

305. Cao, P.; Yang, Z.; Navale, S.T.; Han, S.; Liu, X.; Liu, W.; Lu, Y.; Stadler, F.J.; Zhu, D. Ethanol Sensing Behavior of Pd-Nanoparticles Decorated ZnO-Nanorod Based Chemiresistive Gas Sensors. Sens. Actuators B Chem. 2019, 298, 126850. [CrossRef]

306. Hwang, I.-S.; Choi, J.-K.; Woo, H.-S.; Kim, S.-J.; Jung, S.-Y.; Seong, T.-Y.; Kim, I.-D.; Lee, J.-H. Facile Control of $\mathrm{C}_{2} \mathrm{H}_{5} \mathrm{OH}$ Sensing Characteristics by Decorating Discrete Ag Nanoclusters on $\mathrm{SnO}_{2}$ Nanowire Networks. ACS Appl. Mater. Interfaces 2011, 3 , 3140-3145. [CrossRef]

307. Yang, M.; Zhang, S.; Qu, F.; Gong, S.; Wang, C.; Qiu, L.; Yang, M.; Cheng, W. High performance acetone sensor based on ZnO nanorods modified by Au nanoparticles. J. Alloys Compd. 2019, 797, 246-252. [CrossRef]

308. Zhang, B.; Huang, Y.; Vinluan, R.; Wang, S.; Cui, C.; Lu, X.; Peng, C.; Zhang, M.; Zheng, J.; Gao, P.-X. Enhancing ZnO nanowire gas sensors using $\mathrm{Au} / \mathrm{Fe}_{2} \mathrm{O}_{3}$ hybrid nanoparticle decoration. Nanotechnology 2020, 31, 325505. [CrossRef] [PubMed]

309. Chen, X.; Shen, Y.; Zhou, P.; Zhong, X.; Li, G.; Han, C.; Wei, D.; Li, S. Bimetallic Au/Pd nanoparticles decorated ZnO nanowires for $\mathrm{NO}_{2}$ detection. Sens. Actuators B Chem. 2019, 289, 160-168. [CrossRef]

310. Kim, J.-H.; Lee, J.-H.; Park, Y.; Kim, J.-Y.; Mirzaei, A.; Kim, H.W.; Kim, S.S. Toluene- and benzene-selective gas sensors based on Pt- and Pd-functionalized ZnO nanowires in self-heating mode. Sens. Actuators B Chem. 2019, 294, 78-88. [CrossRef]

311. Hieu, N.M.; Kim, H.; Kim, C.; Hong, S.-K.; Kim, D. A Hydrogen Sulfide Gas Sensor Based on Pd-Decorated ZnO Nanorods. J. Nanosci. Nanotechnol. 2016, 16, 10351-10355. [CrossRef]

312. Yu, A.; Li, Z.; Yi, J. Selective detection of parts-per-billion $\mathrm{H}_{2} \mathrm{~S}$ with Pt-decorated ZnO nanorods. Sens. Actuators B Chem. 2021, 333, 129545. [CrossRef]

313. Zeb, S.; Sun, G.; Nie, Y.; Cui, Y.; Jiang, X. Synthesis of highly oriented $\mathrm{WO}_{3}$ nanowire bundles decorated with Au for gas sensing application. Sens. Actuators B Chem. 2020, 321, 128439. [CrossRef]

314. Kim, S.; Park, S.; Park, S.; Lee, C. Acetone Sensing of Au and Pd-Decorated $\mathrm{WO}_{3}$ Nanorod Sensors. Sens. Actuators B Chem. 2015, 209, 180-185. [CrossRef]

315. Zeb, S.; Peng, X.; Shi, Y.; Su, J.; Sun, J.; Zhang, M.; Sun, G.; Nie, Y.; Cui, Y.; Jiang, X. Bimetal Au-Pd Decorated Hierarchical WO 3 Nanowire Bundles for Gas Sensing Application. Sens. Actuators B Chem. 2021, 129584. [CrossRef]

316. Song, Y.G.; Park, J.Y.; Suh, J.M.; Shim, Y.-S.; Yi, S.Y.; Jang, H.W.; Kim, S.; Yuk, J.M.; Ju, B.-K.; Kang, C.-Y. Heterojunction Based on Rh-Decorated $\mathrm{WO}_{3}$ Nanorods for Morphological Change and Gas Sensor Application Using the Transition Effect. Chem. Mater. 2018, 31, 207-215. [CrossRef]

317. Zou, X.; Wang, J.; Liu, X.; Wang, C.; Jiang, Y.; Wang, Y.; Xiao, X.; Ho, J.C.; Li, J.; Jiang, C.; et al. Rational Design of Sub-Parts per Million Specific Gas Sensors Array Based on Metal Nanoparticles Decorated Nanowire Enhancement-Mode Transistors. Nano Lett. 2013, 13, 3287-3292. [CrossRef] [PubMed]

318. Sarıca, N.; Alev, O.; Arslan, L. Çolakerol; Öztürk, Z.Z. Characterization and gas sensing performances of noble metals decorated $\mathrm{CuO}$ nanorods. Thin Solid Films 2019, 685, 321-328. [CrossRef]

319. Kim, J.-Y.; Lee, J.-H.; Kim, J.-H.; Mirzaei, A.; Kim, H.W.; Kim, S.S. Realization of $\mathrm{H}_{2} \mathrm{~S}$ sensing by Pd-functionalized networked $\mathrm{CuO}$ nanowires in self-heating mode. Sens. Actuators B Chem. 2019, 299, 126965. [CrossRef]

320. Bang, J.H.; Mirzaei, A.; Han, S.; Lee, H.Y.; Shin, K.Y.; Kim, S.S.; Kim, H.W. Realization of low-temperature and selective $\mathrm{NO}_{2}$ sensing of $\mathrm{SnO}_{2}$ nanowires via synergistic effects of $\mathrm{Pt}$ decoration and $\mathrm{Bi}_{2} \mathrm{O}_{3}$ branching. Ceram. Int. 2021, 47, 5099-5111. [CrossRef]

321. Khoang, N.D.; Trung, D.D.; Van Duy, N.; Hoa, N.D.; Van Hieu, N. Design of $\mathrm{SnO}_{2} / \mathrm{ZnO}$ Hierarchical Nanostructures for Enhanced Ethanol Gas-Sensing Performance. Sens. Actuators B Chem. 2012, 174, 594-601. [CrossRef] 
322. Cai, L.; Li, H.; Zhang, H.; Fan, W.; Wang, J.; Wang, Y.; Wang, X.; Tang, Y.; Song, Y. Enhanced Performance of the Tangerines-like CuO-Based Gas Sensor Using ZnO Nanowire Arrays. Mater. Sci. Semicond. Process. 2020, 118, 105196. [CrossRef]

323. Kim, J.-H.; Mirzaei, A.; Kim, H.W.; Kim, S.S. Low power-consumption CO gas sensors based on Au-functionalized SnO 2 -ZnO core-shell nanowires. Sens. Actuators B Chem. 2018, 267, 597-607. [CrossRef]

324. Li, X.; Li, X.; Chen, N.; Li, X.; Zhang, J.; Yu, J.; Wang, J.; Tang, Z. CuO- $\operatorname{In}_{2} \mathrm{O}_{3}$ Core-Shell Nanowire Based Chemical Gas Sensors. J. Nanomater. 2014, 2014, 973156.

325. Tomić, M.; Šetka, M.; Chmela, O.; Gràcia, I.; Figueras, E.; Cané, C.; Vallejos, S. Cerium Oxide-Tungsten Oxide Core-Shell Nanowire-Based Microsensors Sensitive to Acetone. Biosensors 2018, 8, 116. [CrossRef] [PubMed]

326. Rai, P.; Jeon, S.-H.; Lee, C.-H.; Lee, J.-H.; Yu, Y.-T. Functionalization of ZnO nanorods by CuO nanospikes for gas sensor applications. RSC Adv. 2014, 4, 23604-23609. [CrossRef]

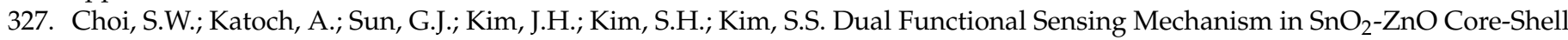
Nanowires. ACS Appl. Mater. Interfaces 2014, 6, 8281-8287. [CrossRef] [PubMed]

328. Park, J.Y.; Choi, S.-W.; Kim, S.S. A model for the enhancement of gas sensing properties in $\mathrm{SnO}_{2}-\mathrm{ZnO}$ core-shell nanofibres. J. Phys. D Appl. Phys. 2011, 44, 44. [CrossRef]

329. Kim, J.-H.; Kim, J.-Y.; Lee, J.-H.; Mirzaei, A.; Kim, H.W.; Hishita, S.; Kim, S.S. Indium-implantation-induced enhancement of gas sensing behaviors of $\mathrm{SnO}_{2}$ nanowires by the formation of homo-core-shell structure. Sens. Actuators B Chem. 2020, $321,128475$. [CrossRef]

330. Katoch, A.; Choi, S.-W.; Sun, G.-J.; Kim, S.S. An approach to detecting a reducing gas by radial modulation of electron-depleted shells in core-shell nanofibers. J. Mater. Chem. A 2013, 1, 13588-13596. [CrossRef]

331. Diao, K.; Xiao, J.; Zheng, Z.; Cui, X. Enhanced sensing performance and mechanism of CuO nanoparticle-loaded ZnO nanowires: Comparison with $\mathrm{ZnO}-\mathrm{CuO}$ core-shell nanowires. Appl. Surf. Sci. 2018, 459, 630-638. [CrossRef]

332. Kim, J.H.; Katoch, A.; Kim, S.S. Optimum Shell Thickness and Underlying Sensing Mechanism in p-n CuO-ZnO Core-Shell Nanowires. Sens. Actuators B Chem. 2016, 222, 249-256. [CrossRef]

333. Mirzaei, A.; Kim, J.-H.; Kim, H.W.; Kim, S.S. How shell thickness can affect the gas sensing properties of nanostructured materials: Survey of literature. Sens. Actuators B Chem. 2018, 258, 270-294. [CrossRef]

334. Singh, N.; Ponzoni, A.; Gupta, R.K.; Lee, P.S.; Comini, E. Synthesis of $\operatorname{In}_{2} \mathrm{O}_{3}-\mathrm{ZnO}$ core-shell nanowires and their application in gas sensing. Sens. Actuators B Chem. 2011, 160, 1346-1351. [CrossRef]

335. Kwon, Y.J.; Gil Na, H.; Kang, S.Y.; Choi, M.S.; Bang, J.H.; Kim, T.W.; Mirzaei, A.; Kim, H.W. Attachment of $\mathrm{Co}_{3} \mathrm{O}_{4}$ layer to SnO 2 nanowires for enhanced gas sensing properties. Sens. Actuators B Chem. 2017, 239, 180-192. [CrossRef]

336. Zhang, G.; Liu, M. Effect of particle size and dopant on properties of $\mathrm{SnO}_{2}$-based gas sensors. Sens. Actuators B Chem. 2000, 69, 144-152. [CrossRef]

337. Tahar, R.B.H.; Ban, T.; Ohya, Y.; Takahashi, Y. Tin doped indium oxide thin films: Electrical properties. J. Appl. Phys. 1998, 83, 2631-2645. [CrossRef]

338. Parthibavarman, M.; Hariharan, V.; Sekar, C.; Singh, V.N. Effect of Copper on Structural, Optical and Electrochemical Properties of $\mathrm{SnO}_{2}$ Nanoparticles. J. Optoelectron. Adv. Mater. 2010, 12, 1894-1898.

339. Degler, D.; Weimar, U.; Barsan, N. Current Understanding of the Fundamental Mechanisms of Doped and Loaded Semiconducting Metal-Oxide-Based Gas Sensing Materials. ACS Sens. 2019, 4, 2228-2249. [CrossRef]

340. Zhang, D.; Li, C.; Liu, X.; Han, S.; Tang, T.; Zhou, C. Doping dependent $\mathrm{NH}_{3}$ sensing of indium oxide nanowires. Appl. Phys. Lett. 2003, 83, 1845-1847. [CrossRef]

341. Singh, N.; Yan, C.; Lee, P.S. Room temperature CO gas sensing using Zn-doped $\operatorname{In}_{2} \mathrm{O}_{3}$ single nanowire field effect transistors. Sens. Actuators B Chem. 2010, 150, 19-24. [CrossRef]

342. Yamazoe, N. New approaches for improving semiconductor gas sensors. Sens. Actuators B Chem. 1991, 5, 7-19. [CrossRef]

343. Xu, C.; Tamaki, J.; Miura, N.; Yamazoe, N. Grain size effects on gas sensitivity of porous $\mathrm{SnO}_{2}$-based elements. Sens. Actuators $B$ Chem. 1991, 3, 147-155. [CrossRef]

344. Wei, T.-Y.; Yeh, P.-H.; Lu, S.-Y.; Wang, Z.L. Gigantic Enhancement in Sensitivity Using Schottky Contacted Nanowire Nanosensor. J. Am. Chem. Soc. 2009, 131, 17690-17695. [CrossRef]

345. Wang, W.-C.; Lai, C.-Y.; Lin, Y.-T.; Yua, T.-H.; Chen, Z.-Y.; Wu, W.-W.; Yeh, P.-H. Surface defect engineering: Gigantic enhancement in the optical and gas detection ability of metal oxide sensor. RSC Adv. 2016, 6, 65146-65151. [CrossRef]

346. Singh, N.; Gupta, R.K.; Lee, P.S. Gold-Nanoparticle-Functionalized $\operatorname{In}_{2} \mathrm{O}_{3}$ Nanowires as CO Gas Sensors with a Significant Enhancement in Response. ACS Appl. Mater. Interfaces 2011, 3, 2246-2252. [CrossRef] [PubMed]

347. Van, P.T.H.; Dai, D.D.; Van Duy, N.; Hoa, N.D.; Van Hieu, N. Ultrasensitive $\mathrm{NO}_{2}$ gas sensors using tungsten oxide nanowires with multiple junctions self-assembled on discrete catalyst islands via on-chip fabrication. Sens. Actuators B Chem. 2016, 227, 198-203. [CrossRef]

348. Lee, J.; Jung, Y.; Sung, S.-H.; Lee, G.-H.; Kim, J.; Seong, J.; Shim, Y.-S.; Jun, S.C.; Jeon, S. High-performance gas sensor array for indoor air quality monitoring: The role of $\mathrm{Au}$ nanoparticles on $\mathrm{WO}_{3}, \mathrm{SnO}_{2}$, and $\mathrm{NiO}$-based gas sensors. J. Mater. Chem. A 2021, 9 , 1159-1167. [CrossRef]

349. Khan, A.H.; Thomson, B.; Debnath, R.; Motayed, A.; Rao, M.V. Nanowire-Based Sensor Array for Detection of Cross-Sensitive Gases Using PCA and Machine Learning Algorithms. IEEE Sens. J. 2020, 20, 6020-6028. [CrossRef] 
350. Chen, P.-C.; Ishikawa, F.N.; Chang, H.-K.; Ryu, K.; Zhou, C. A nanoelectronic nose: A hybrid nanowire/carbon nanotube sensor array with integrated micromachined hotplates for sensitive gas discrimination. Nanotechnology 2009, 20, 125503. [CrossRef] [PubMed]

351. Sysoev, V.; Schneider, T.; Goschnick, J.; A Kiselev, I.; Habicht, W.; Hahn, H.; Strelcov, E.; Kolmakov, A. Percolating SnO 2 nanowire network as a stable gas sensor: Direct comparison of long-term performance versus $\mathrm{SnO}_{2}$ nanoparticle films. Sens. Actuators $B$ Chem. 2009, 139, 699-703. [CrossRef]

352. Lupan, O.; Postica, V.; Labat, F.; Ciofini, I.; Pauporté, T.; Adelung, R. Ultra-Sensitive and Selective Hydrogen Nanosensor with Fast Response at Room Temperature Based on a Single Pd/ZnO Nanowire. Sens. Actuators B Chem. 2018, 254, 1259-1270. [CrossRef]

353. Prades, J.D.; Jimenez-Diaz, R.; Hernández-Ramírez, F.; Pan, J.; Romano-Rodriguez, A.; Mathur, S.; Morante, J.R. Direct observation of the gas-surface interaction kinetics in nanowires through pulsed self-heating assisted conductometric measurements. Appl. Phys. Lett. 2009, 95, 53101. [CrossRef]

354. Subannajui, K.; Güder, F.; Zacharias, M. Bringing Order to the World of Nanowire Devices by Phase Shift Lithography. Nano Lett. 2011, 11, 3513-3518. [CrossRef] [PubMed]

355. Zhao, X.; Nagashima, K.; Zhang, G.; Hosomi, T.; Yoshida, H.; Akihiro, Y.; Kanai, M.; Mizukami, W.; Zhu, Z.; Takahashi, T.; et al. Synthesis of Monodispersedly Sized ZnO Nanowires from Randomly Sized Seeds. Nano Lett. 2019, 20, 599-605. [CrossRef] [PubMed]

356. Hall, A.S.; Yoon, Y.; Wuttig, A.; Surendranath, Y. Mesostructure-Induced Selectivity in $\mathrm{CO}_{2}$ Reduction Catalysis. J. Am. Chem. Soc. 2015, 137, 14834-14837. [CrossRef]

357. Liu, J.; Chen, L.; Cui, H.; Zhang, J.; Zhang, L.; Su, C.-Y. Applications of metal-organic frameworks in heterogeneous supramolecular catalysis. Chem. Soc. Rev. 2014, 43, 6011-6061. [CrossRef] [PubMed]

358. Nugent, P.; Belmabkhout, Y.; Burd, S.D.; Cairns, A.J.; Luebke, R.; A Forrest, K.; Pham, T.; Ma, S.; Space, B.; Wojtas, L.; et al. Porous materials with optimal adsorption thermodynamics and kinetics for $\mathrm{CO}_{2}$ separation. Nat. Cell Biol. 2013, 495, 80-84. [CrossRef]

359. Canlas, C.P.; Lu, J.; Ray, N.A.; Grosso-Giordano, N.A.; Lee, S.; Elam, J.W.; Winans, R.E.; Van Duyne, R.P.; Stair, P.C.; Notestein, J.M. Shape-selective sieving layers on an oxide catalyst surface. Nat. Chem. 2012, 4, 1030-1036. [CrossRef]

360. Yan, R.; Takahashi, T.; Kanai, M.; Hosomi, T.; Zhang, G.; Nagashima, K.; Yanagida, T. Unusual Sequential Annealing Effect in Achieving High Thermal Stability of Conductive Al-Doped ZnO Nanofilms. ACS Appl. Electron. Mater. 2020, 2, 2064-2070. [CrossRef]

361. Yan, R.; Takahashi, T.; Zeng, H.; Hosomi, T.; Kanai, M.; Zhang, G.; Nagashima, K.; Yanagida, T. Enhancement of PH Tolerance in Conductive Al-Doped ZnO Nanofilms via Sequential Annealing. ACS Appl. Electron. Mater. 2021. [CrossRef] 